\title{
Synthesis of Polyfuran and Thiophene-Furan Alternating Copolymers Using Catalyst-Transfer Polycondensation
}

Yunyan Qiu, Andria Fortney, Chia-Hua Tsai, Matthew A. Baker, Roberto R. Gil, Tomasz Kowalewski, Kevin J. T. Noonan

Department of Chemistry, Carnegie Mellon University, 440o Fifth Ave, Pittsburgh, Pennsylvania 15213, United States

Corresponding author: noonan@andrew.cmu.edu, 1-412-268-3128

Table of Contents

Materials and Methods

S4-S7

Experimental Procedures

S8-S11

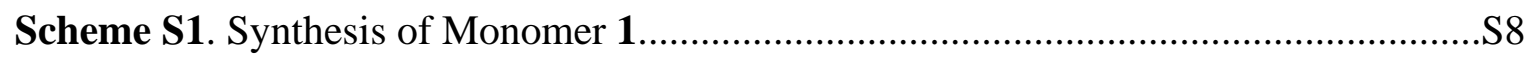

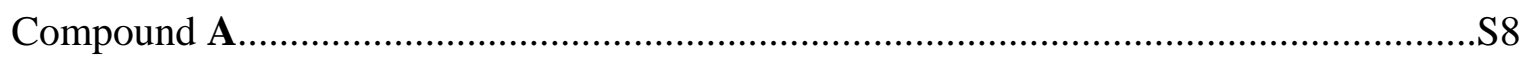

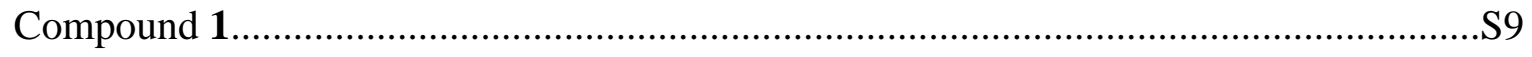

Scheme S2. Synthesis of Monomer 3 ……………….................................................

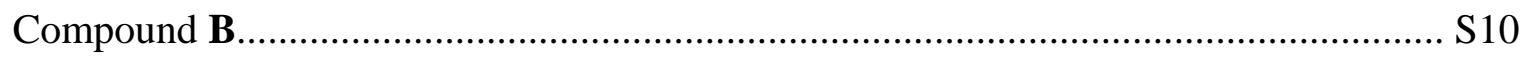

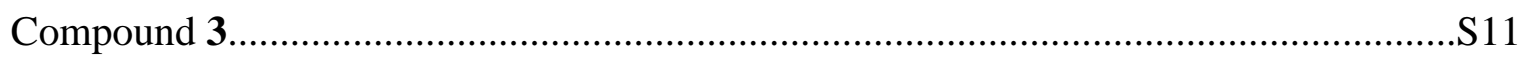

Model Compound Reaction .................................................................................... S12-S13

Figure S1. GC-MS chromatograms of the model compound reaction............................. S13

Quenching Study for Monomer 1.............................................................................. $14-$ S15

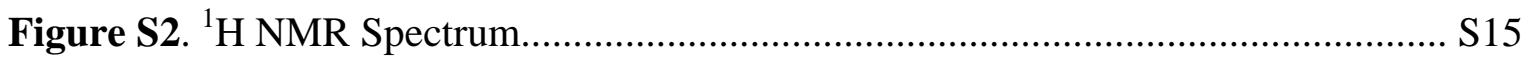

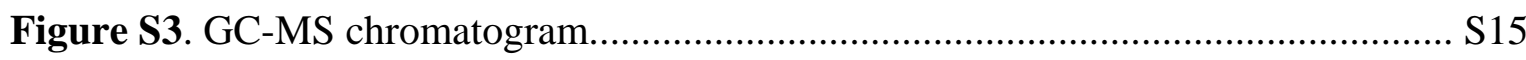

Quenching Study for Monomer 3.............................................................................. $16-$ S17

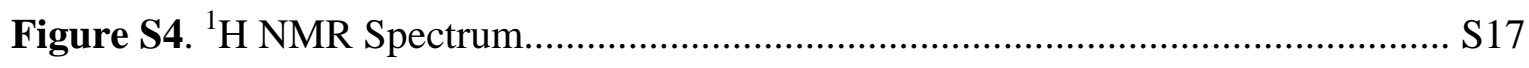

Figure S5. GC-MS chromatogram.......................................................................... S17

Additional Competition Experiment: 2-Bromofuran and 2-Bromo-3-hexylthiophene........S18-S20

Figure S6. GC-MS chromatogram when using $i$-PrMgCl- $\mathrm{LiCl}$....................................... S19 
Figure S7. GC-MS chromatogram when using $i$-PrMgCl S20

General Polymerization Conditions.

S21-S23

Polymer HT-P3HF $\mathrm{S} 21$

Polymer HH-P3HF

$\mathrm{S} 21-\mathrm{S} 22$

Polymer P3HF-a-P3HT

S22-S23

Procedure for Obtaining $M_{\mathrm{n}}$ versus Conversion Plot.

S23-S24

Table S1. Data used to construct $M_{\mathrm{n}}$ versus monomer conversion plot.........................S23

Figure S8. GC-MS chromatograms of the $M_{\mathrm{n}}$ versus conversion plot............................S24

NMR Spectra

$\mathrm{S} 25-\mathrm{S} 46$

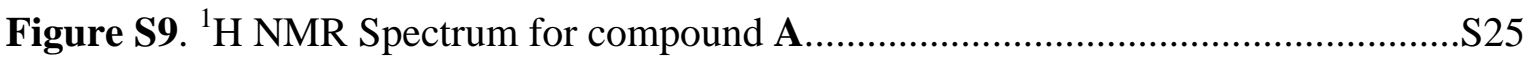

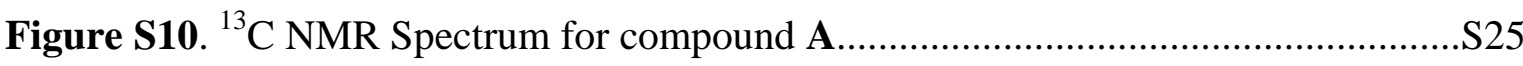

Figure S11. ${ }^{1}$ H NMR Spectrum for compound 1................................................S26

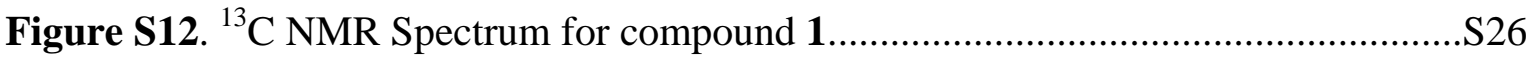

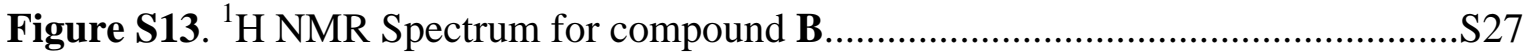

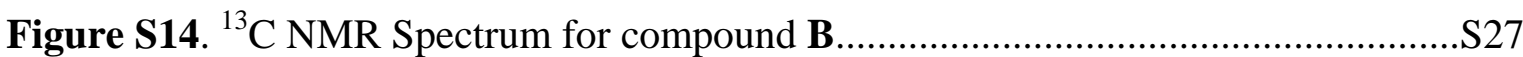

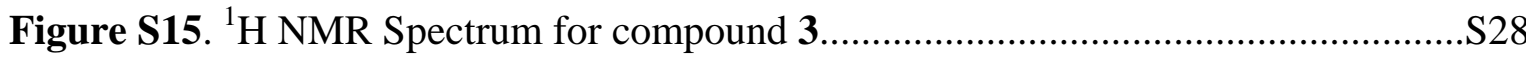

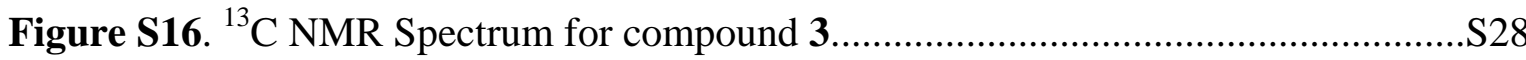

Figure S17. ${ }^{1} \mathrm{H}$ NMR Spectrum for polymer HT-P3HF .....................................S29

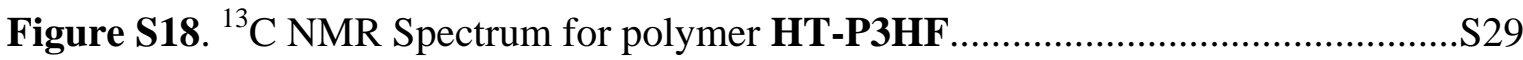

Figure S19-S26. 2D NMR Spectra for polymer HT-P3HF..................................S30-S37

Figure S27. ${ }^{1} \mathrm{H}$ NMR Spectrum for polymer HH-P3HF........................................S38

Figure S28. ${ }^{13} \mathrm{C}$ NMR Spectrum for polymer HH-P3HF.......................................S38

Figure S29-S32. 2D NMR Spectra for polymer HH-P3HF .................................S39-S42

Figure S33. ${ }^{1} \mathrm{H}$ NMR Spectrum for polymer P3HF-a-P3HT...................................S43

Figure S34. ${ }^{13} \mathrm{C}$ NMR Spectrum for polymer P3HF-a-P3HT ...................................S43

Figure S35-S37. 2D NMR Spectra for polymer HH-P3HF ................................S44-S46

Table S2. Summary of optical and electrochemical properties of HT-P3HF, HH-P3HF and P3HF-a-P3HT. 


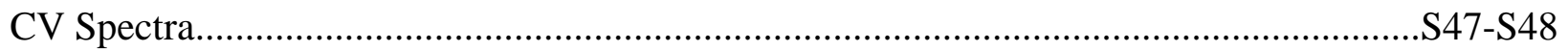

Figure S38. CV Spectrum for polymer HT-P3HF ..............................................S47

Figure S39. CV Spectrum for polymer HH-P3HF ..............................................S48

Figure S40. CV Spectrum for polymer P3HF-a-P3HT ...........................................S48

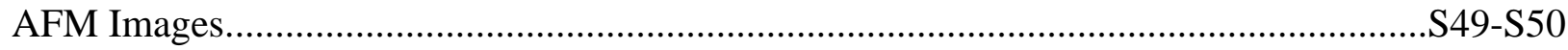

Figure S41. AFM images for polymer HT-P3HF ...........................................S49

Figure S42. AFM images for polymer HH-P3HF ...............................................S49

Figure S43. AFM images for polymer P3HF-a-P3HT........................................S50

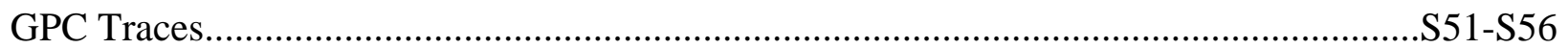

Figure S44. GPC Chromatogram and analysis of HT-P3HF Entry 1 Table 1...............S51

Figure S45. GPC Chromatogram and analysis of HT-P3HT Entry 2 Table 1 ...............S52

Figure S46. GPC Chromatogram and analysis of HH-P3HF Entry 3 Table 1...............S53

Figure S47. GPC Chromatogram and analysis of P3HF-a-P3HT Entry 4 Table 1........S54

Figure S48. GPC Chromatogram and analysis of P3HF-a-P3HT Entry 5 Table 1........S55

Figure S49. GPC Chromatogram and analysis of P3HF-a-P3HT Entry 6 Table 1........S56

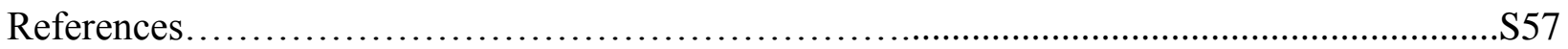


Materials and Methods. All reactions and manipulations of air or water sensitive compounds were carried out under dry nitrogen using an mBraun glovebox or standard Schlenk techniques unless otherwise stated. Tetrahydrofuran was purchased from commercial sources, degassed with argon, and dried prior to use. Anhydrous dioxane was purchased and degassed with nitrogen prior to use. N-bromosuccinimide (NBS) was recrystallized from hot water prior to use. $\mathrm{Ni}(\mathrm{dppp}) \mathrm{Cl}_{2}$ was obtained from Accela and 3-bromofuran from ChemImpex. All other solvents and chemicals were used as received from commercial sources.

$\mathrm{TMPMgCl} \cdot \mathrm{LiCl}$ and $i$-PrMgCl$\cdot \mathrm{LiCl}$ were titrated against benzoic acid using fluorene as the indicator. 2-(4-hexylthiophen-2-yl)-4,4,5,5-tetramethyl-1,3,2-dioxaborolane ${ }^{1}$ and 5,5'-dibromo3,3'-dihexyl-2,2'-bifuran $(\mathbf{2})^{2}$ were prepared according to literature procedures. 2,5-dibromo-3hexylfuran was prepared similarly to 2,5-dibromo-3-octylfuran. ${ }^{3}$ Poly(3-hexylthiophene) $\left(M_{\mathrm{n}}=\right.$ 23,800, $D=1.3$ determined versus polystyrene standards in $\mathrm{CHCl}_{3}$ ) used in the UV-Vis study was prepared according to a literature procedure. ${ }^{4}$

Polymer samples were precipitated with methanol and washed with both methanol and acetone before GPC analysis (Table 1). Polymer samples used for NMR analysis, UV-Vis spectroscopy, atomic force microscopy and cyclic voltammetry were further purified by Soxhlet extraction using methanol, acetone, hexanes and chloroform. The chloroform extracts were used in the analysis.

NMR Analysis. All NMR experiments were collected at $300 \mathrm{~K}$ on a two-channel Bruker Avance $^{\mathrm{TM}}$ III NMR instrument equipped with a Broad Band Inverse (BBI) probe, operating at $500 \mathrm{MHz}$ for ${ }^{1} \mathrm{H}$ (126 MHz for $\left.{ }^{13} \mathrm{C}\right) .{ }^{1} \mathrm{H}$ NMR spectra are referenced to residual protio solvent (7.26 for $\mathrm{CHCl}_{3}$ ) and ${ }^{13} \mathrm{C}$ NMR spectra are referenced to the solvent signal $\left(\delta 77.23\right.$ for $\left.\mathrm{CDCl}_{3}\right)$. Long-range COSY (cosylrqf), edited-HSQC (hsqceedetgpsisp2.2) and echo/antiecho-HMBC 
with triple low-pass filter to remove one-bond correlations (hmbcetgpl3nd) are standard experiments from the Bruker pulseprogram library in TopSpin 3.1. The F2 proton-coupled HSQC was performed using the recently published Perfect-HSQC pulse program, ${ }^{5}$ kindly provided by Dr. Teodor Parella (http://sermn.uab.cat/2014/10/perfect-hsqc-experimentspure-in-phase-spectra/). The HMBC experiments were optimized for 4 and $8 \mathrm{~Hz}$ long-range proton-coupling $\left({ }^{\mathrm{n}} J_{\mathrm{CH}}\right)$.

Mass Spectrometry. High-resolution mass spectrometry experiments (electrospray and electron impact) were performed in the School of Chemical Sciences Mass Spectrometry Laboratory at the University of Illinois, Urbana-Champaign.

Gel-Permeation Chromatography. GPC measurements were performed on a Waters Instrument equipped with a 717 plus autosampler, a Waters 2414 refractive index (RI) detector and two SDV columns (Porosity 1000 and $100000 \AA$ A; Polymer Standard Services) with THF as the eluent (flow rate $1 \mathrm{~mL} / \mathrm{min}, 40^{\circ} \mathrm{C}$ ). A 10 -point calibration based on polystyrene standards (Polystyrene, ReadyCal Kit, Polymer Standard Services) was applied for determination of molecular weights. All polymer aliquots subjected to GPC were prepared by quenching $\sim 0.2 \mathrm{~mL}$ of the polymer solution with $\sim 1.0 \mathrm{~mL}$ of $6 \mathrm{M}$ methanolic $\mathrm{HCl}$. The precipitate was filtered and washed with cold methanol. The resultant polymer was dissolved in $\sim 1 \mathrm{~mL}$ of THF, filtered through a $0.22 \mu \mathrm{m}$ PTFE syringe filter, and analyzed.

GC-MS Analysis. GC-MS analysis was performed on a Hewlett-Packard Agilent 6890-5973 GC-MS workstation. The GC column was a Hewlett-Packard fused silica capillary column crosslinked with 5\% phenylmethylsiloxane. Helium was used as the carrier gas. The following conditions were used for all GC-MS analyses: injector temperature, $250{ }^{\circ} \mathrm{C}$; initial temperature, $70{ }^{\circ} \mathrm{C}$; temperature ramp, $10{ }^{\circ} \mathrm{C} / \mathrm{min}$; final temperature, $280{ }^{\circ} \mathrm{C}$. All polymer aliquots subjected 
to GC-MS were prepared by quenching $\sim 0.2 \mathrm{~mL}$ of the polymer solution with $\sim 1.0 \mathrm{~mL}$ of acidic methanol ( $\mathrm{HCl}$ :methanol, 1:200 v/v). This was diluted with $1 \mathrm{~mL}$ of diethyl ether in a $20 \mathrm{~mL}$ scintillation vial. $0.2 \mathrm{~mL}$ of this resultant solution was filtered through a $0.22 \mu \mathrm{m}$ PTFE syringe filter into a $2 \mathrm{~mL}$ vial and diethyl ether was added to fill the vial. Due to hydrolysis of the monomer in acidic methanol, conversion was calculated by integration of the nonadecane internal standard to protonated monomer.

UV-Vis Spectroscopy. UV-Vis spectra of all three polymers were recorded on a Varian Cary 5000 spectrophotometer. Solution measurements were conducted in THF at $0.005 \mathrm{mg} / \mathrm{mL}$ concentration. In the dark, under a dry nitrogen environment in a VAC glovebox, thin film samples were prepared from a spin-coating process. $22 \times 22 \mathrm{~mm}$ glass cover slips were cleaned by spraying with fresh acetone, isopropanol and dried under a jet of filtered, dry $\mathrm{N}_{2} .5 \mathrm{mg} / \mathrm{mL}$ solutions of HT-P3HF, HH-P3HF, P3HF-a-P3HT and P3HT in dry toluene were heated to $80{ }^{\circ} \mathrm{C}$ in amber glass vials for $10 \mathrm{~min}$, filtered through a $0.22 \mu \mathrm{m}$ PTFE syringe filter using a glass syringe, and re-heated for 5 min prior to spin-casting from hot solutions. The spin-coating conditions consisted of three cycles, a 400 RPM spreading cycle for 5 s, a 1000 RPM main cycle for $30 \mathrm{~s}$ and a $2000 \mathrm{RPM}$ wicking cycle for $15 \mathrm{~s}$. The films were annealed at $150{ }^{\circ} \mathrm{C}$ for $1 \mathrm{~h}$ under $\mathrm{N}_{2}$.

Cyclic Voltammetry. Electrochemical potentials were determined using a $\mathrm{CH}$ Instruments Model 600C Series Electrochemical Analyzer/Workstation and a three electrode system consisting of a $1 \mathrm{~mm}^{2}$ platinum disk working electrode, a coiled platinum counter electrode, and a silver wire pseudo-reference electrode. Acetonitrile was degassed using Ar prior to use. A solution of the polymer $(0.5 \mathrm{mg} / \mathrm{mL}$ in toluene $)$ was drop cast onto the working electrode. The electrode was immersed in acetonitrile with $0.1 \mathrm{M}$ tetrabutylammonium hexafluorophosphate 
(Fluka, electrochemical grade) as the supporting electrolyte. Scans were collected under a constant argon purge at a scan rate of $100 \mathrm{mV} / \mathrm{s}$. Ferrocene was used as an internal standard and measurements were referenced to $\mathrm{Fc} / \mathrm{Fc}^{+}$. Considering the oxidation potential of ferrocene is $+0.40 \mathrm{~V}$ versus SCE in acetonitrile and the SCE electrode is $-4.7 \mathrm{eV}$ from vacuum, ${ }^{6}$ the $\mathrm{HOMO}$ and LUMO energy levels were estimated according to:

$\left.\mathrm{E}_{\mathrm{HOMO}}=-\left(\mathrm{E}_{[\text {onset, ox vs. Fc/Fc }}^{+}+5.1\right)(\mathrm{eV}) \quad \mathrm{E}_{\mathrm{LUMO}}=-\left(\mathrm{E}_{[\text {onset, red vs. Fc/Fc }}{ }^{+}\right]+5.1\right)(\mathrm{eV})$.

Atomic Force Microscopy. The HT-P3HF and HH-P3HF samples were prepared under a dry nitrogen environment in a glovebox, whereas the P3HF-a-P3HT sample was prepared under ambient conditions. All samples were prepared from $0.5 \mathrm{mg} / \mathrm{mL}$ solutions in dry toluene, on $2 \times$ $2 \mathrm{~cm}$ silicon wafers with native oxide. In the dark, the solutions were heated to $80{ }^{\circ} \mathrm{C}$ in amber glass vials for $30 \mathrm{~min}$, filtered through a $0.22 \mu \mathrm{m}$ PTFE syringe filter using a glass syringe, and re-heated for $5 \mathrm{~min}$ prior to drop-casting hot solutions onto the wafers. The wafers were cleaned by spraying with fresh acetone and isopropanol and dried under a jet of filtered, dry nitrogen, followed by $\mathrm{UV} / \mathrm{Ozone}$ treatment at $120^{\circ} \mathrm{C}$ for $45 \mathrm{~min}$, followed by an incubation period of 45 min until cooled to $42{ }^{\circ} \mathrm{C}$ (Novascan PSD-UVT). The wafers were then placed under vacuum (10 mTorr) for 90 min. The as-treated wafers were placed in a petri dish, completely covered with a minimum amount of solution, and allowed to dry slowly. The as-obtained films were imaged with a Bruker Dimension V hybrid AFM in tapping mode. 


\section{Experimental Procedures}

Scheme S1. Synthesis of Monomer 1

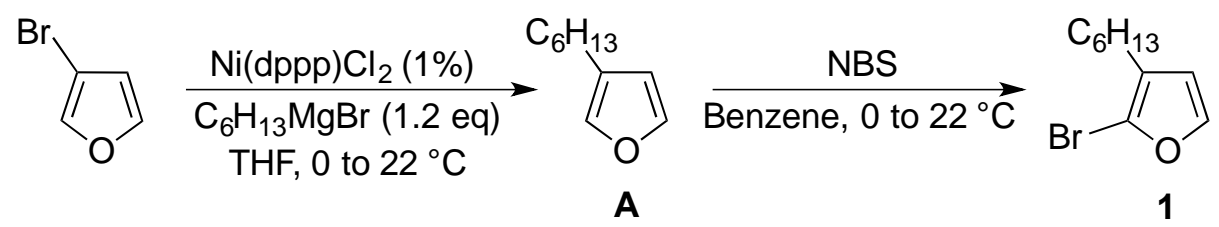

3-hexylfuran (A). An oven-dried $500 \mathrm{~mL}$ Schlenk flask was charged with 3- $\mathrm{C}_{6} \mathrm{H}_{13}$

bromofuran (15.0 g, $0.102 \mathrm{~mol}), \mathrm{Ni}(\mathrm{dppp}) \mathrm{Cl}_{2}(0.555 \mathrm{~g}, 1.02 \mathrm{mmol})$ and $200 \mathrm{~mL}$ of<smiles>[c-]1ccoc1</smiles>

dry THF. The flask was cooled to $0{ }^{\circ} \mathrm{C}$ using an ice-water bath. Hexylmagnesium bromide solution $(2.0 \mathrm{M}, 61.2 \mathrm{~mL}, 0.122 \mathrm{~mol})$ was added dropwise to the solution by syringe. After stirring at $0{ }^{\circ} \mathrm{C}$ for $0.5 \mathrm{~h}$, the mixture was warmed to room temperature overnight. The reaction was carefully quenched with saturated $\mathrm{NaHCO}_{3}$ solution at $0{ }^{\circ} \mathrm{C}$ and stirred for another $0.5 \mathrm{~h}$ before filtration through Celite. The solution was diluted with $150 \mathrm{~mL}$ of diethyl ether and transferred to a $500 \mathrm{~mL}$ separatory funnel. The organic layer was separated, washed with additional saturated $\mathrm{NaHCO}_{3}$ solution, dried over $\mathrm{Na}_{2} \mathrm{SO}_{4}$ and concentrated using rotary evaporation. The resultant yellow oily product was dissolved in $100 \mathrm{~mL}$ of hexanes and filtered through a basic alumina plug to remove residual catalyst and other impurities. The final product was purified by distillation at $55{ }^{\circ} \mathrm{C}$ under static vacuum and obtained as a clear liquid $(6.24 \mathrm{~g}$, $40 \%)$. Dodecane is typically observed as a byproduct in these reactions and co-distills with the desired product. It is present in the ${ }^{1} \mathrm{H}$ and ${ }^{13} \mathrm{C}$ NMR spectra and there is some overlap with the alkyl signals of the 3-hexylfuran. ${ }^{1} \mathrm{H}$ NMR $\left(500 \mathrm{MHz}, \mathrm{CDCl}_{3}\right) \delta 7.34(\mathrm{t}, J=1.7 \mathrm{~Hz}, 1 \mathrm{H}), 7.21-$ $7.19(\mathrm{~m}, 1 \mathrm{H}), 6.28-6.25(\mathrm{~m}, 1 \mathrm{H}), 2.41(\mathrm{t}, J=7.6 \mathrm{~Hz}, 2 \mathrm{H}), 1.59-1.50(\mathrm{~m}, 2 \mathrm{H}), 1.38-1.28(\mathrm{~m}$, 6H), $0.91-0.86(\mathrm{~m}, 3 \mathrm{H}) .{ }^{13} \mathrm{C} \mathrm{NMR}\left(126 \mathrm{MHz}, \mathrm{CDCl}_{3}\right) \delta 142.8,138.9,125.6,111.3,31.9,30.2$, 29.2, 25.0, 22.8, 14.3. HR-EIMS $(\mathrm{m} / \mathrm{z})$ : $[\mathrm{M}]^{+}$calculated for $\mathrm{C}_{10} \mathrm{H}_{16} \mathrm{O}$ : 152.1201; found 152.1202 . 
2-bromo-3-hexylfuran (1). In a $250 \mathrm{~mL}$ round-bottom flask, 3-hexylfuran (A) $\left(6.24 \quad \mathrm{C}_{6} \mathrm{H}_{13}\right.$

$\mathrm{g}, 0.041 \mathrm{~mol}$ ) was dissolved in $100 \mathrm{~mL}$ of benzene. The flask was cooled to $0{ }^{\circ} \mathrm{C}$ using an ice-water bath. NBS (7.44 g, $0.042 \mathrm{~mol})$ was added into the solution in one portion and the reaction mixture was protected from ambient light. The mixture was slowly warmed to room temperature and stirred overnight. The reaction was quenched with saturated $\mathrm{NaHCO}_{3}$ solution and transferred to a $500 \mathrm{~mL}$ of separatory funnel. The organic layer was separated and the aqueous layer was extracted two more times using diethyl ether $(2 \times 50 \mathrm{~mL})$. The organic extracts were combined and washed with saturated $\mathrm{NaHCO}_{3}$ solution, dried over $\mathrm{Na}_{2} \mathrm{SO}_{4}$ and concentrated using rotary evaporation. The resultant crude product was dissolved in $100 \mathrm{~mL}$ of hexanes and filtered through a basic alumina plug to remove succinimide. The crude product was purified by distillation at $43{ }^{\circ} \mathrm{C}(100 \mathrm{mtorr})$ and the final product was obtained as a clear liquid $(5.10 \mathrm{~g}, 54 \%) .{ }^{1} \mathrm{H}$ NMR $\left(500 \mathrm{MHz}, \mathrm{CDCl}_{3}\right) \delta 7.37(\mathrm{~d}, J=2.1 \mathrm{~Hz}, 1 \mathrm{H}), 6.29(\mathrm{~d}, J=2.0 \mathrm{~Hz}, 1 \mathrm{H})$, $2.33(\mathrm{t}, J=7.6 \mathrm{~Hz}, 2 \mathrm{H}), 1.57-1.48(\mathrm{~m}, 2 \mathrm{H}), 1.36-1.27(\mathrm{~m}, 6 \mathrm{H}), 0.92-0.84(\mathrm{~m}, 3 \mathrm{H}) .{ }^{13} \mathrm{C} \mathrm{NMR}$ $\left(126 \mathrm{MHz}, \mathrm{CDCl}_{3}\right) \delta 143.7,124.2,119.9,113.2,31.8,29.6,29.0,25.3,22.8,14.3$. HR-EIMS $(\mathrm{m} / \mathrm{z}):[\mathrm{M}]^{+}$calculated for $\mathrm{C}_{10} \mathrm{H}_{15} \mathrm{BrO}$ : 230.0306; found 230.0313 . 
Scheme S2. Synthesis of Monomer 3

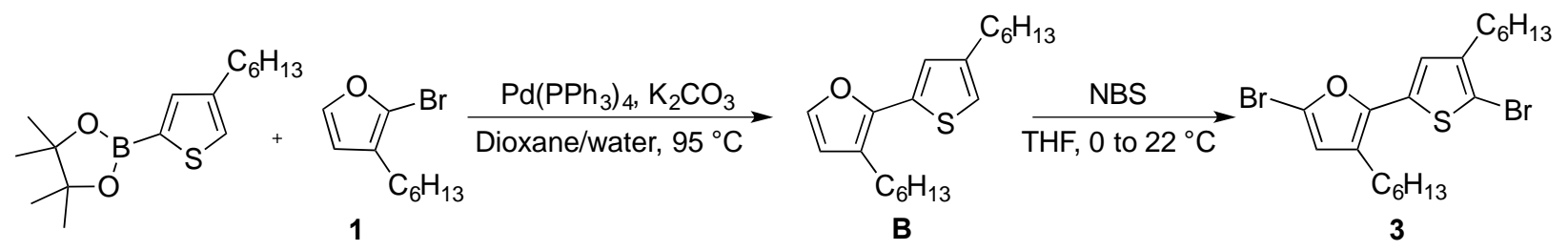

3-hexyl-2-(4-hexylthiophen-2-yl)furan (B). In a $\mathrm{N}_{2}$ filled glovebox, a 20

$\mathrm{mL}$ scintillation vial was charged with compound $\mathbf{1}(1.71 \mathrm{~g}, 7.40 \mathrm{mmol}), 2-$

(4-hexylthiophen-2-yl)-4,4,5,5-tetramethyl-1,3,2-dioxaborolane

$\mathrm{g}$,

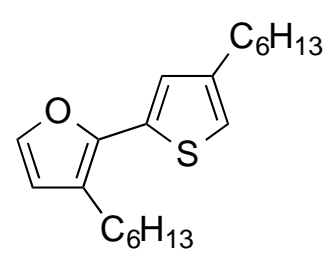

$7.40 \mathrm{mmol}), \mathrm{Pd}\left(\mathrm{PPh}_{3}\right)_{4}(0.43 \mathrm{~g}, 0.37 \mathrm{mmol}), \mathrm{K}_{2} \mathrm{CO}_{3}(3.07 \mathrm{~g}, 22 \mathrm{mmol})$ and $10 \mathrm{~mL}$ of dioxane.

The vial was removed from the glovebox and $4 \mathrm{~mL}$ of water was added into the vial by syringe.

The vial was immersed in an oil bath at $95{ }^{\circ} \mathrm{C}$ and the solution was stirred for $36 \mathrm{~h}$ before cooling to room temperature. The mixture was transferred to a separatory funnel, diluted with $100 \mathrm{~mL}$ of diethyl ether and washed with saturated $\mathrm{NaHCO}_{3}$ solution. The organic layer was dried over $\mathrm{Na}_{2} \mathrm{SO}_{4}$ and concentrated using rotary evaporation. The crude material was purified using column chromatography on silica gel using hexanes $\left(\mathrm{R}_{\mathrm{f}} \sim 0.7\right)$ to afford the final product as a clear liquid (1.89 g, 80\%). ${ }^{1} \mathrm{H}$ NMR $\left(500 \mathrm{MHz}, \mathrm{CDCl}_{3}\right) \delta 7.30(\mathrm{~d}, J=1.8 \mathrm{~Hz}, 1 \mathrm{H}), 7.05(\mathrm{~d}, J=$ $1.4 \mathrm{~Hz}, 1 \mathrm{H}), 6.83(\mathrm{q}, J=1.1 \mathrm{~Hz}, 1 \mathrm{H}), 6.33(\mathrm{~d}, J=1.8 \mathrm{~Hz}, 1 \mathrm{H}), 2.65-2.57(\mathrm{~m}, 4 \mathrm{H}), 1.68-1.57$ (m, 4H), $1.45-1.24(\mathrm{~m}, 12 \mathrm{H}), 0.93-0.85(\mathrm{~m}, 6 \mathrm{H}) .{ }^{13} \mathrm{C} \mathrm{NMR}\left(126 \mathrm{MHz}, \mathrm{CDCl}_{3}\right) \delta$ 145.0, 143.7, $140.8,133.6,124.3,121.3,118.7,113.5,31.9,30.7,30.6,29.9,29.4,29.2,25.9,22.9,14.32$ and 14.30 (two overlapping signals). Note: only 10 of the 12 possible signals from the hexyl chains are visible due to similarities between chemical environments. HRMS (ESI-TOF) $(m / z)$ : $[\mathrm{M}+$ $\mathrm{H}]^{+}$calculated for $\mathrm{C}_{20} \mathrm{H}_{31} \mathrm{OS}: 319.2096$; found 319.2095. 
5-bromo-2-(5-bromo-4-hexylthiophen-2-yl)-3-hexylfuran (3). In a 250

$\mathrm{mL}$ round-bottom flask, compound $\mathbf{B}(1.70 \mathrm{~g}, 5.34 \mathrm{mmol})$ was dissolved in $100 \mathrm{~mL}$ of THF. The flask was cooled to $0{ }^{\circ} \mathrm{C}$ using an

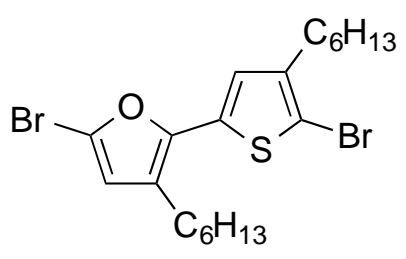
ice-water bath, and NBS (1.94 g, $10.9 \mathrm{mmol})$ was slowly added to the solution under protection from ambient light. The reaction mixture was slowly warmed to room temperature and stirred overnight. The mixture was quenched with saturated $\mathrm{NaHCO}_{3}$ solution and transferred to a 500 $\mathrm{mL}$ of separatory funnel. The organic layer was separated and the aqueous layer was extracted two more times using diethyl ether $(2 \times 50 \mathrm{~mL})$. The organic extracts were combined and washed with saturated $\mathrm{NaHCO}_{3}$ solution, dried over $\mathrm{Na}_{2} \mathrm{SO}_{4}$ and concentrated using rotary evaporation. The crude material was purified using column chromatography on basic alumina using hexanes $\left(\mathrm{R}_{\mathrm{f}} \sim 0.8\right)$ to afford the final product as a clear yellow liquid $(1.69 \mathrm{~g}, 66 \%) .{ }^{1} \mathrm{H}$ NMR (500 MHz, $\left.\mathrm{CDCl}_{3}\right) \delta 6.89(\mathrm{br} \mathrm{s}, 1 \mathrm{H}), 6.24(\mathrm{br} \mathrm{s}, 1 \mathrm{H}), 2.59-2.48(\mathrm{~m}, 4 \mathrm{H}), 1.64-1.50(\mathrm{~m}$, $4 \mathrm{H}), 1.41-1.23(\mathrm{~m}, 12 \mathrm{H}), 0.93-0.82(\mathrm{~m}, 6 \mathrm{H}) .{ }^{13} \mathrm{C} \mathrm{NMR}\left(126 \mathrm{MHz}, \mathrm{CDCl}_{3}\right) \delta$ 146.3, 142.6, 132.0, 124.5, 124.2, 120.9, 115.1, 108.4, 31.8, 29.9, 29.73 and 29.72 (two overlapping signals), 29.3, 29.1, 25.8, 22.82 and 22.81 (2 overlapping signals), 14.31 and 14.29 (2 overlapping signals). Note: only 11 of the 12 possible signals from the hexyl chains are visible due to similarities between chemical environments. HRMS (ESI-TOF) $(\mathrm{m} / z):[\mathrm{M}+\mathrm{H}]^{+}$calculated for $\mathrm{C}_{20} \mathrm{H}_{29} \mathrm{Br}_{2} \mathrm{OS}$ : 475.0306; found 475.0304. 


\section{Model Compound Reaction}

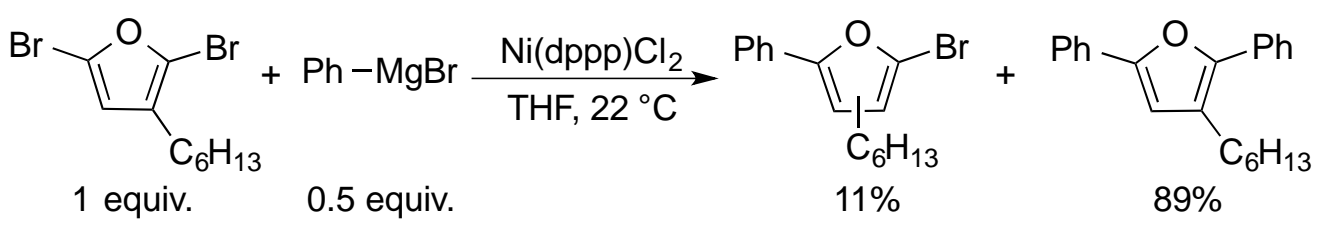

In a $\mathrm{N}_{2}$ filled glovebox, a $20 \mathrm{~mL}$ vial was charged with 2,5-dibromo-3-hexylfuran (1.0 equiv. $0.25 \mathrm{~g}, 0.81 \mathrm{mmol}), \mathrm{Ni}(\mathrm{dppp}) \mathrm{Cl}_{2}(2 \mathrm{~mol} \%, 0.0087 \mathrm{~g}, 0.016 \mathrm{mmol})$, nonadecane as the internal standard (0.206 g, $0.77 \mathrm{mmol})$ and $5 \mathrm{~mL}$ of THF. After $30 \mathrm{~s}$ of stirring inside the glovebox, an aliquot was withdrawn from the solution and subjected to GC-MS analysis to determine the initial ratios of starting material to the internal standard. Phenylmagnesium bromide (1.6 M, 0.25 $\mathrm{mL}, 0.4 \mathrm{mmol}$ ) was then added to the vial dropwise at room temperature. After stirring for $1 \mathrm{~h}$, an aliquot was removed and GC-MS analysis was performed to determine the relative ratio of 2,5-diphenyl-3-hexylfuran and the bromophenylfuran isomers. 

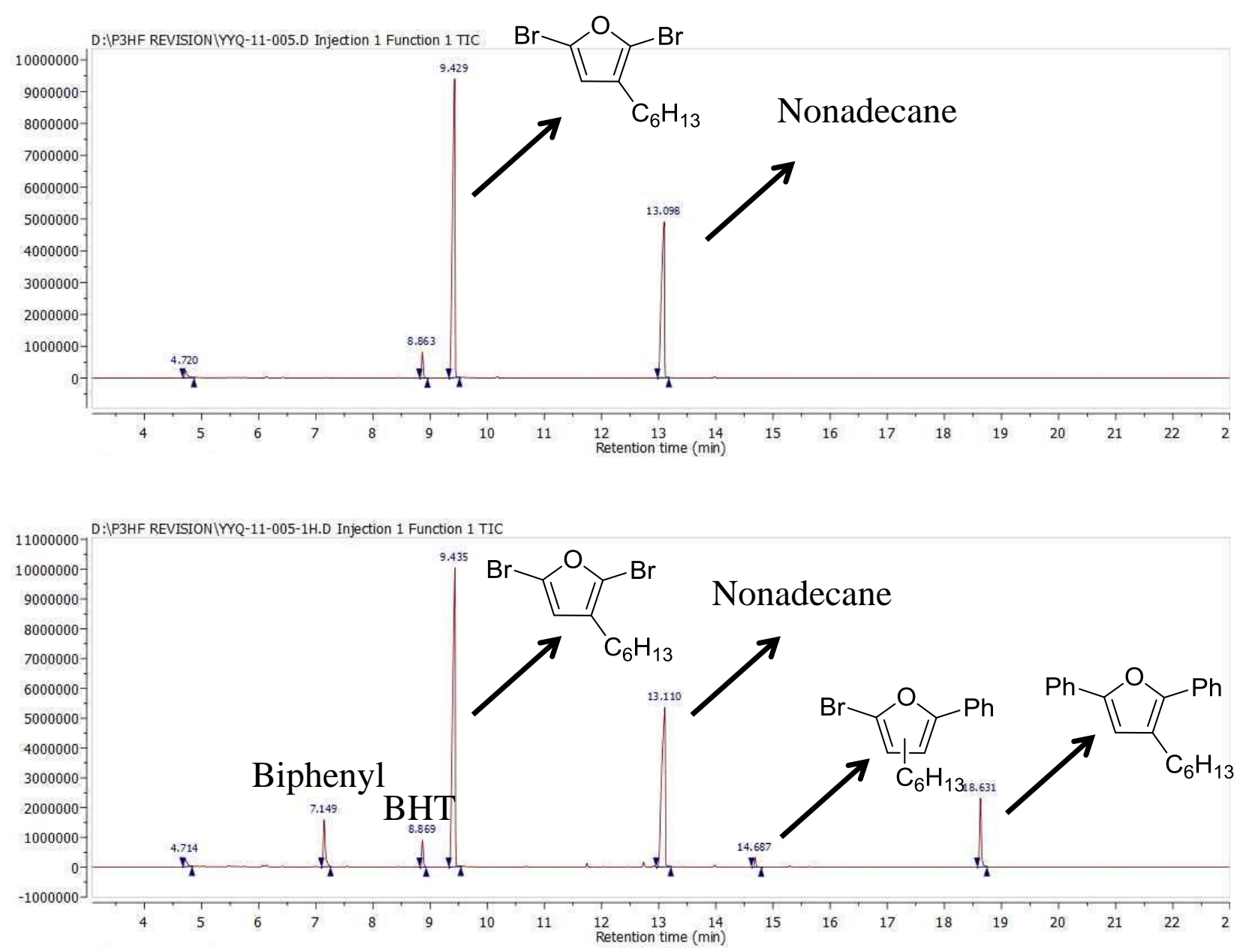

Figure S1. GC-MS chromatograms of the model compound reaction. Top - chromatogram of the reaction mixture at time $=0 \mathrm{~h}$. Bottom - chromatogram of the reaction mixture after $1 \mathrm{~h}$. 


\section{Quenching Study For Monomer 1.}

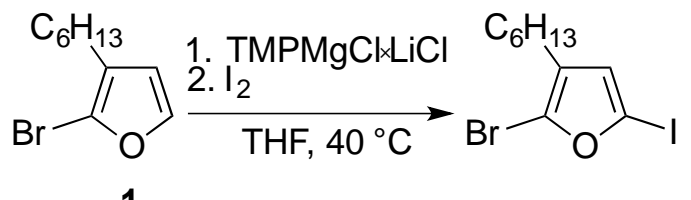

A $50 \mathrm{~mL}$ Schlenk flask was charged with compound $1(0.14 \mathrm{~g}, 0.61 \mathrm{mmol})$ and $20 \mathrm{~mL}$ of THF. TMPMgCl$\cdot \mathrm{LiCl}$ solution $(0.76 \mathrm{M}, 0.8 \mathrm{~mL}, 0.61 \mathrm{mmol})$ was slowly added to the reaction solution at room temperature. The flask was then immersed in an oil bath at $40{ }^{\circ} \mathrm{C}$. After stirring at $40{ }^{\circ} \mathrm{C}$ for $1 \mathrm{~h}$, iodine $(0.16 \mathrm{~g}, 0.63 \mathrm{mmol})$ was added into the reaction mixture and the mixture was stirred for 30 min while cooling to room temperature. The crude mixture was analyzed using GC-MS and ${ }^{1} \mathrm{H}$ NMR spectroscopy, which are shown below (Figure S2 and S3). The major product formed is the 2-bromo-3-hexyl-5-iodofuran with some starting material remaining in the reaction (2:1 ratio of product:starting material). Aromatic signal of the product: ${ }^{1} \mathrm{H}$ NMR (500 $\left.\mathrm{MHz} \mathrm{CDCl}_{3}\right) \delta 6.45(\mathrm{~s}, 1 \mathrm{H})$. 

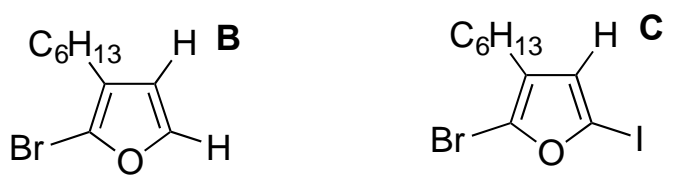

A
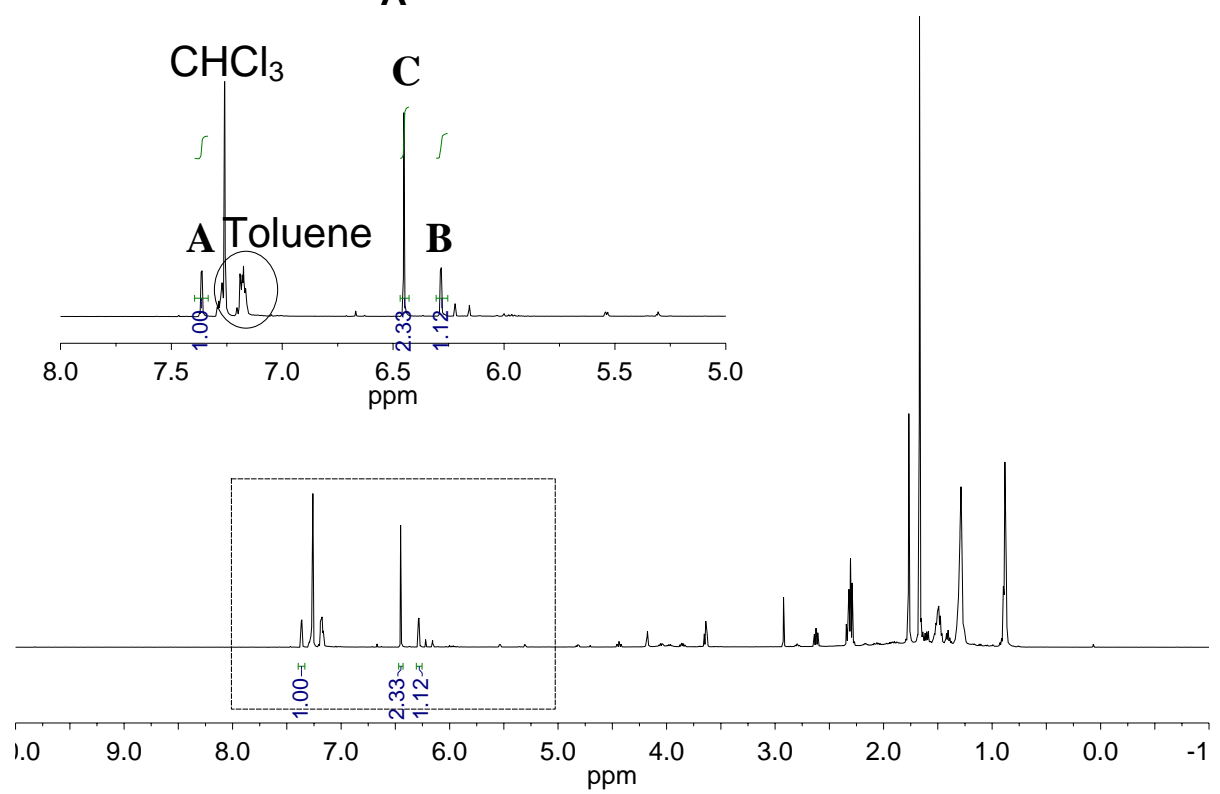

Figure S2. ${ }^{1} \mathrm{H}$ NMR spectrum of the crude reaction mixture. Insert is an expansion of the aromatic region (between 8 and $5 \mathrm{ppm}$ ). Signals of the product and starting material are labeled.

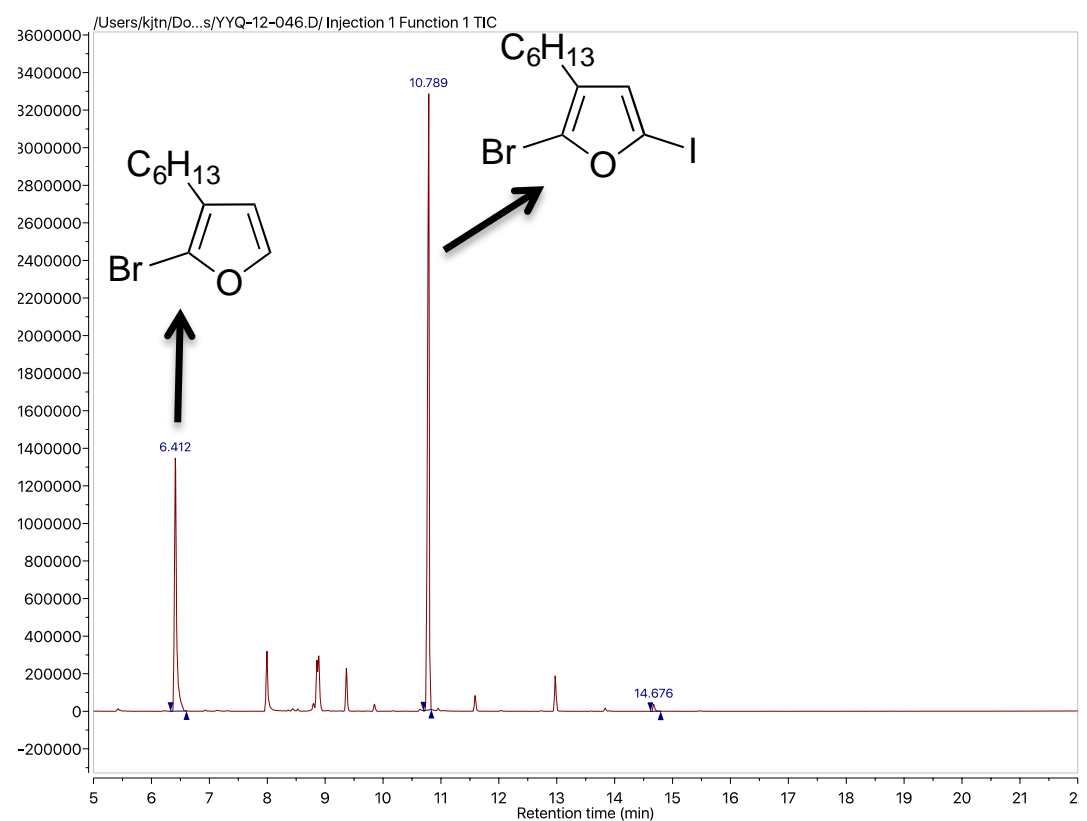

Figure S3. GC-MS chromatogram of the crude reaction mixture. Signals of the product and starting material are labeled. 


\section{Quenching Study For Monomer 3.}

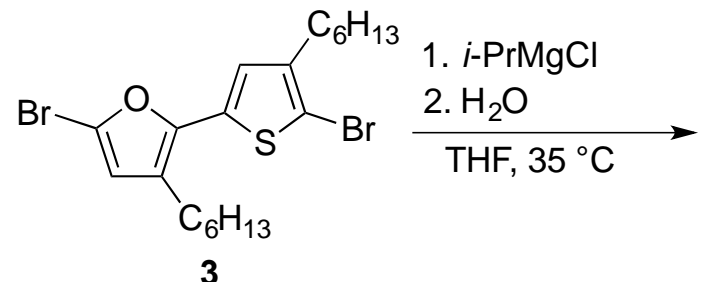

3

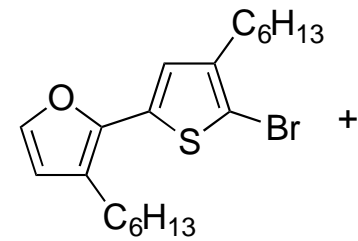

1

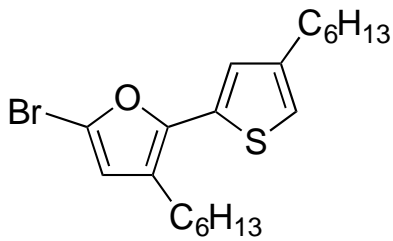

4

A $50 \mathrm{~mL}$ Schlenk flask was charged with compound $3(0.15 \mathrm{~g}, 0.31 \mathrm{mmol})$ and $10 \mathrm{~mL}$ of THF. The flask was cooled to $0{ }^{\circ} \mathrm{C}$, and $i$-PrMgCl solution $(2.0 \mathrm{M}, 0.15 \mathrm{~mL}, 0.30 \mathrm{mmol})$ was slowly added to the reaction mixture. After stirring at $0{ }^{\circ} \mathrm{C}$ for $15 \mathrm{~min}$, the flask was immersed into an oil bath at $35{ }^{\circ} \mathrm{C}$ and stirred for $0.5 \mathrm{~h}$ before being quenched with water . The crude mixture was analyzed using GC-MS and ${ }^{1} \mathrm{H}$ NMR spectroscopy, which are shown below (Figure S4 and S5). The major product formed is the 5-bromo-3-hexyl-2-(4-hexylthiophen-2-yl)furan and the minor product is the 2-(5-bromo-4-hexylthiophen-2-yl)-3-hexylfuran in a $\sim 4$ :1 ratio (major:minor determined by GC). Aromatic signals of major isomer: ${ }^{1} \mathrm{H} \mathrm{NMR}\left(500 \mathrm{MHz}, \mathrm{CDCl}_{3}\right) \delta 7.05(\mathrm{~d}, J$ $=1.4 \mathrm{~Hz}, 1 \mathrm{H}), 6.85(\mathrm{~d}, J=1.3 \mathrm{~Hz}, 1 \mathrm{H}), 6.25(\mathrm{~s}, 1 \mathrm{H})$. Aromatic signals of minor isomer: ${ }^{1} \mathrm{H}$ NMR $\left(500 \mathrm{MHz}, \mathrm{CDCl}_{3}\right) \delta 7.30(\mathrm{~d}, J=1.8 \mathrm{~Hz}, 1 \mathrm{H}), 6.89(\mathrm{~s}, 1 \mathrm{H}), 6.33(\mathrm{~d}, J=1.9 \mathrm{~Hz}, 1 \mathrm{H})$. 
<smiles>[B]c1c(C)oc(-c2sc(Br)c(CCCCCC)c2C)c1CCCCC</smiles>

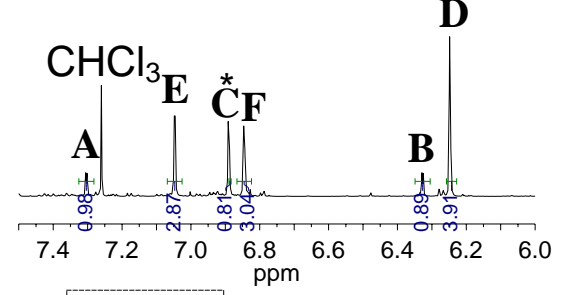

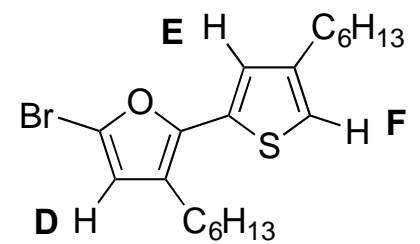

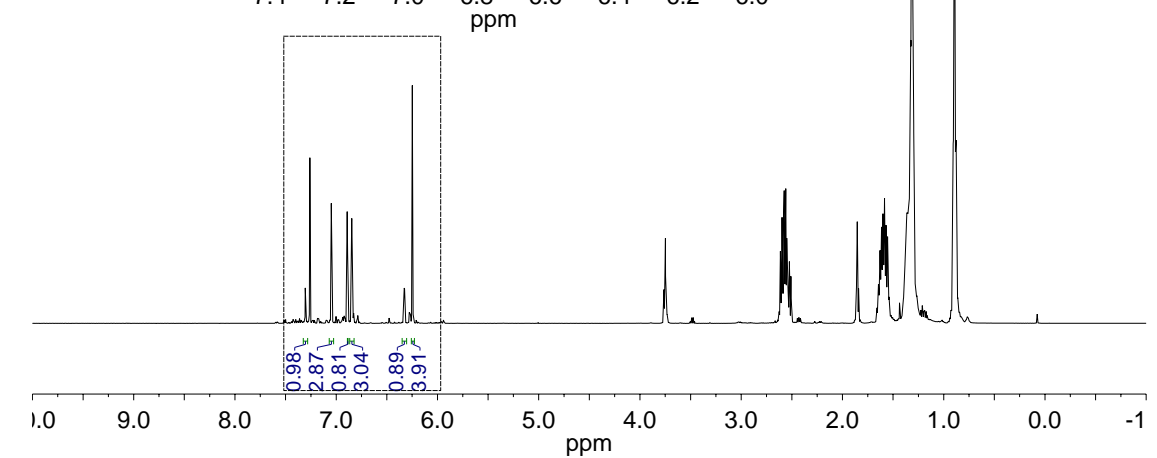

Figure S4. ${ }^{1} \mathrm{H}$ NMR spectrum of the crude reaction mixture. Insert is an expansion of the aromatic region (between 7.5 and $6 \mathrm{ppm}$ ). Signals of the product and starting material are labeled. The stars indicate two signals that are overlapping with some starting material in the mixture.

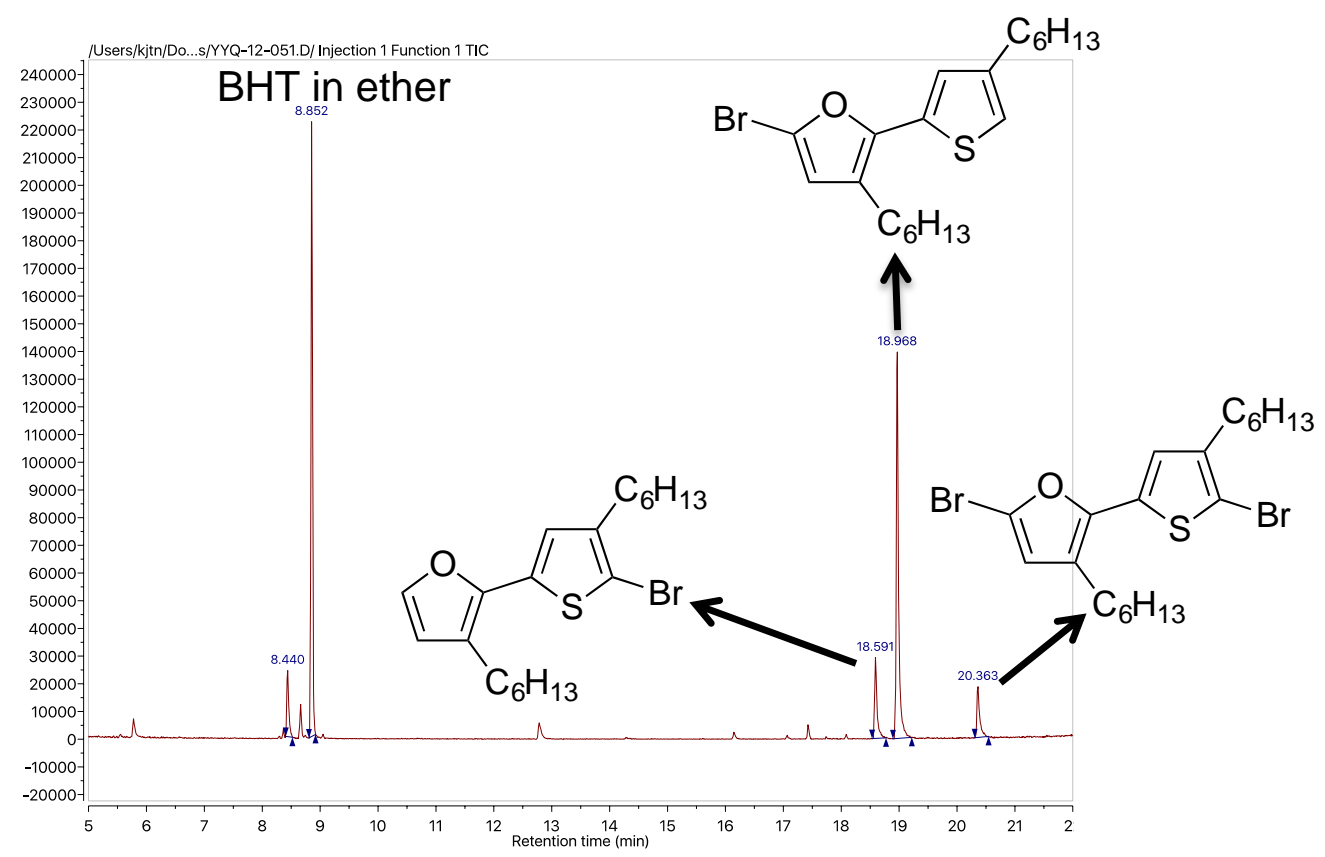

Figure S5. GC-MS chromatogram of the crude reaction mixture. Signals of the product and starting material are labeled. 


\section{Additional Competition Experiment for 2-Bromofuran and 2-Bromo-3-hexylthiophene.}

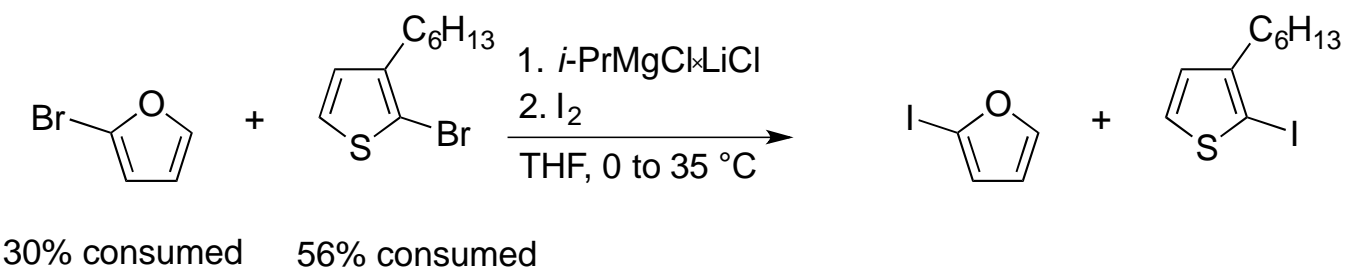

To better understand the quenching experiment for monomer $\mathbf{3}$, a competition experiment was also conducted. In a $40 \mathrm{~mL}$ vial, 2-bromofuran (0.088 g, $0.6 \mathrm{mmol})$ and 2-bromo-3hexylthiophene $(0.148 \mathrm{~g}, 0.6 \mathrm{mmol})$ were dissolved with $20 \mathrm{~mL}$ THF. The vial was cooled to $0{ }^{\circ} \mathrm{C}, i-\mathrm{PrMgCl} \cdot \mathrm{LiCl}$ solution $(1.3 \mathrm{M}, 0.46 \mathrm{~mL}, 0.6 \mathrm{mmol})$ was added to the reaction mixture. After stirring at $0{ }^{\circ} \mathrm{C}$ for $15 \mathrm{~min}$, the vial was immersed into an oil bath at $35{ }^{\circ} \mathrm{C}$ and stirred for $0.5 \mathrm{~h}$, and subsequently quenched with iodine. The crude mixture was analyzed using GC-MS, which is shown below (Figure S6). While 56\% of the 2-bromo-3-hexylthiophene was consumed, only $30 \%$ of the 2 -bromofuran was consumed. This indicates bromine magnesium exchange is more facile on the thiophene ring as compared to furan. To investigate the role of $\mathrm{LiCl}$ a similar investigation was carried out using $i$ - $\mathrm{PrMgCl}$ solution and the GC-MS analysis of the reaction mixture is shown in Figure S7. In this case, 64\% of the 2-bromo-3-hexylthiophene was consumed, while only $28 \%$ of the 2 -bromofuran was consumed. 

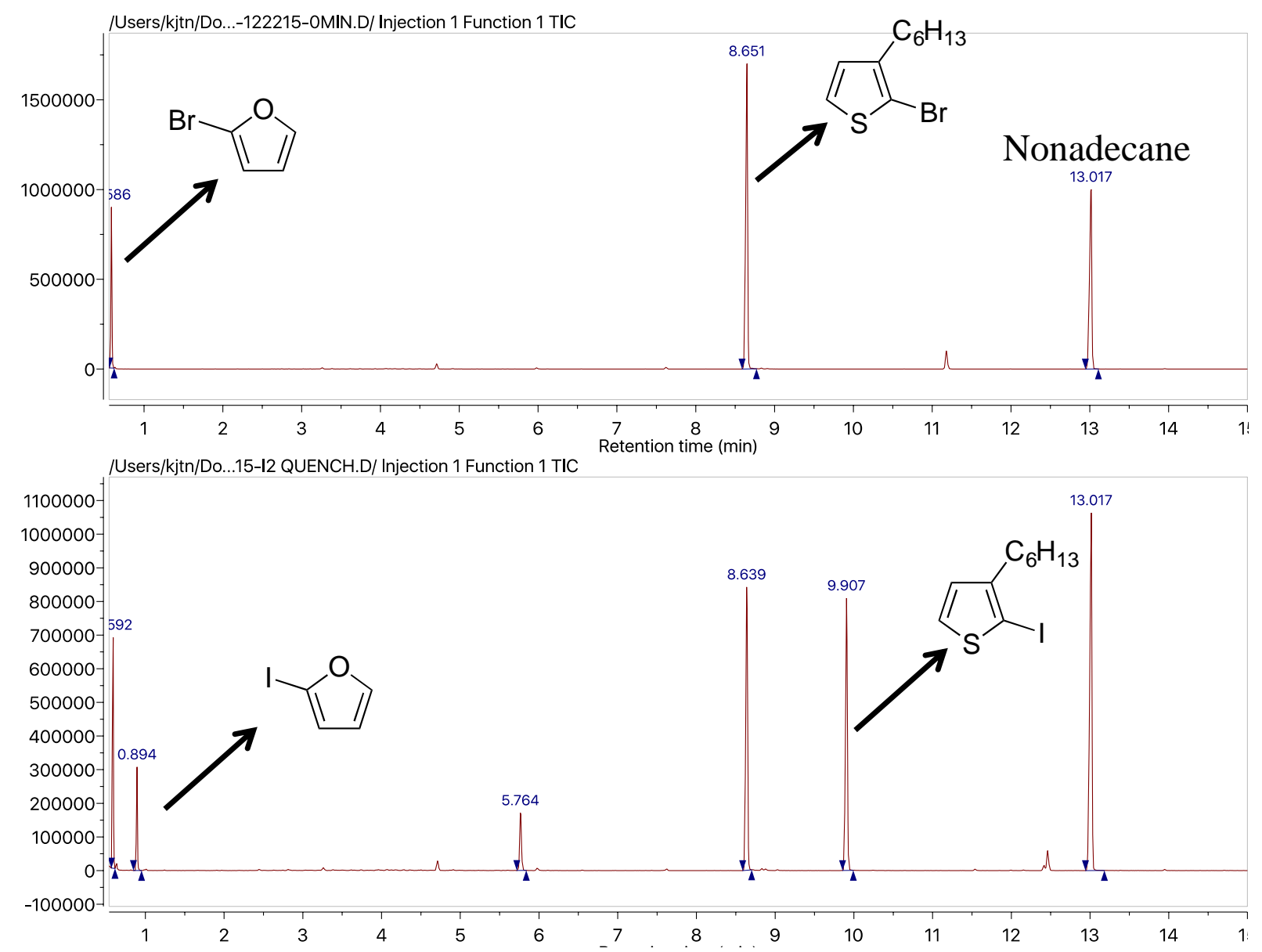

Figure S6. GC-MS chromatogram of the crude reaction mixture using $i$-PrMgCl$\cdot \mathrm{LiCl}$ solution. Top is at $\mathrm{t}=0 \mathrm{~h}$, bottom -reaction mixture after $\mathrm{I}_{2}$ quench. Signals of the product and starting material are labeled. 

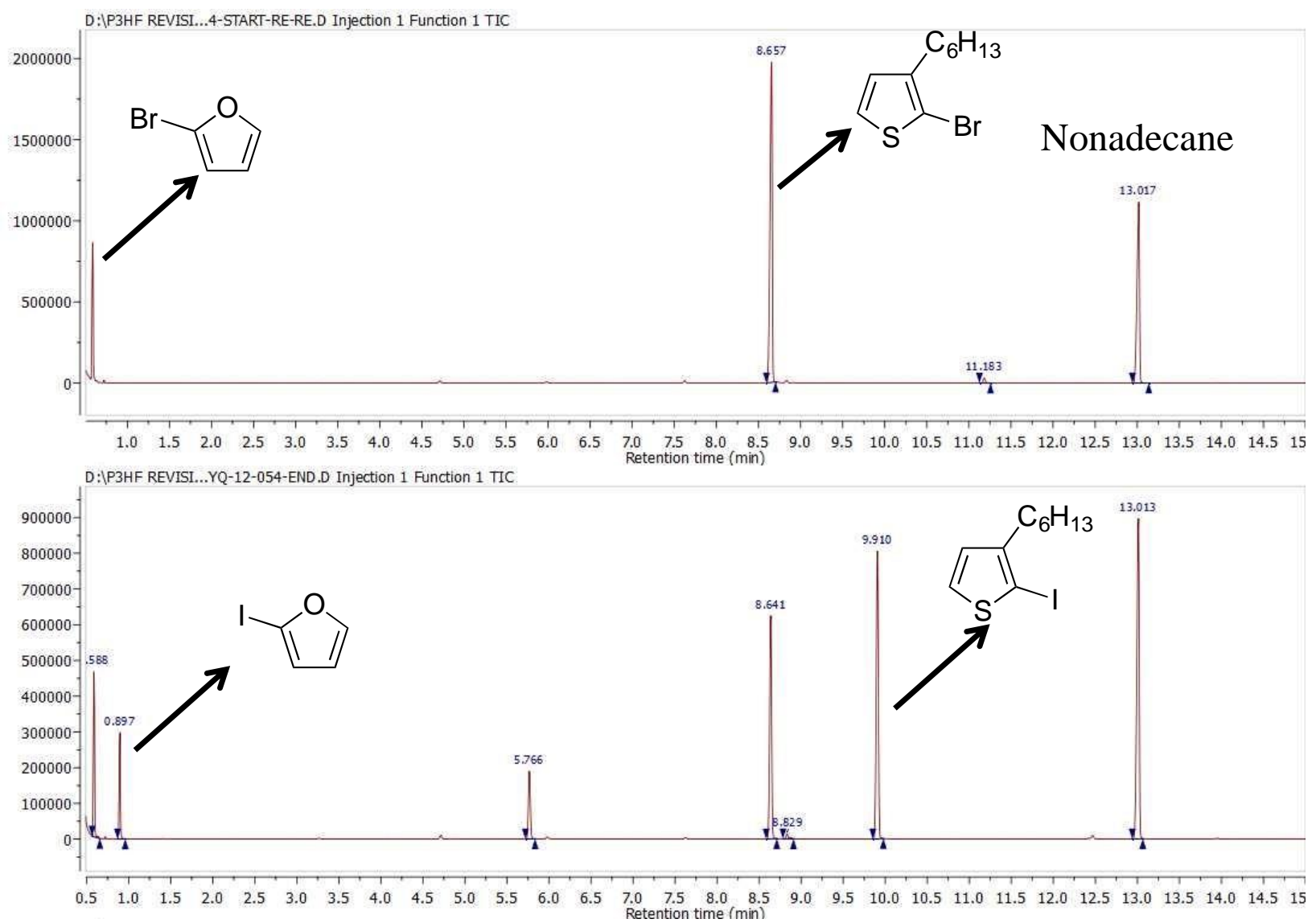

Figure S7. GC-MS chromatogram of the crude reaction mixture using $i$-PrMgCl solution. Top is at $\mathrm{t}=0 \mathrm{~h}$, bottom -reaction mixture after $\mathrm{I}_{2}$ quench. Signals of the product and starting material are labeled. 


\section{General Polymerization Conditions}

HT-P3HF. The polymerization reaction was conducted under a $\mathrm{N}_{2}$ atmosphere.

A $100 \mathrm{~mL}$ Schlenk flask was charged with compound $\mathbf{1}(0.28 \mathrm{~g}, 1.21 \mathrm{mmol})$ and

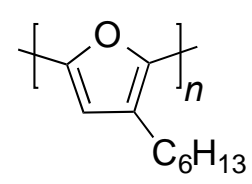
$40 \mathrm{~mL}$ of THF. TMPMgCl$\cdot \mathrm{LiCl}$ solution $(0.76 \mathrm{M}, 1.6 \mathrm{~mL}, 1.22 \mathrm{mmol})$ was slowly added to the reaction solution at room temperature. The flask was then immersed in an oil bath at $40{ }^{\circ} \mathrm{C}$. After stirring at $40{ }^{\circ} \mathrm{C}$ for $1 \mathrm{~h}$, a calculated amount of $\mathrm{Ni}(\mathrm{dppp}) \mathrm{Cl}_{2}(20$ or $10 \mathrm{~mol} \%)$ was quickly added into the solution in one portion. The polymerization was stirred at $40{ }^{\circ} \mathrm{C}$ for $20 \mathrm{~min}$ and subsequently quenched with $6 \mathrm{M}$ methanolic $\mathrm{HCl} .200 \mathrm{~mL}$ of methanol was then added to the red polymer suspension along with dimethylglyoxime to scavenge the nickel catalyst. The resultant mixture was stirred at room temperature for $1 \mathrm{~h}$ under protection from ambient light. The final polymer was collected by centrifugation, dried in vacuo and stored in the glovebox as a red powder. Yield: Entry 1 (0.10 g, 55\%), Entry 2 (0.13 g, 73\%) from Table 1 in the paper. Note: The integrations include the small aromatic signals observed downfield from the major signal at 6.47 ppm. ${ }^{1} \mathrm{H}$ NMR $\left(500 \mathrm{MHz}, \mathrm{CDCl}_{3}\right) \delta 6.47(\mathrm{~s}, 1 \mathrm{H}), 2.90-2.75(\mathrm{~m}, 2 \mathrm{H}), 1.79-1.65(\mathrm{~m}, 2 \mathrm{H})$, $1.52-1.43(\mathrm{~m}, 2 \mathrm{H}), 1.43-1.22(\mathrm{~m}, 4 \mathrm{H}), 0.97-0.81(\mathrm{~m}, 3 \mathrm{H}) .{ }^{13} \mathrm{C} \mathrm{NMR}\left(126 \mathrm{MHz}, \mathrm{CDCl}_{3}\right) \delta$ $146.0,140.9,124.5,109.0,32.0,30.3,29.5,25.6,22.9,14.4$.

HH-P3HF. The polymerization reaction was conducted under a $\mathrm{N}_{2}$

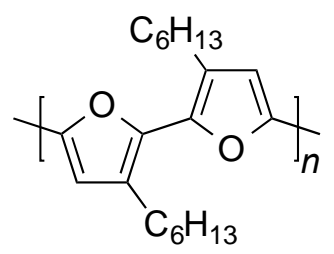
$\mathrm{g}, 1.24 \mathrm{mmol})$ and $40 \mathrm{~mL}$ of THF. $i$-PrMgCl$\cdot \mathrm{LiCl}$ solution $(1.3 \mathrm{M}, 0.9 \mathrm{~mL}$, $1.17 \mathrm{mmol}$ ) was slowly added to the reaction at room temperature. The flask was then immersed in an oil bath at $40{ }^{\circ} \mathrm{C}$. After stirring at $40{ }^{\circ} \mathrm{C}$ for $1 \mathrm{~h}$, an aliquot was withdrawn and subjected to GC-MS analysis to determine the monomer content (84\% active monomer, $11 \%$ starting material, $5 \%$ bismetallated compound $). \mathrm{Ni}(\mathrm{dppp}) \mathrm{Cl}_{2}(66.7 \mathrm{mg}, 0.12 \mathrm{mmol})$ was then quickly added into 
the solution in one portion. The polymerization was stirred at $40{ }^{\circ} \mathrm{C}$ for $20 \mathrm{~min}$ and subsequently quenched with $6 \mathrm{M}$ methanolic $\mathrm{HCl} .200 \mathrm{~mL}$ of methanol was then added to the red polymer suspension along with dimethylglyoxime to scavenge the nickel catalyst. The resultant mixture was stirred at room temperature for $1 \mathrm{~h}$ under protection from ambient light. The final polymer was collected by centrifuge, dried in vacuo and stored in the glovebox as a red powder. Yield: Entry $3(0.16 \mathrm{~g}, 42 \%)$ from Table 1 in the paper. ${ }^{1} \mathrm{H} \mathrm{NMR}\left(500 \mathrm{MHz}, \mathrm{CDCl}_{3}\right) \delta 6.52(\mathrm{~s}, 2 \mathrm{H})$, $2.85-2.70(\mathrm{~m}, 4 \mathrm{H}), 1.75-1.65(\mathrm{~m}, 4 \mathrm{H}), 1.50-1.40(\mathrm{~m}, 4 \mathrm{H}), 1.40-1.21(\mathrm{~m}, 8 \mathrm{H}), 0.95-0.80$ $(\mathrm{m}, 6 \mathrm{H}) .{ }^{13} \mathrm{C} \mathrm{NMR}\left(126 \mathrm{MHz}, \mathrm{CDCl}_{3}\right) \delta 145.0,142.0,124.9,108.8,32.0,30.5,29.5,25.6,23.0$, 14.3.

P3HF-a-P3HT. The polymerization reaction was conducted under a $\mathrm{N}_{2}$ atmosphere. A $50 \mathrm{~mL}$ Schlenk flask was charged with compound $\mathbf{3}$ $(0.29 \mathrm{~g}, 0.61 \mathrm{mmol})$ and $20 \mathrm{~mL}$ of THF. The flask was cooled to $0{ }^{\circ} \mathrm{C}$,

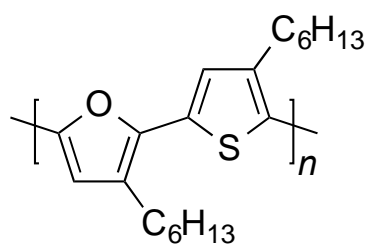
and $i-\mathrm{PrMgCl} \cdot \mathrm{LiCl}$ solution $(1.3 \mathrm{M}, 0.46 \mathrm{~mL}, 0.60 \mathrm{mmol})$ was slowly added to the reaction mixture. After stirring at $0{ }^{\circ} \mathrm{C}$ for $15 \mathrm{~min}$, the flask was immersed in an oil bath at $35{ }^{\circ} \mathrm{C}$ and stirred for $0.5 \mathrm{~h}$. An aliquot was then withdrawn and subjected to GC-MS analysis to determine the content of active monomer (70\% major, $17 \%$ minor, $11 \%$ starting material and $2 \%$ bismetallated compound). The mixture was cooled to room temperature and stirred for another $0.5 \mathrm{~h}$. A calculated amount of $\mathrm{Ni}(\mathrm{dppp}) \mathrm{Cl}_{2}(5,2.5$ and $1.25 \mathrm{~mol} \%)$ was then quickly added into the solution in one portion. The polymerization was stirred at $22{ }^{\circ} \mathrm{C}$ for 30 to $40 \mathrm{~min}$ then quenched with $6 \mathrm{M}$ methanolic $\mathrm{HCl} .200 \mathrm{~mL}$ of methanol was then added to the red polymer suspension along with dimethylglyoxime to scavenge the nickel catalyst. The resultant mixture was stirred at room temperature for $1 \mathrm{~h}$ under protection from ambient light. The final polymer was collected by suction filtration, washed with methanol and acetone, dried in vacuo and stored 
in the glovebox as a red powder. Yield: Entry $4(0.09 \mathrm{~g}, 46 \%)$, Entry $5(0.11 \mathrm{~g}, 57 \%)$ and Entry 6 $(0.07 \mathrm{~g}, 35 \%)$ from Table 1 in the paper. ${ }^{1} \mathrm{H}$ NMR $\left(500 \mathrm{MHz}, \mathrm{CDCl}_{3}\right) \delta 7.06(\mathrm{br} \mathrm{s}, 1 \mathrm{H}), 6.42(\mathrm{br}$ $\mathrm{s}, 1 \mathrm{H}), 2.97-2.78(\mathrm{~m}, 2 \mathrm{H}), 2.73-2.63(\mathrm{~m}, 2 \mathrm{H}), 1.81-1.65(\mathrm{~m}, 4 \mathrm{H}), 1.58-1.43(\mathrm{~m}, 4 \mathrm{H}), 1.42$ $-1.20(\mathrm{~m}, 8 \mathrm{H}), 0.96-0.80(\mathrm{~m}, 6 \mathrm{H}) .{ }^{13} \mathrm{C} \mathrm{NMR}\left(126 \mathrm{MHz}, \mathrm{CDCl}_{3}\right) \delta 147.7,143.9,140.0,131.0$, $125.8,125.7,124.3,110.6,32.1,32.0,30.5,30.2,29.8,29.4,26.2,23.0,22.9,14.4$. Note: only 10 of the 12 possible signals from the hexyl chains are visible due to similarities between chemical environments.

\section{Procedure for obtaining $M_{\mathrm{n}}$ versus conversion plot}

The polymerization reaction was conducted under a $\mathrm{N}_{2}$ atmosphere. A $50 \mathrm{~mL}$ Schlenk flask was charged with compound $3(0.29 \mathrm{~g}, 0.61 \mathrm{mmol})$, nonadecane as internal standard and $20 \mathrm{~mL}$ of THF. The flask was cooled to $0{ }^{\circ} \mathrm{C}$ using an ice-water bath, and $i$-PrMgCl$\cdot \mathrm{LiCl}$ solution $(1.3 \mathrm{M}$, $0.46 \mathrm{~mL}, 0.60 \mathrm{mmol}$ ) was slowly added to the reaction mixture. After stirring at $0{ }^{\circ} \mathrm{C}$ for $15 \mathrm{~min}$, the flask was immersed into an oil bath at $35{ }^{\circ} \mathrm{C}$ and stirred for $0.5 \mathrm{~h}$. An aliquot was then withdrawn and subjected to GC-MS analysis to determine the initial ratio of monomer to the internal standard. The mixture was cooled to room temperature and stirred for another $0.5 \mathrm{~h}$. $\mathrm{Ni}(\mathrm{dppp}) \mathrm{Cl}_{2}(4.2 \mathrm{mg}, 0.0077 \mathrm{mmol})$ was then quickly added into the solution in one portion. Aliquots $(\sim 0.4 \mathrm{~mL})$ were withdrawn after $0.5,2,5,10,20$ and $40 \mathrm{~min}$ to determine the monomer conversion (major + minor using GC-MS) and polymer molecular weight (GPC).

Table S1. Data used to construct $M_{\mathrm{n}}$ versus total monomer conversion plot.

\begin{tabular}{cccc}
\hline Time $(\mathrm{min})$ & Total Monomer Conv. & Molecular Weight $\left(M_{\mathrm{n}}\right)$ & Dispersity \\
\hline 0.5 & 16 & 3300 & 1.32 \\
2 & 25 & 6500 & 1.50 \\
5 & 52 & 9200 & 1.43 \\
10 & 67 & 10600 & 1.41 \\
20 & 73 & 11700 & 1.40 \\
40 & 79 & 11900 & 1.41 \\
\hline
\end{tabular}



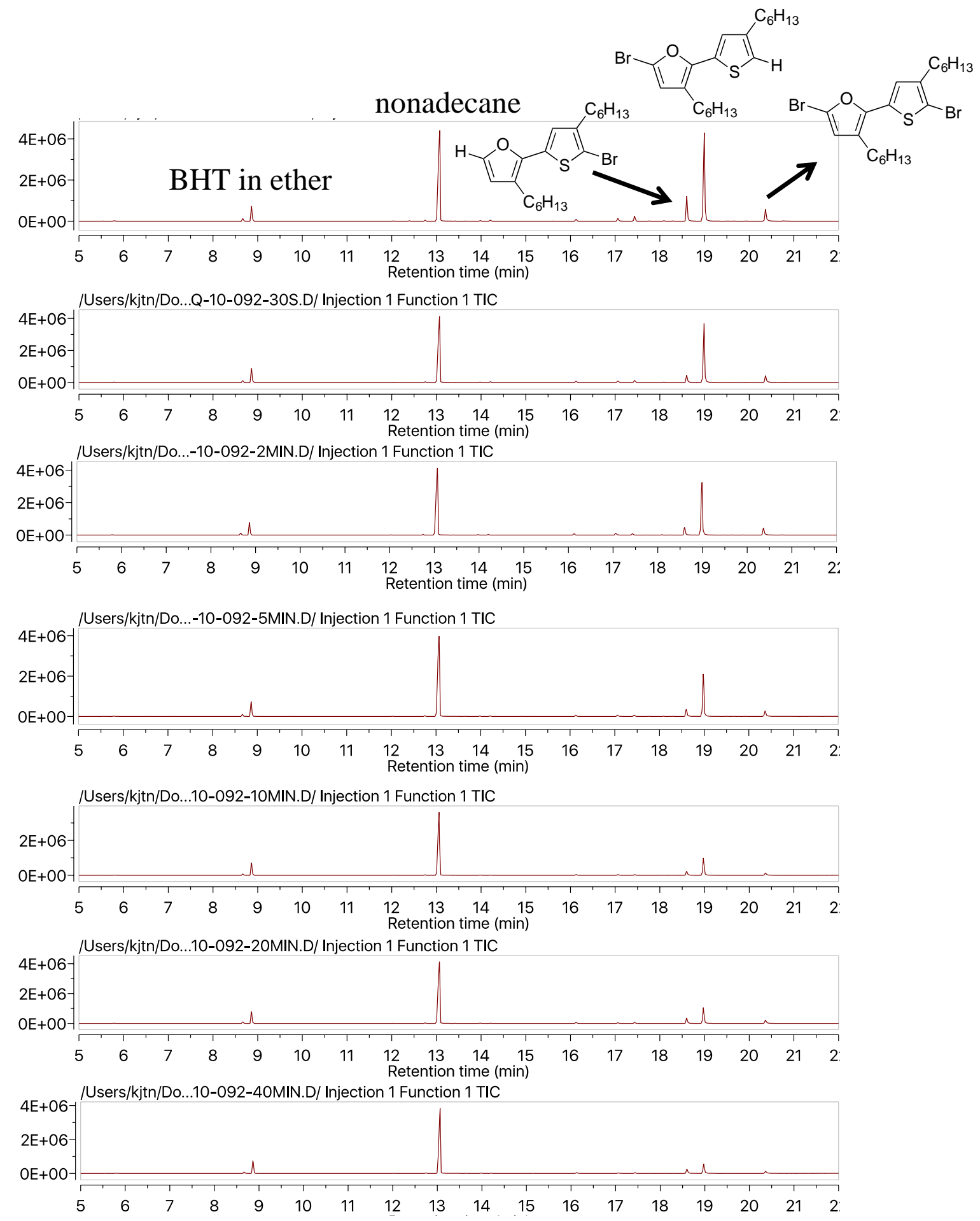

Figure S8. Stack Plot of GC-MS Traces from the $M_{\mathrm{n}}$ versus conversion plot. The signal at $\sim 13$ min corresponds to nonadecane which was used to determine conversion. The two isomers correspond to H-terminated monomer and are observed near $19 \mathrm{~min}$. The dibromo starting material $\mathbf{3}$ is observed at $\sim 21 \mathrm{~min}$. 


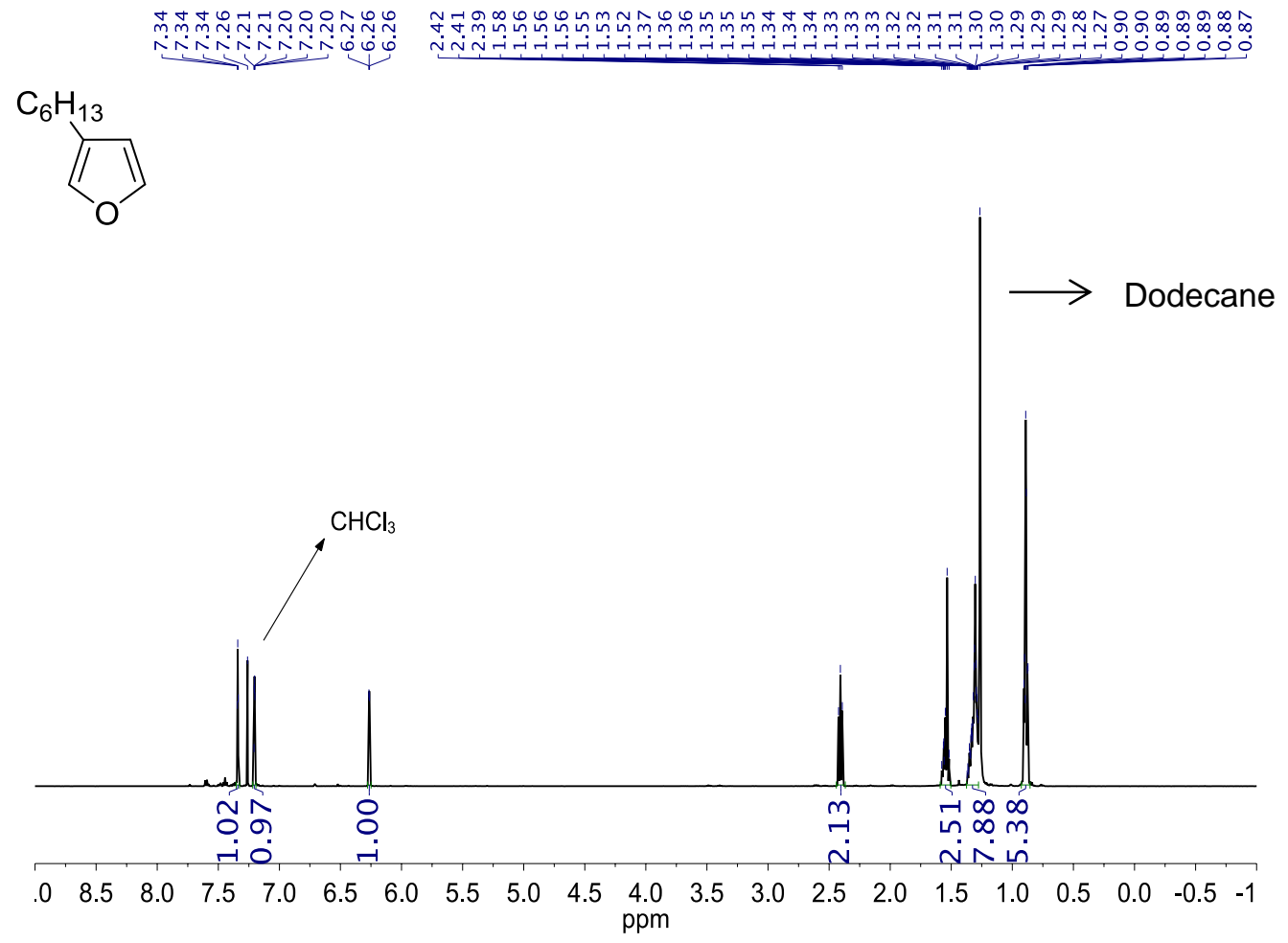

Figure S9. Compound $\mathbf{A}^{1} \mathrm{H}$ NMR Spectrum $-500 \mathrm{MHz}, \mathrm{CDCl}_{3}$.

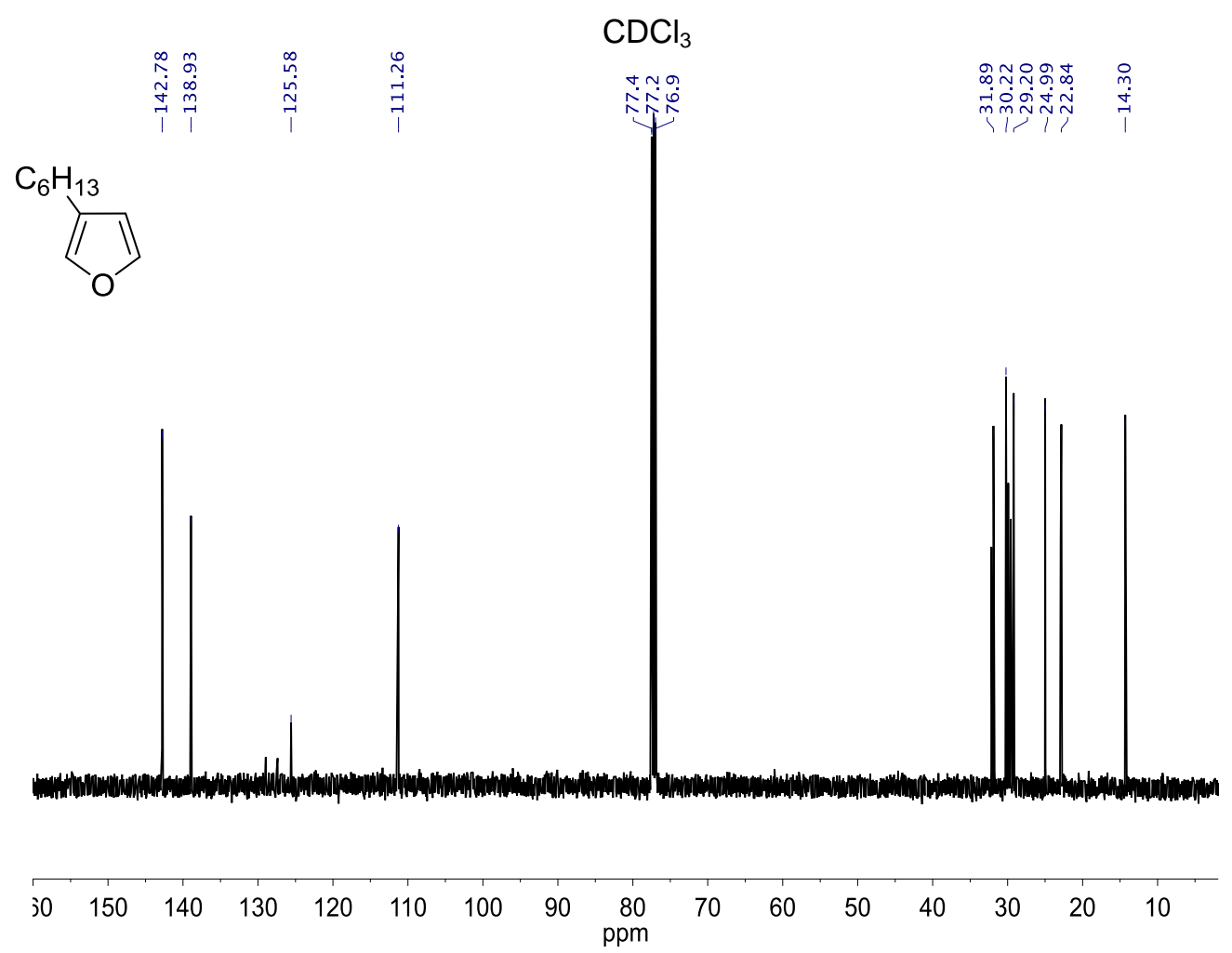

Figure S10. Compound $\mathbf{A}{ }^{13} \mathrm{C}$ NMR Spectrum $-126 \mathrm{MHz}, \mathrm{CDCl}_{3}$. 


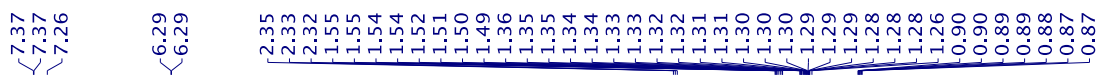

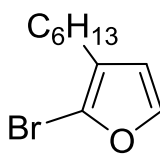

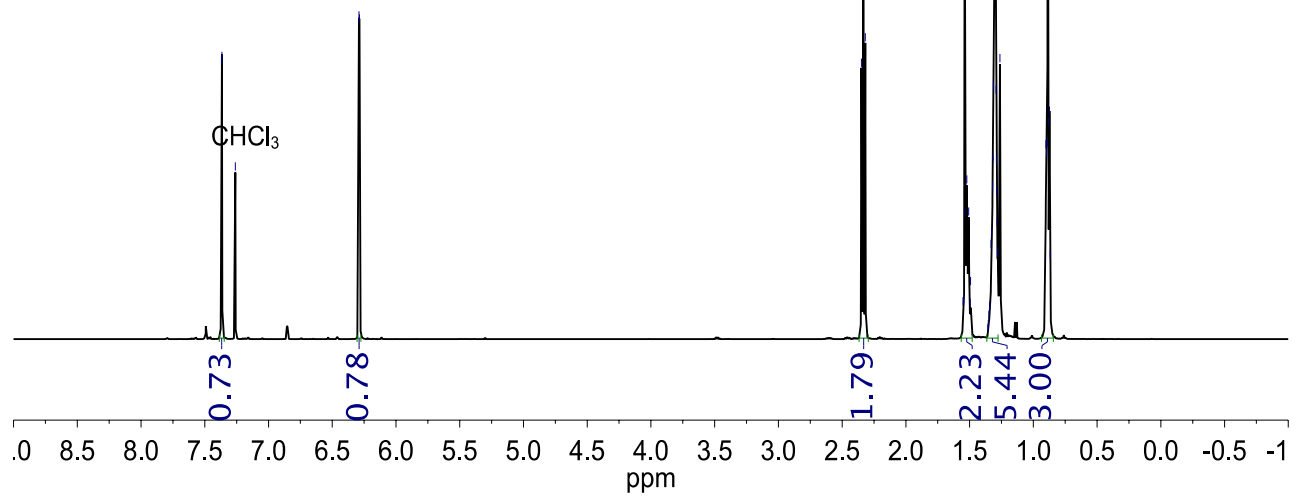

Figure S11. Compound $1{ }^{1} \mathrm{H}$ NMR Spectrum - $500 \mathrm{MHz}, \mathrm{CDCl}_{3}$.

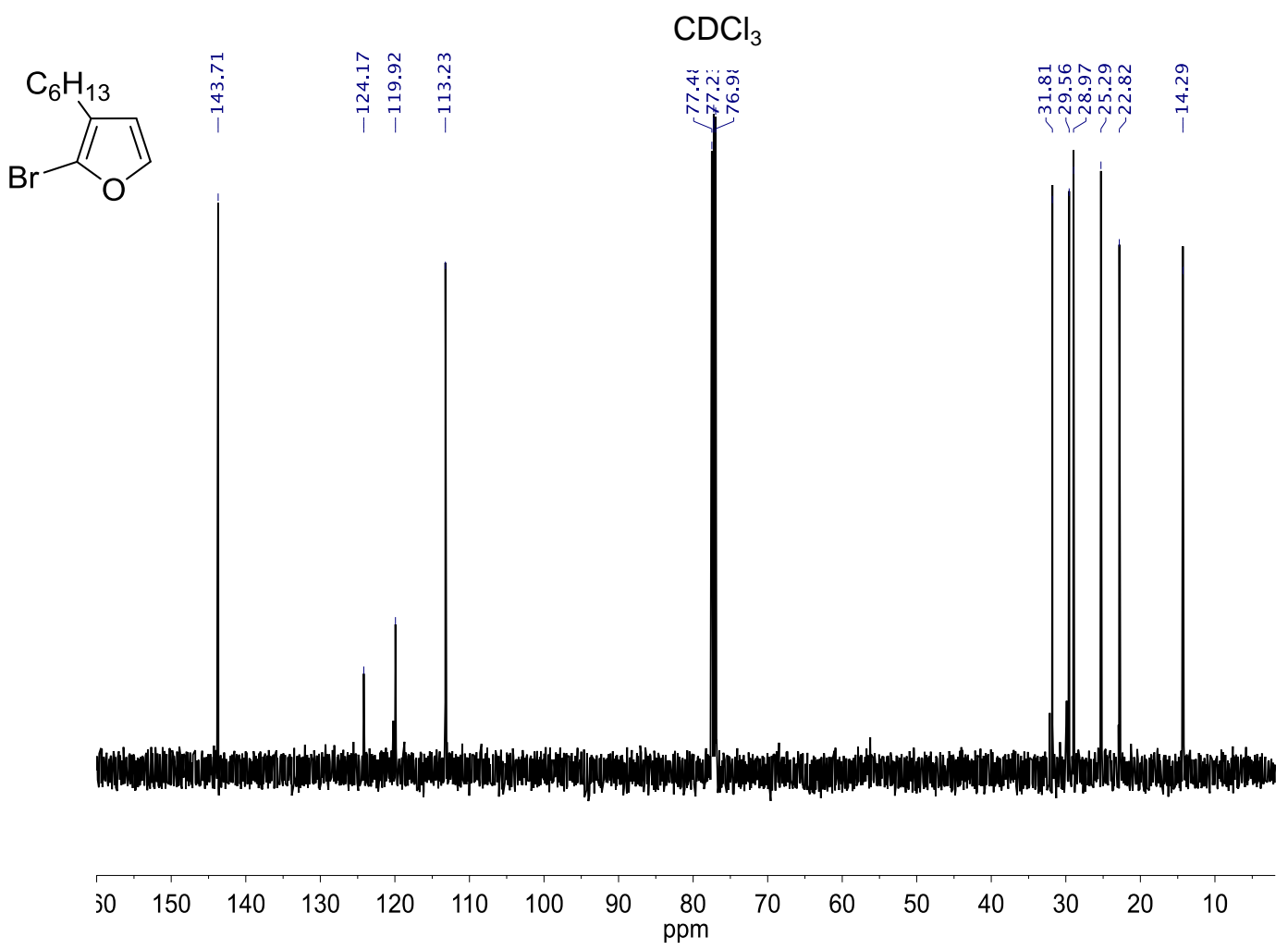

Figure S12. Compound $1{ }^{13} \mathrm{C}$ NMR Spectrum - $126 \mathrm{MHz}, \mathrm{CDCl}_{3}$. 


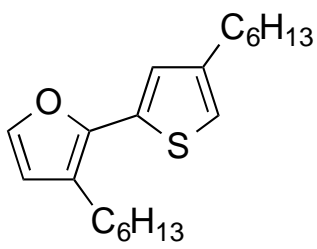
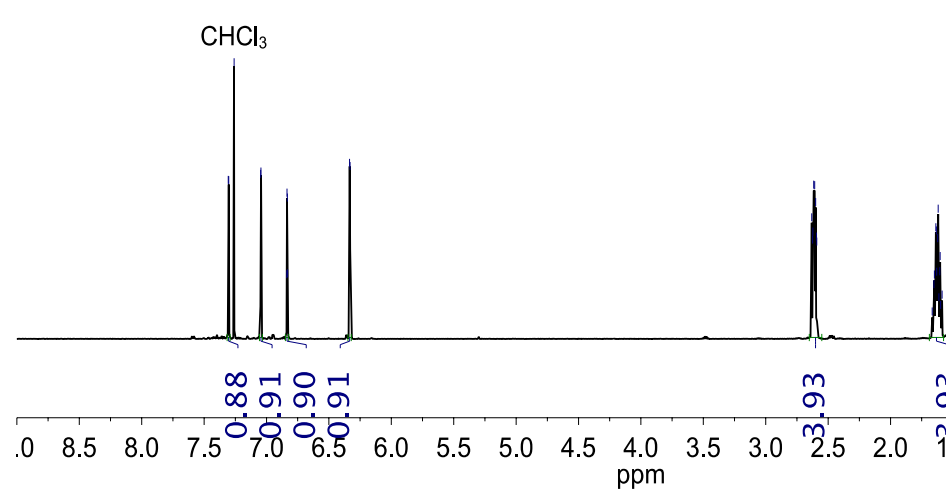

Figure S13. Compound B ${ }^{1} \mathrm{H}$ NMR Spectrum - $500 \mathrm{MHz}, \mathrm{CDCl}_{3}$.

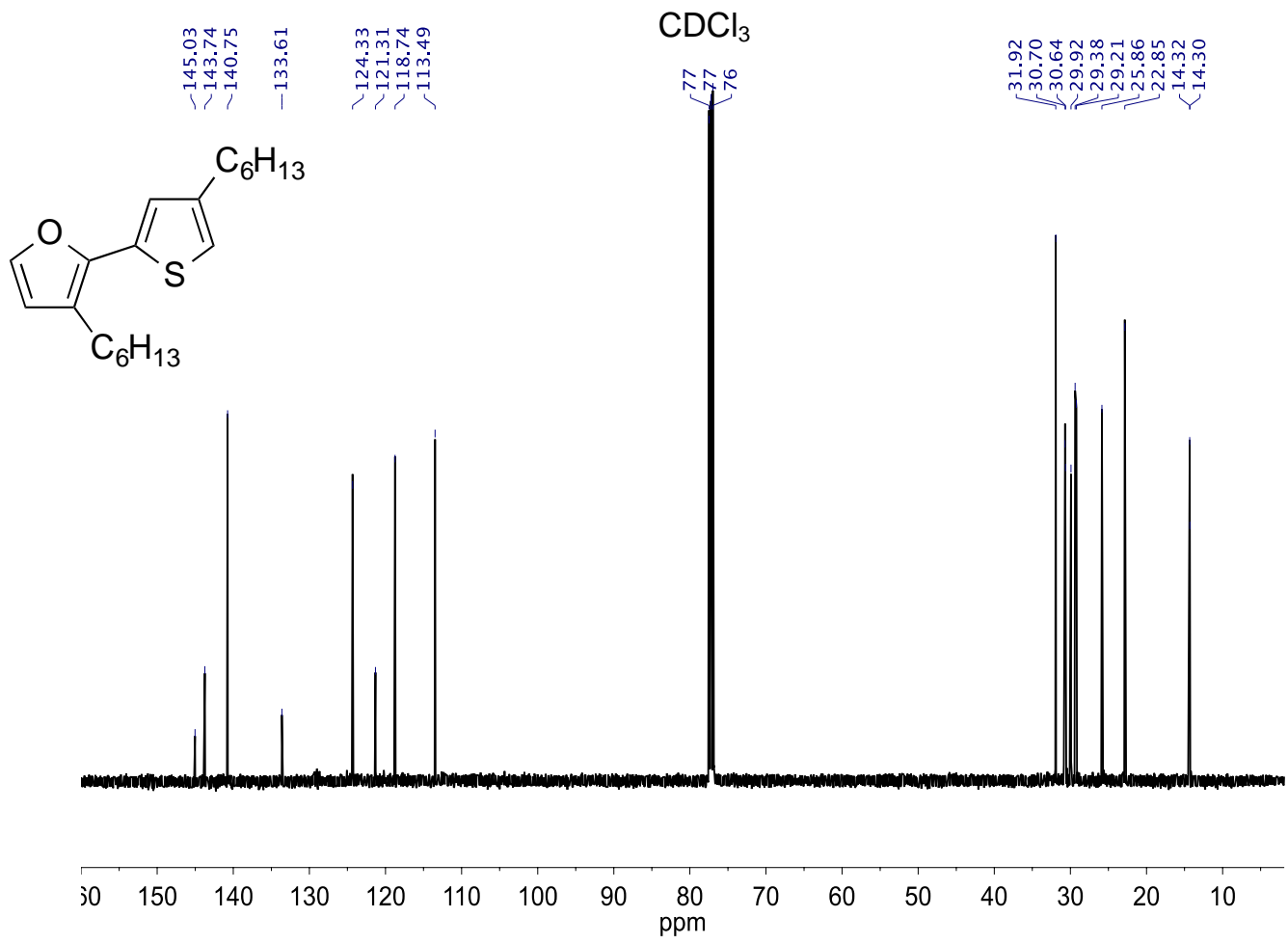

Figure S14. Compound $\mathbf{B}{ }^{13} \mathrm{C}$ NMR Spectrum - $126 \mathrm{MHz}, \mathrm{CDCl}_{3}$. 


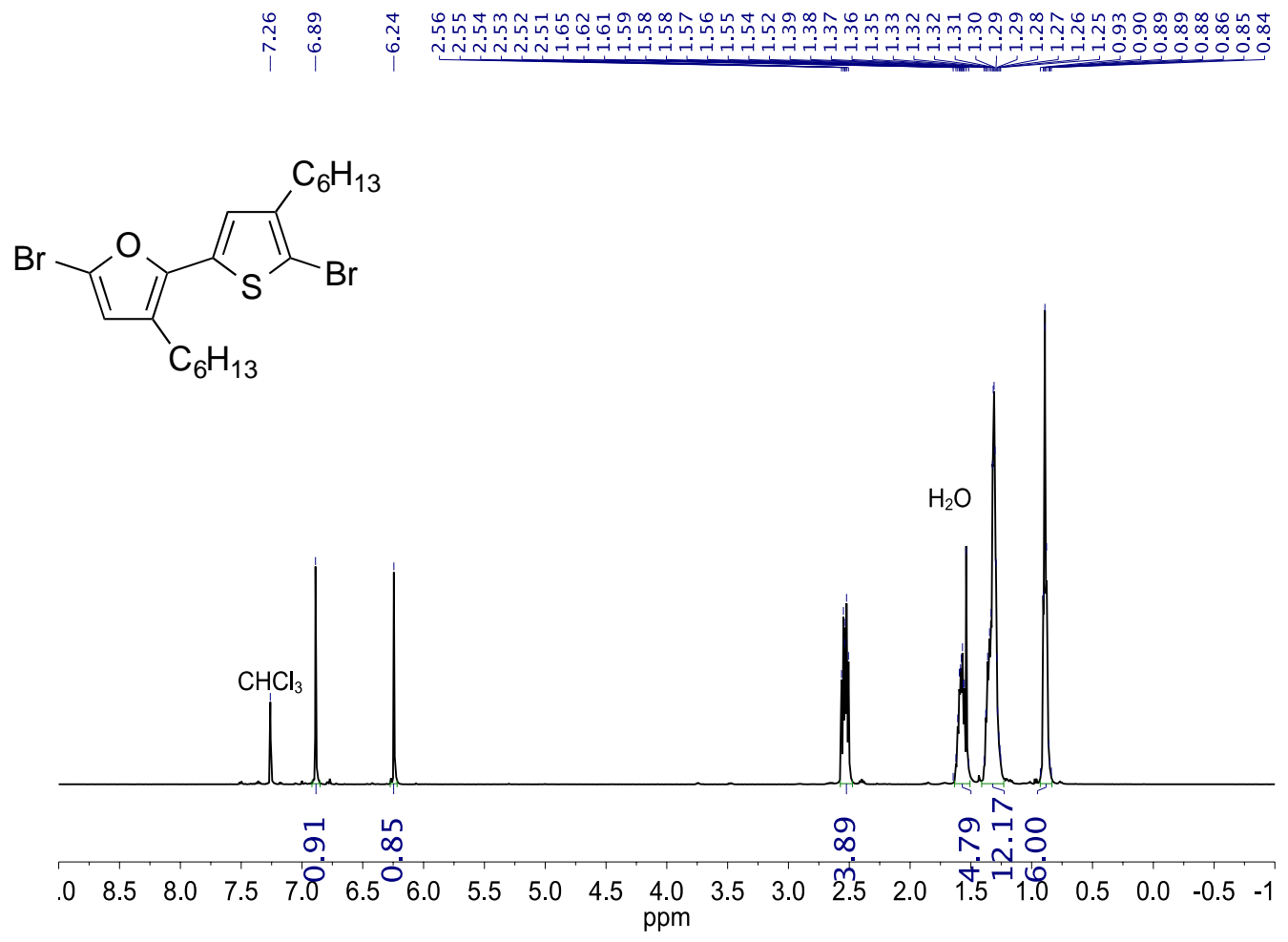

Figure S15. Compound $3{ }^{1} \mathrm{H}$ NMR Spectrum - $500 \mathrm{MHz}, \mathrm{CDCl}_{3}$.

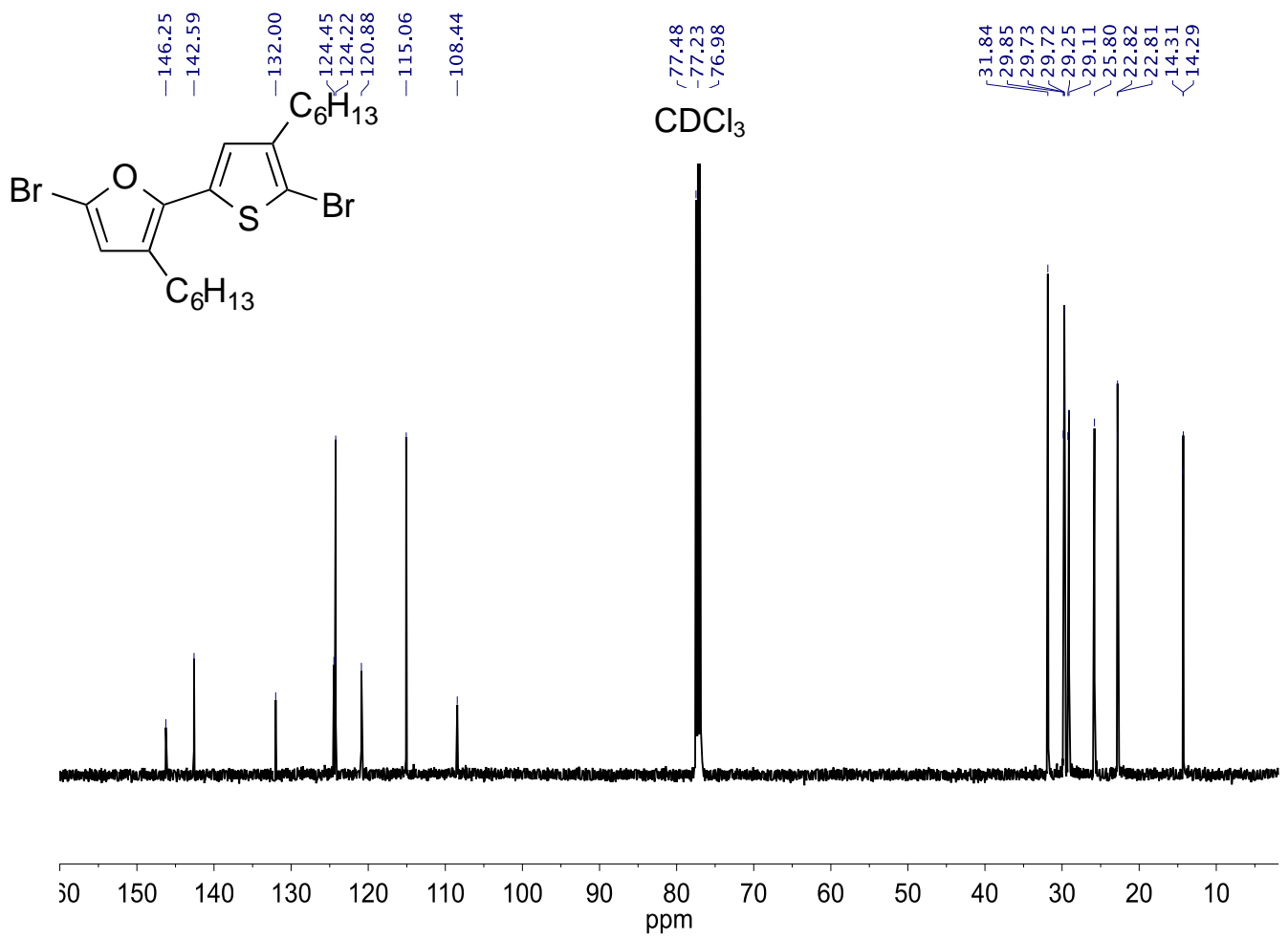

Figure S16. Compound $3{ }^{13} \mathrm{C}$ NMR Spectrum - $126 \mathrm{MHz}, \mathrm{CDCl}_{3}$. 


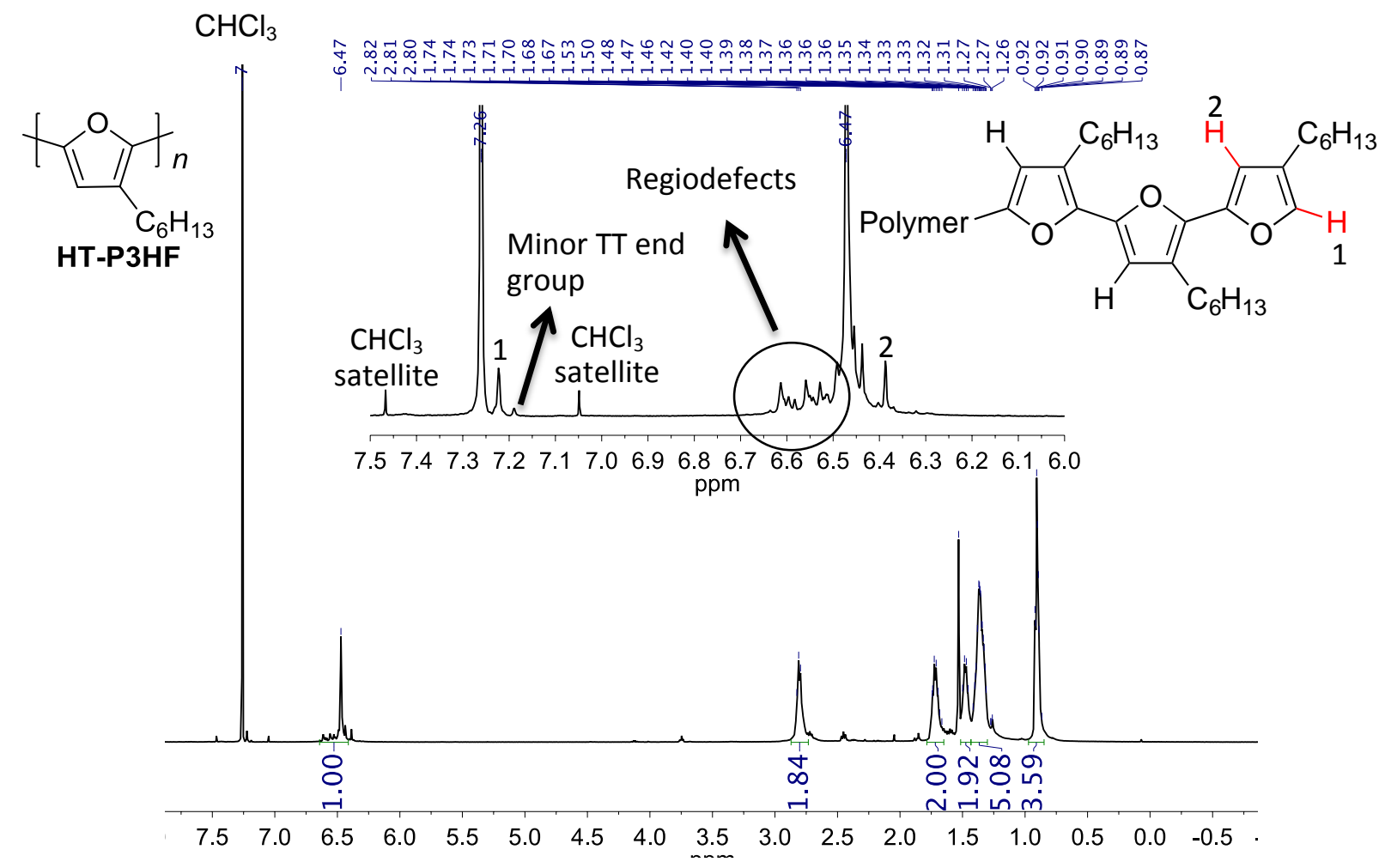

Figure S17. Polymer HT-P3HF ${ }^{1} \mathrm{H}$ NMR Spectrum - $500 \mathrm{MHz}, \mathrm{CDCl}_{3}$.
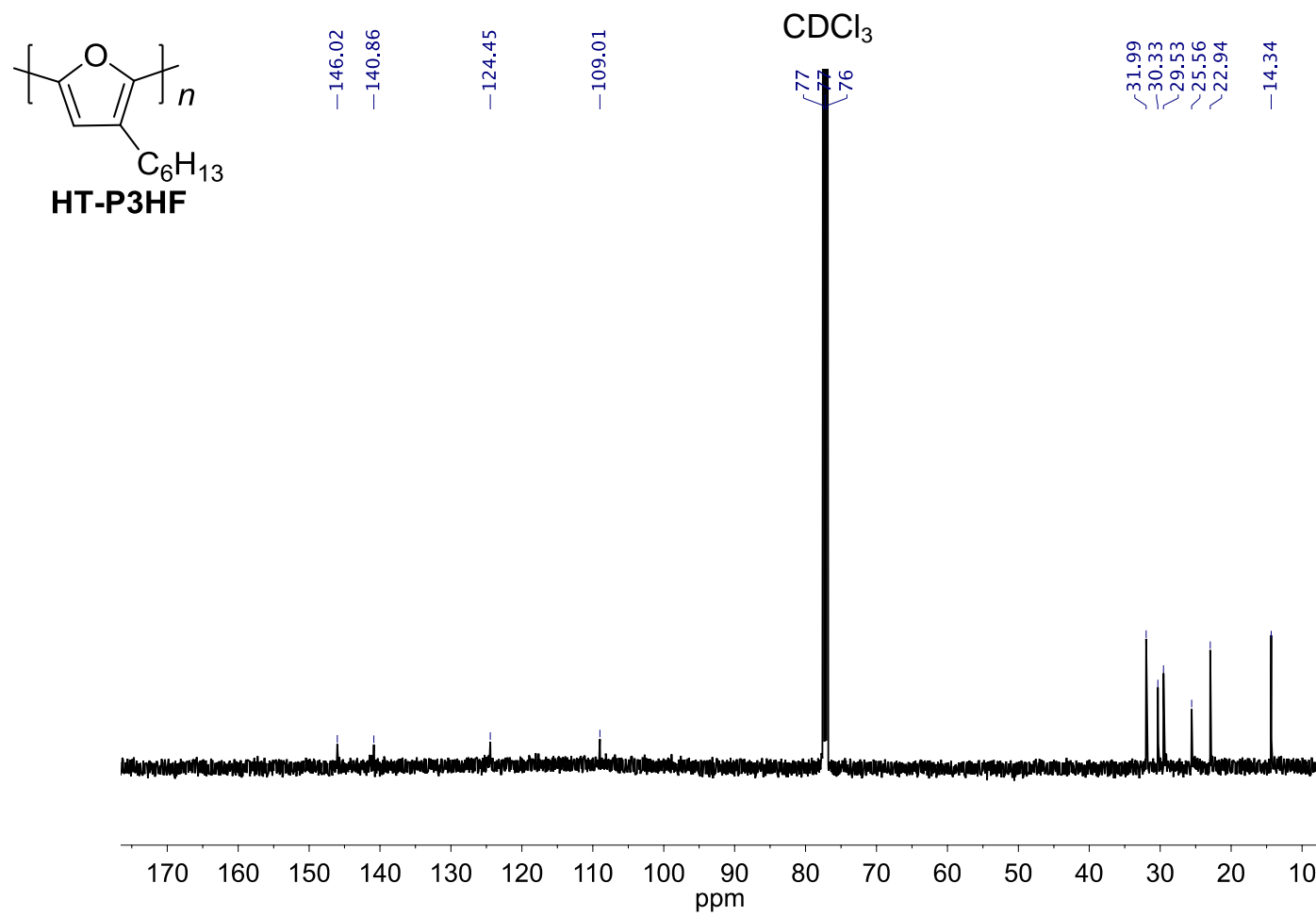

Figure S18. Polymer HT-P3HF ${ }^{13} \mathrm{C}$ NMR Spectrum - $126 \mathrm{MHz}, \mathrm{CDCl}_{3}$. 


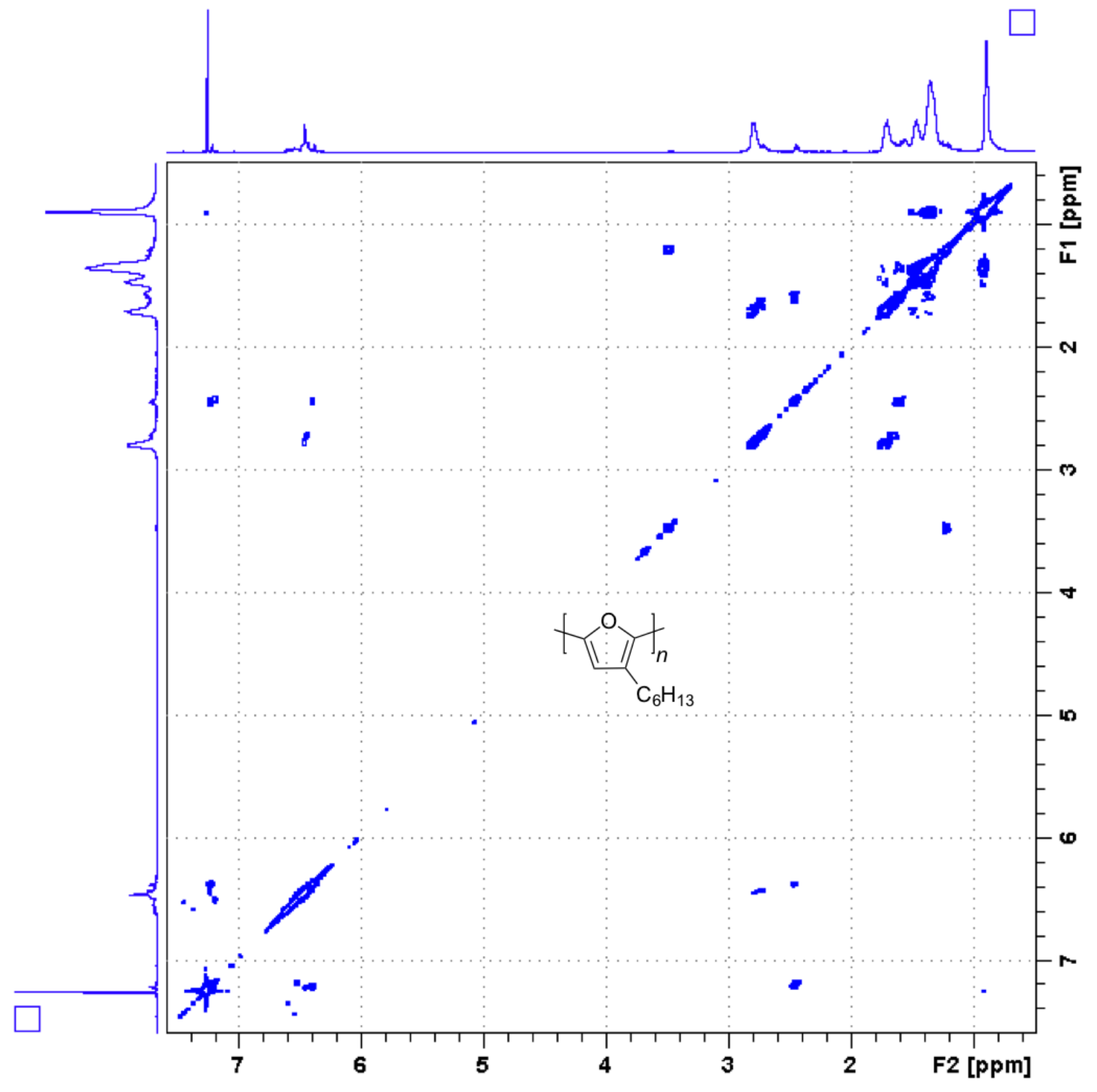

Figure S19. Long-range COSY of HT-P3HF. 


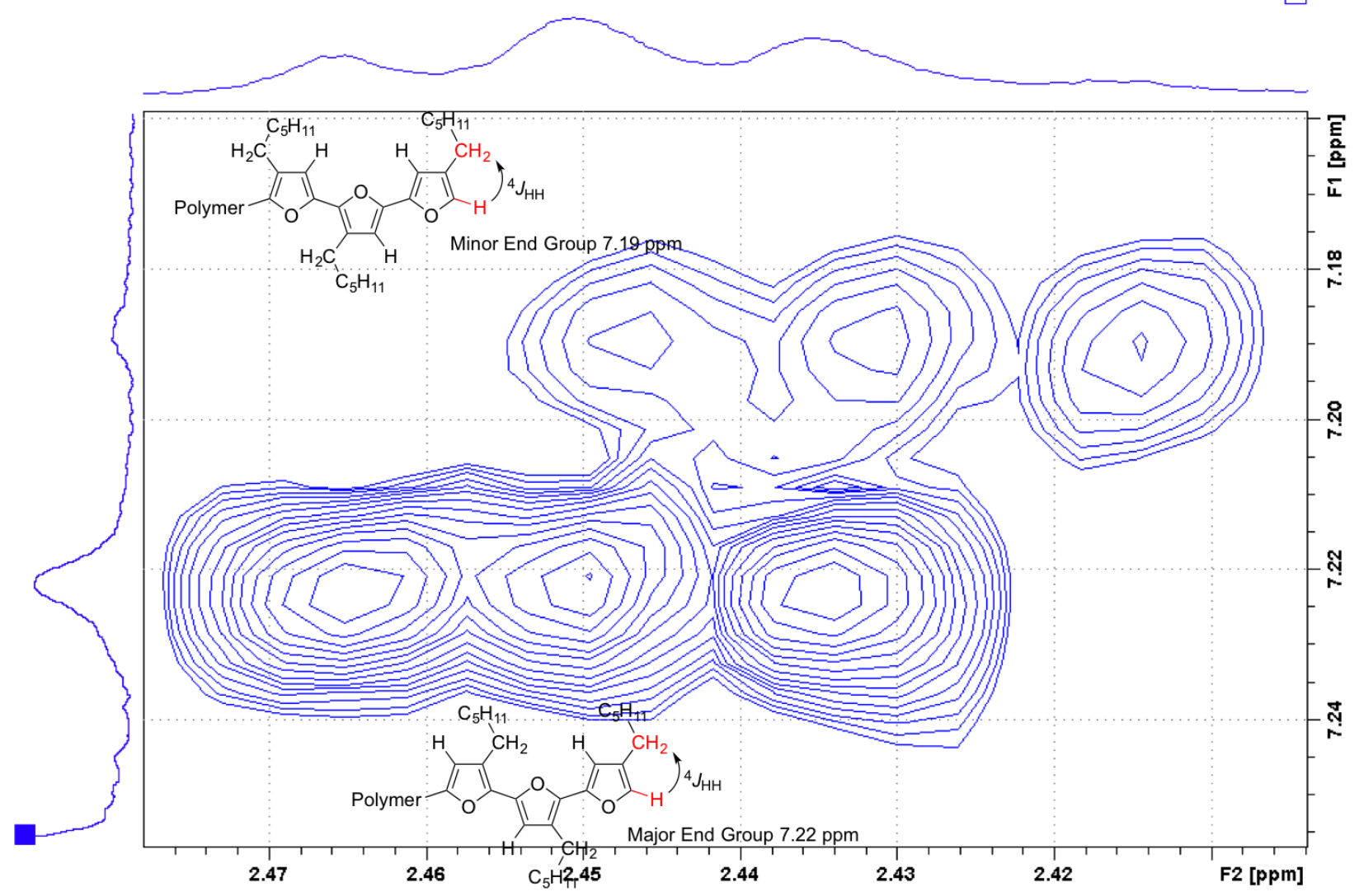

Figure S20. Long range COSY of HT-P3HF illustrating the weak coupling of the H terminated end group with the methylene signal. Major and minor end groups (HT and TT, respectively) are labeled. 


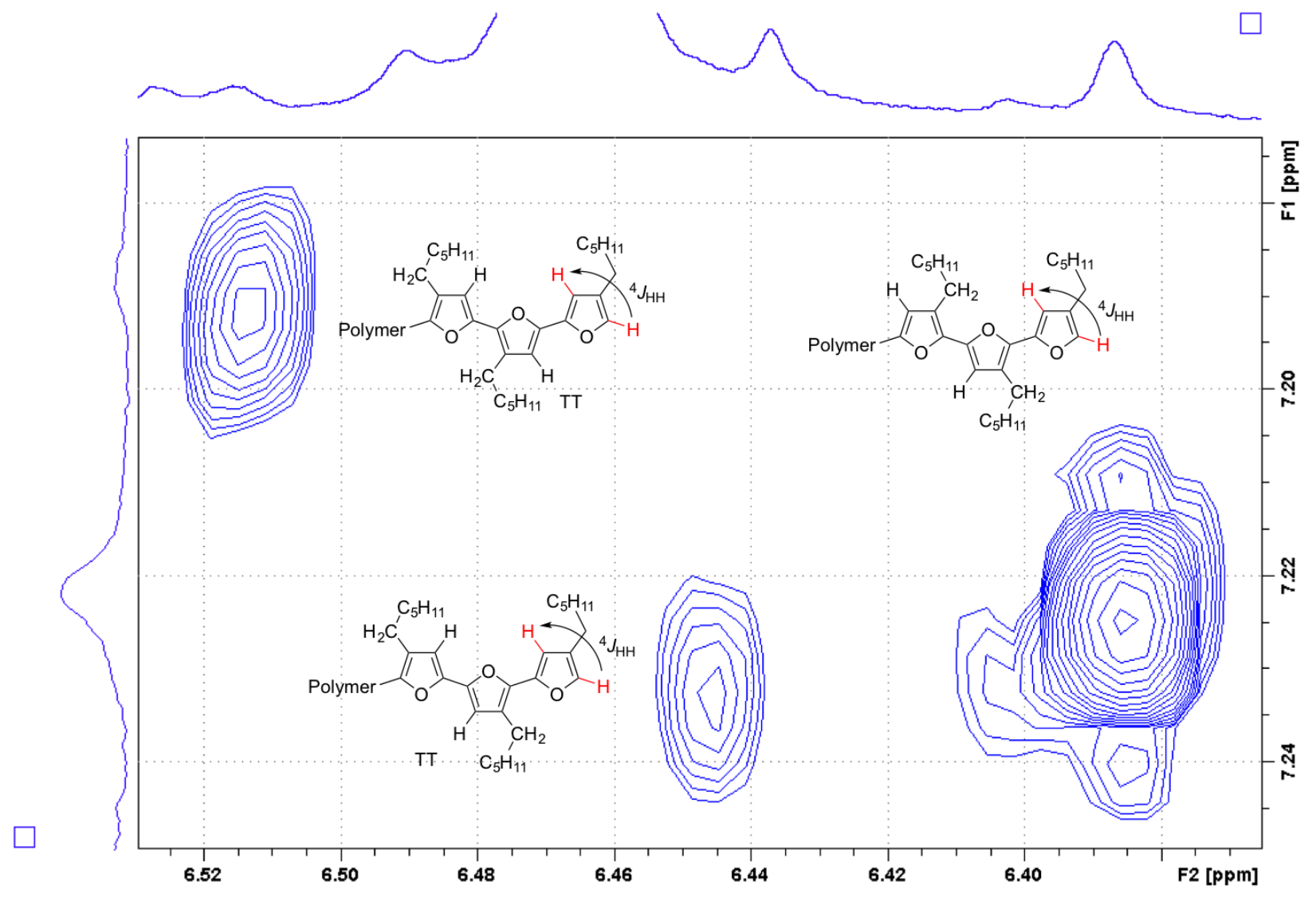

Figure S21. Long range COSY of HT-P3HF illustrating the weak coupling of the H terminated end group with the inner $\mathrm{H}$ proton residue. Different end groups are labeled. 


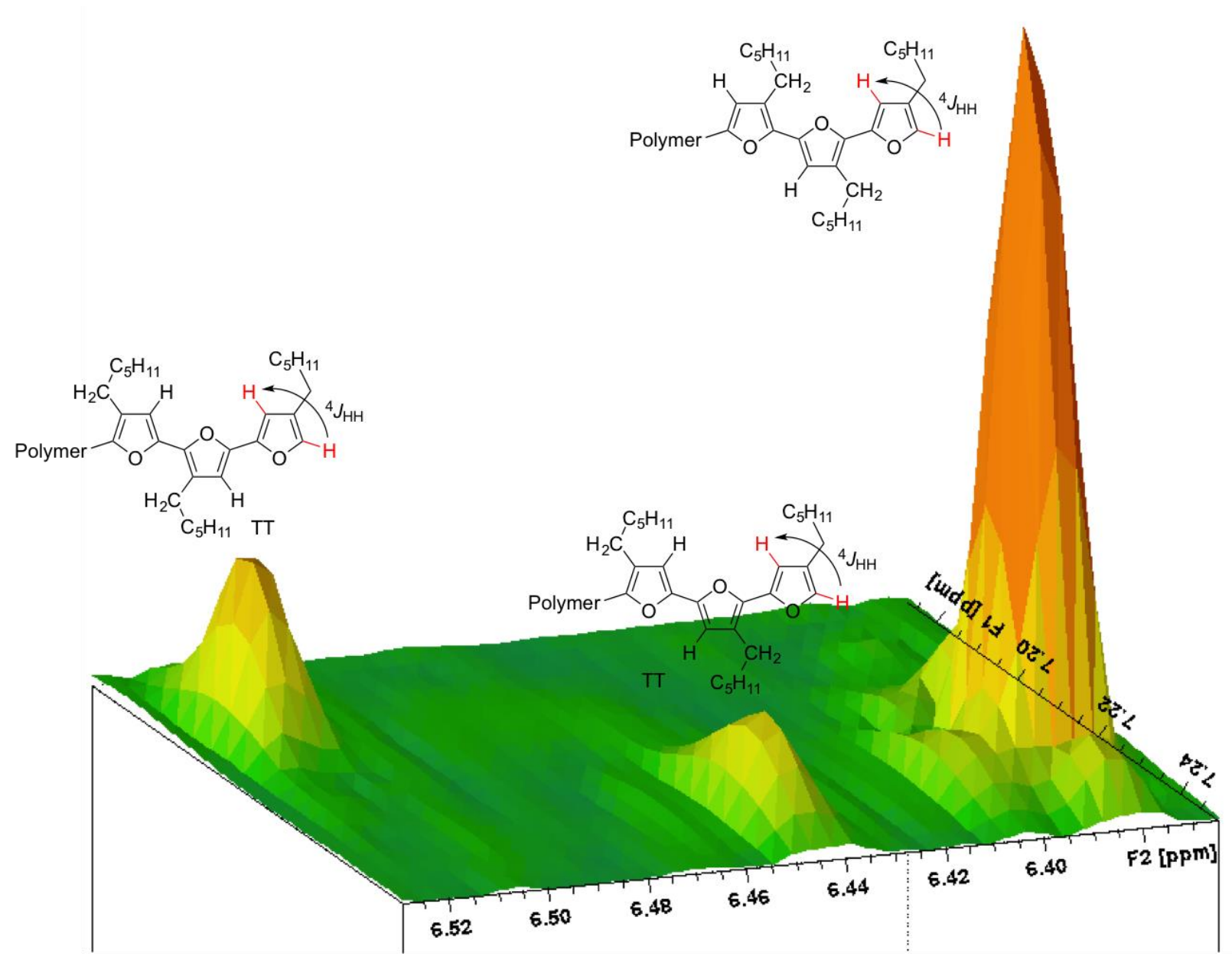

Figure S22. Long range COSY 3D plot of HT-P3HF illustrating the intensities of the different end groups. 


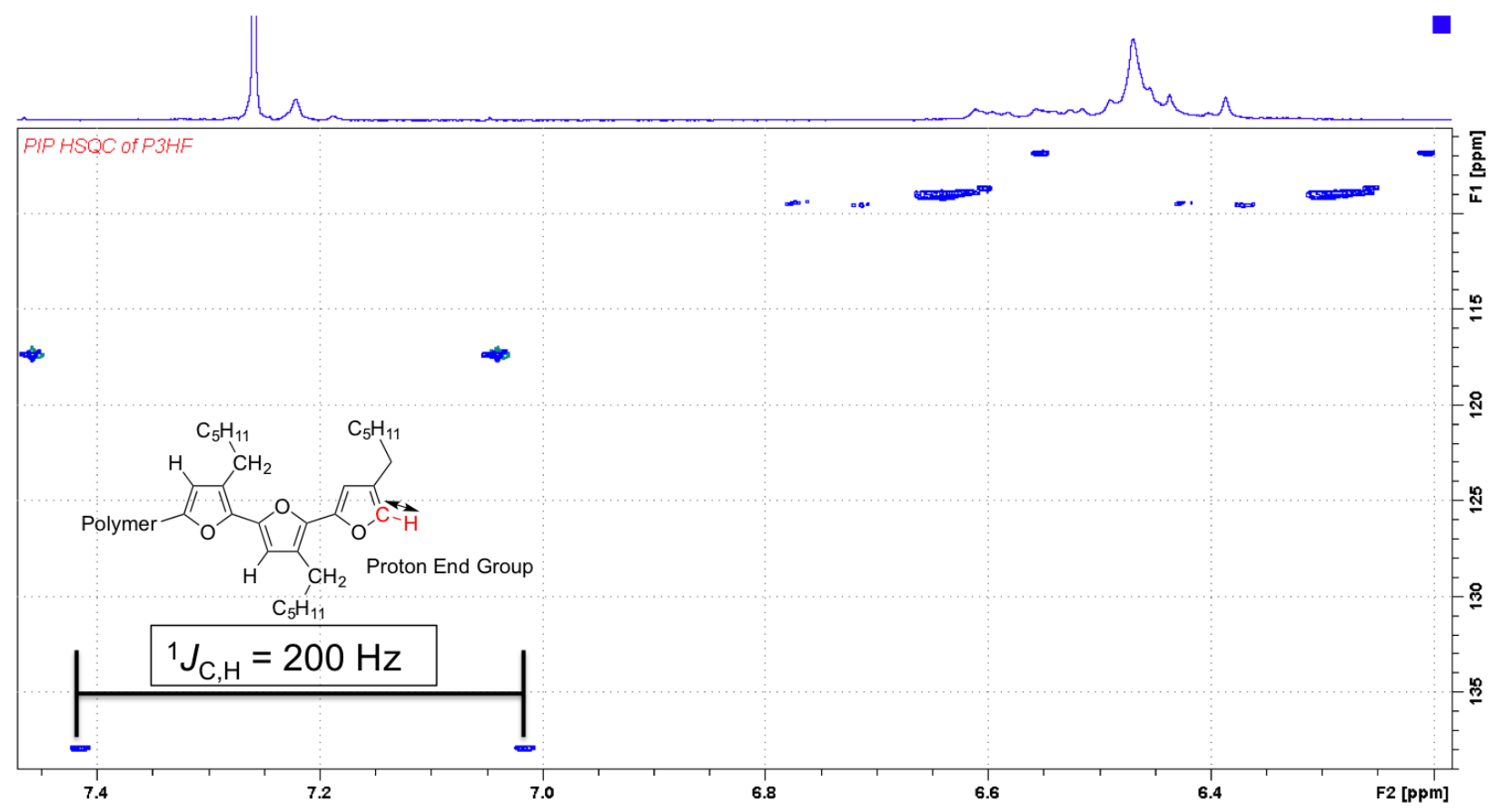

Figure S23. Coupled HSQC illustrating ${ }^{1} J_{\mathrm{C}, \mathrm{H}}$ coupling constant between the aromatic proton and attached carbon atom for the H-terminated end group for HT-P3HF. 


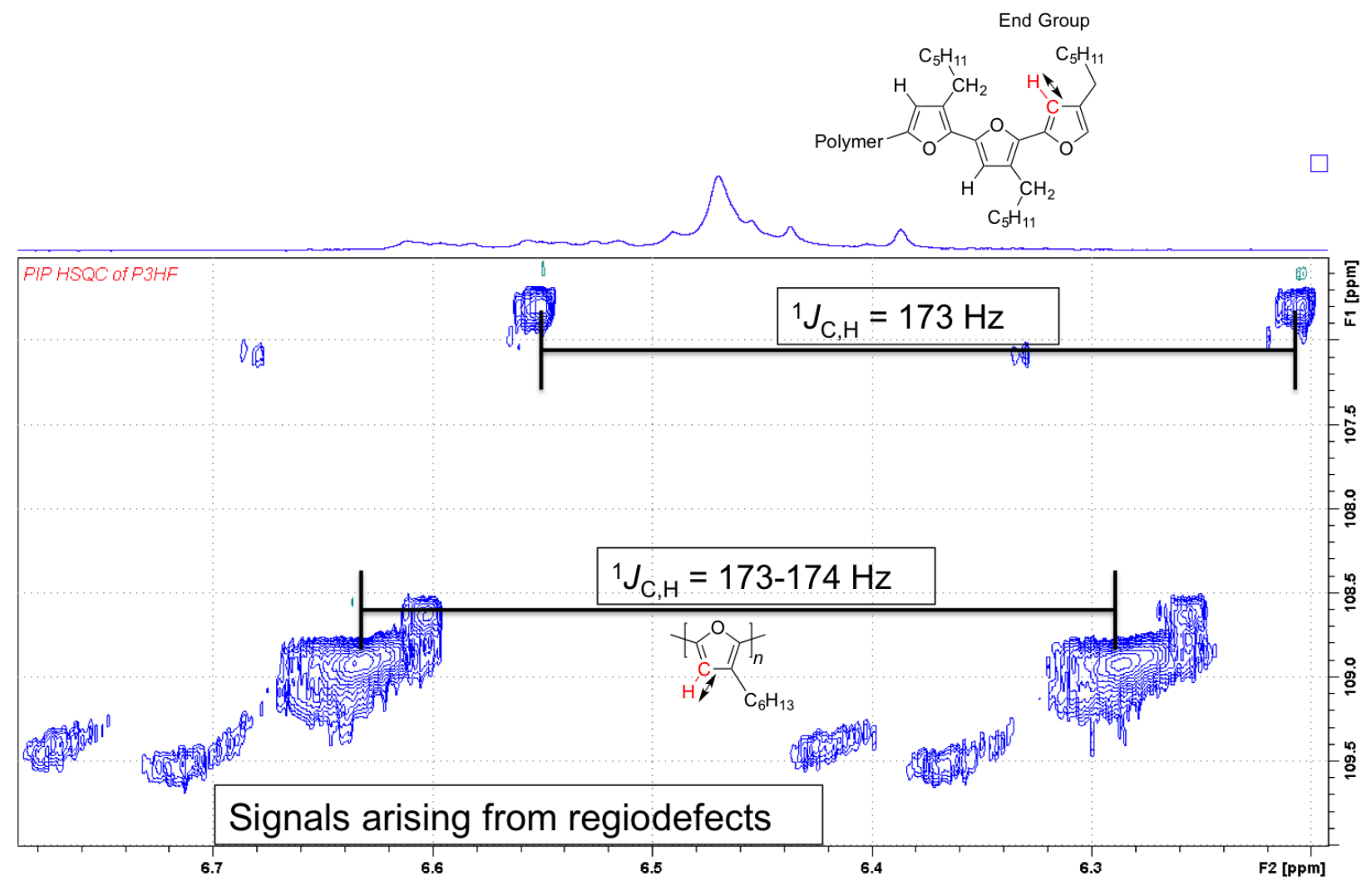

Figure S24. Coupled HSQC illustrating ${ }^{1} J_{\mathrm{C}, \mathrm{H}}$ coupling constant between the aromatic proton and attached carbon atom for the polymer main chain as well as the H-terminated end group (HTP3HF). 


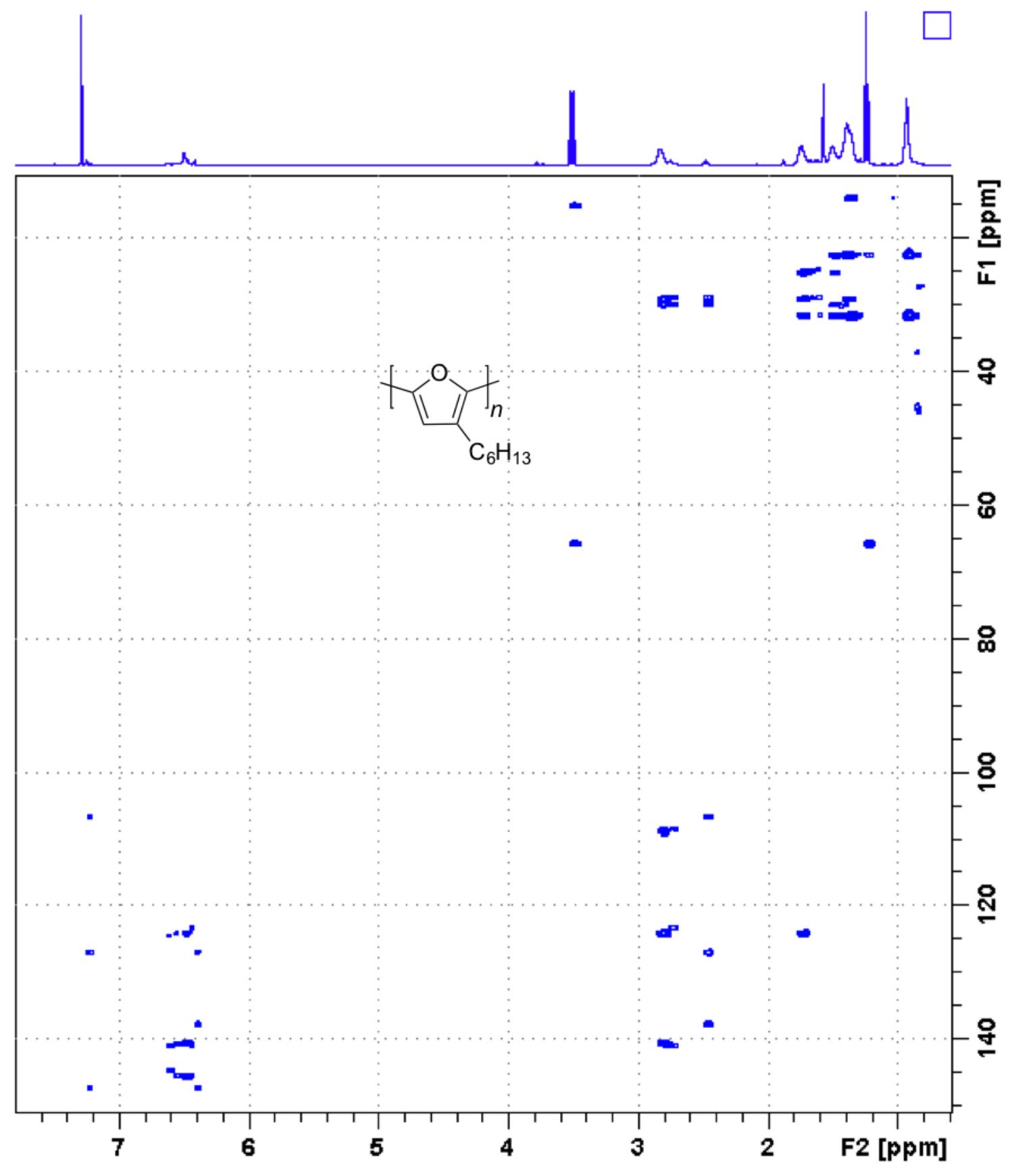

Figure S25. HMBC (4 Hz) illustrating the long range proton-carbon coupling for HT-P3HF. 


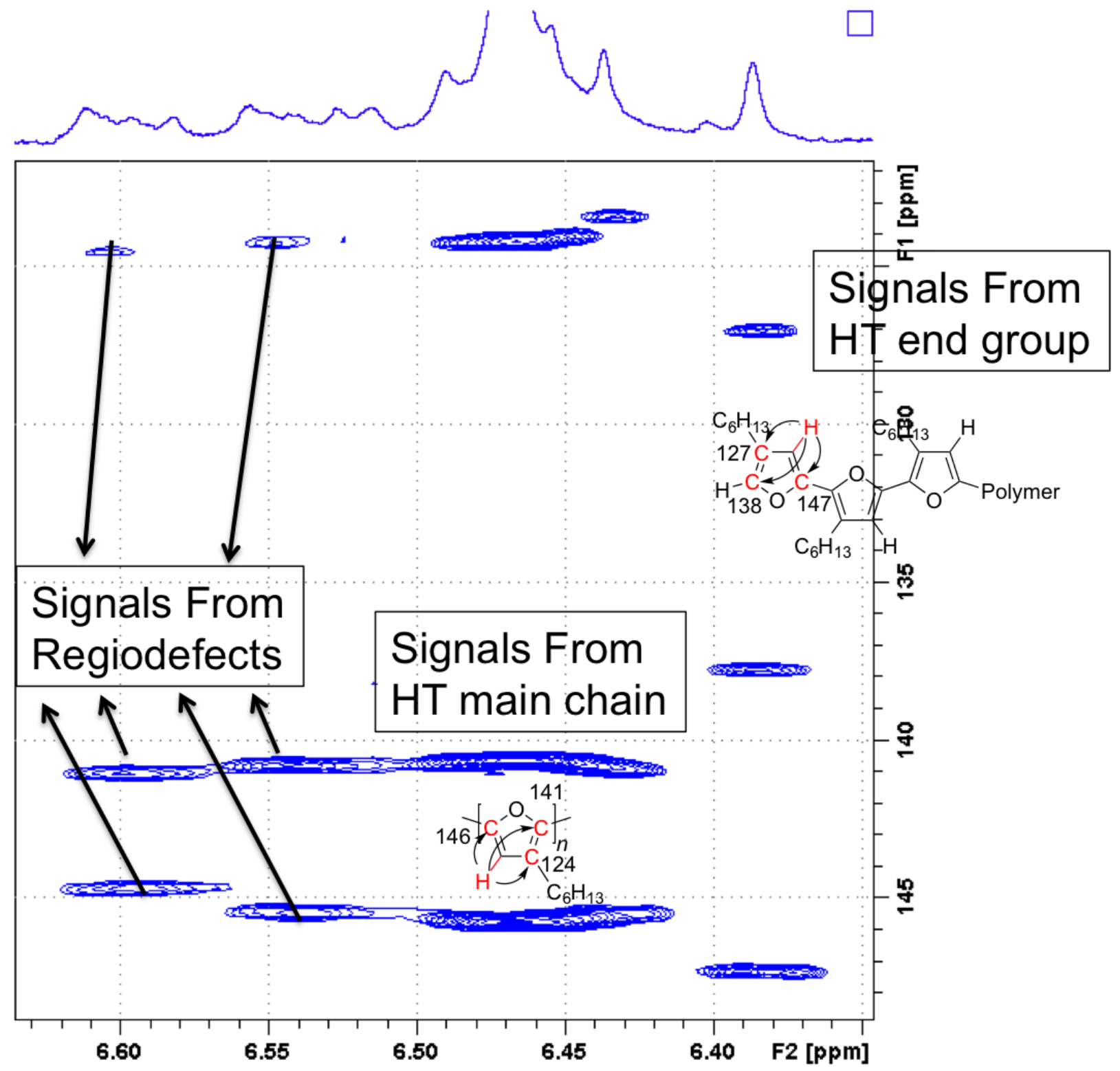

Figure S26. HMBC ( $4 \mathrm{~Hz}$ ) illustrating the long-range proton-carbon coupling for the main chain aromatic proton with the carbons of the furan ring (HT-P3HF). The same signals of the HT end group are also visible. 


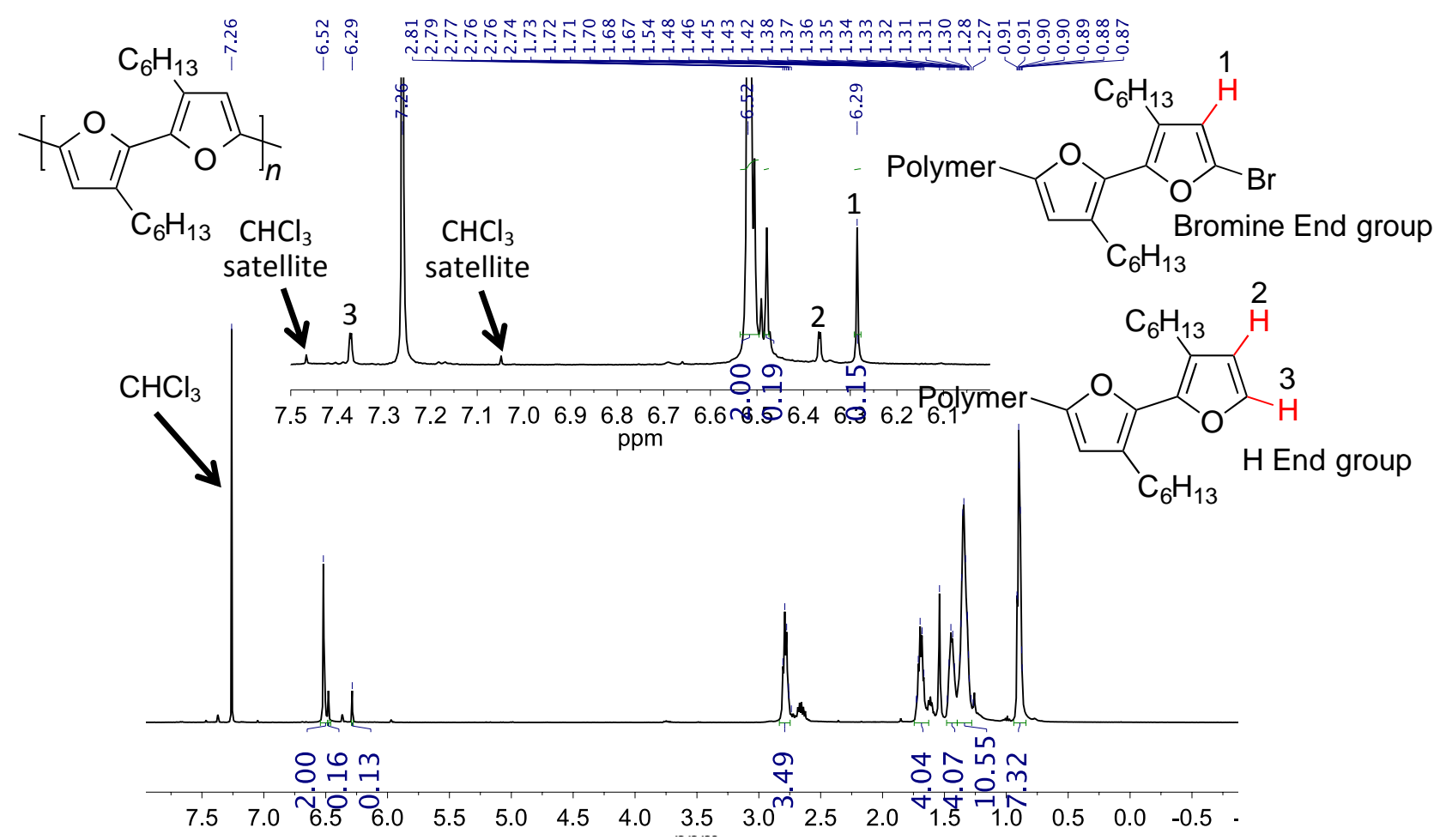

Figure S27. Polymer HH-P3HF ${ }^{1} \mathrm{H}$ NMR Spectrum $-500 \mathrm{MHz}, \mathrm{CDCl}_{3}$.

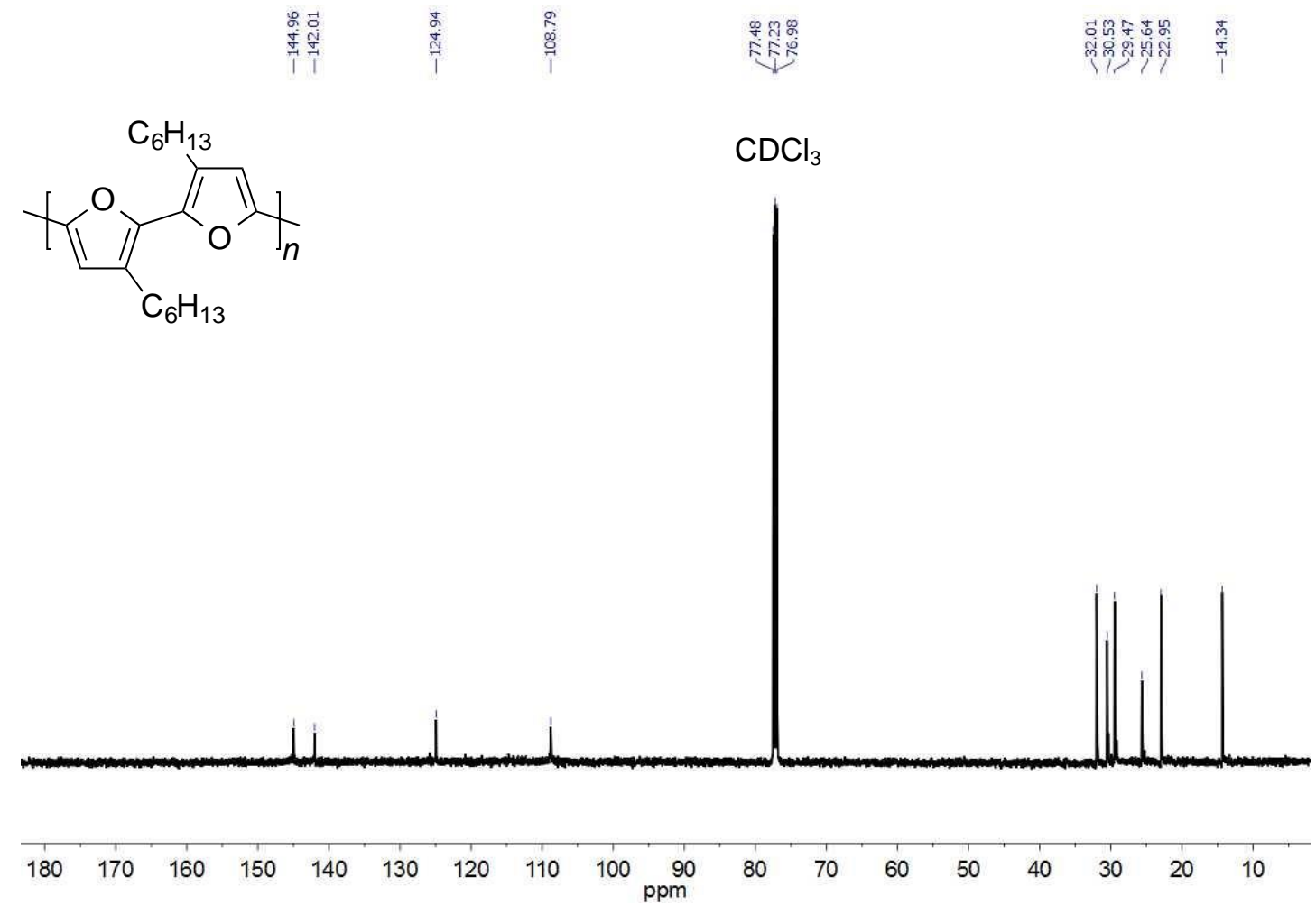

Figure S28. Polymer HH-P3HF ${ }^{13} \mathrm{C}$ NMR Spectrum - $126 \mathrm{MHz}, \mathrm{CDCl}_{3}$. 


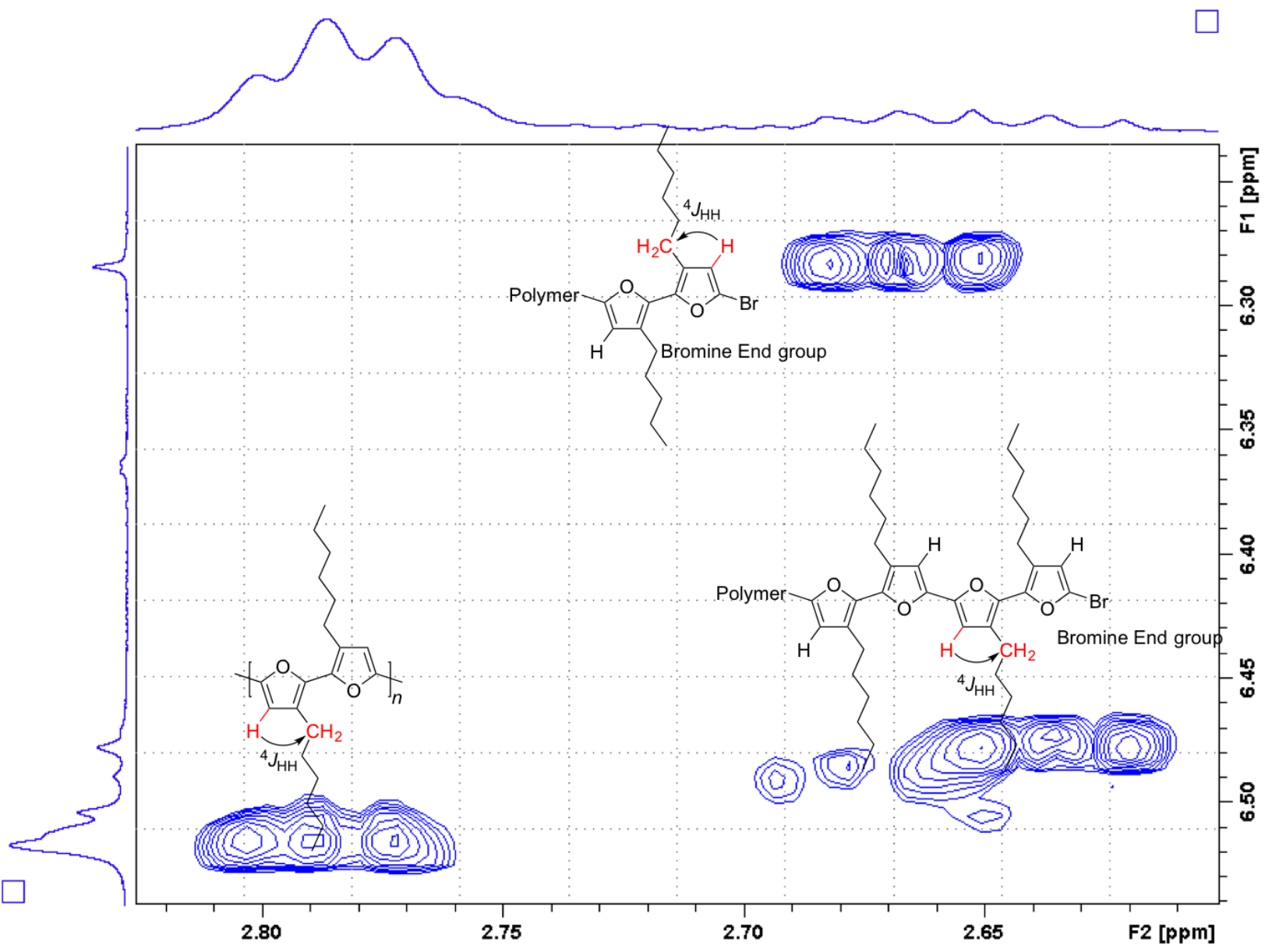

Figure S29. Long-range COSY illustrating the weak coupling in HH-P3HF between the aromatic proton and the methylene signal of the hexyl chain. The same signal at the bromine end-group as well as the second site in the polymer chain are also visible. 


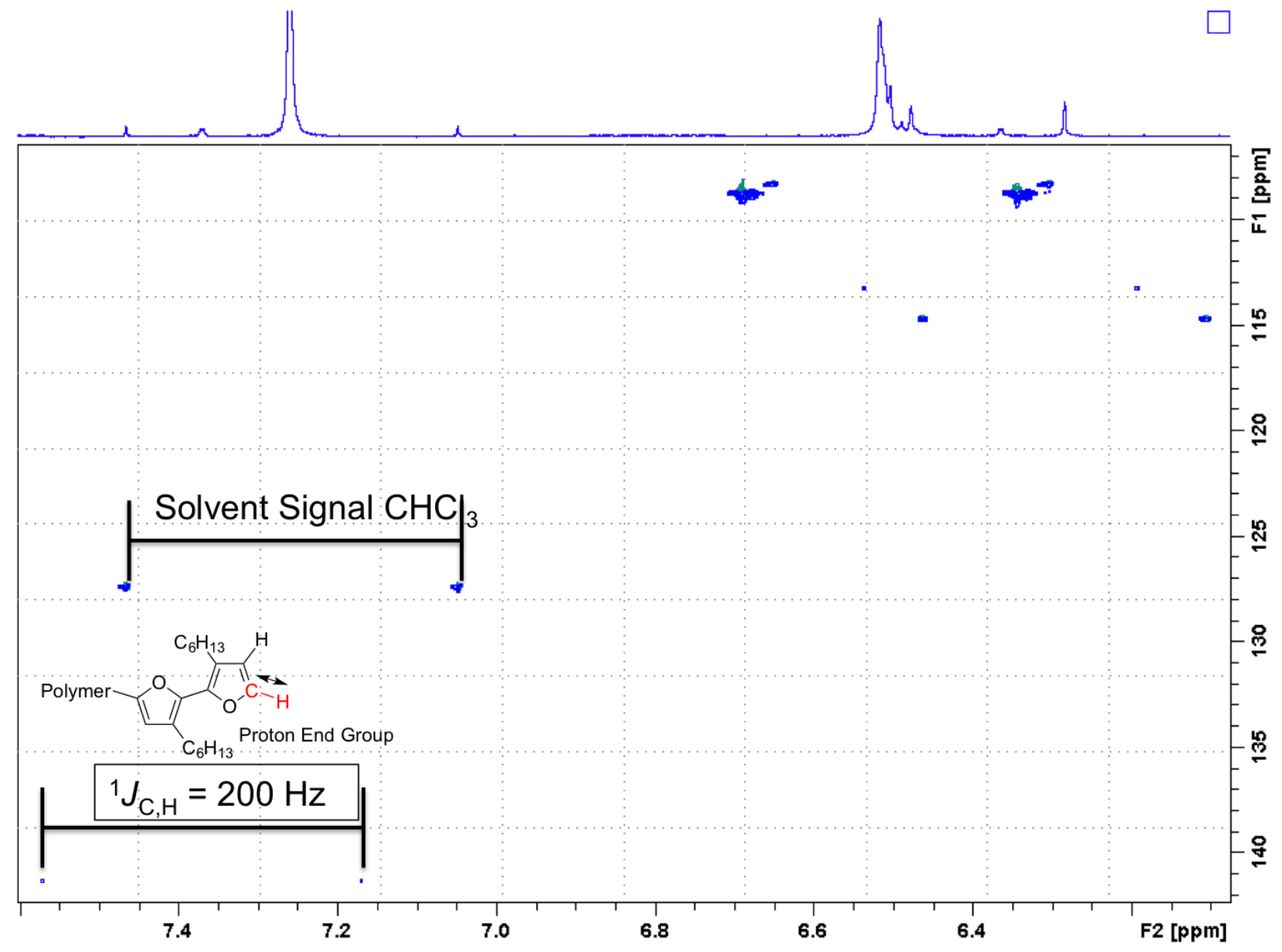

Figure S30. High resolution coupling HSQC illustrating ${ }^{1} J_{\mathrm{C}, \mathrm{H}}$ coupling constant between the aromatic proton and attached carbon atom for the H-terminated end group for HH-P3HF. 


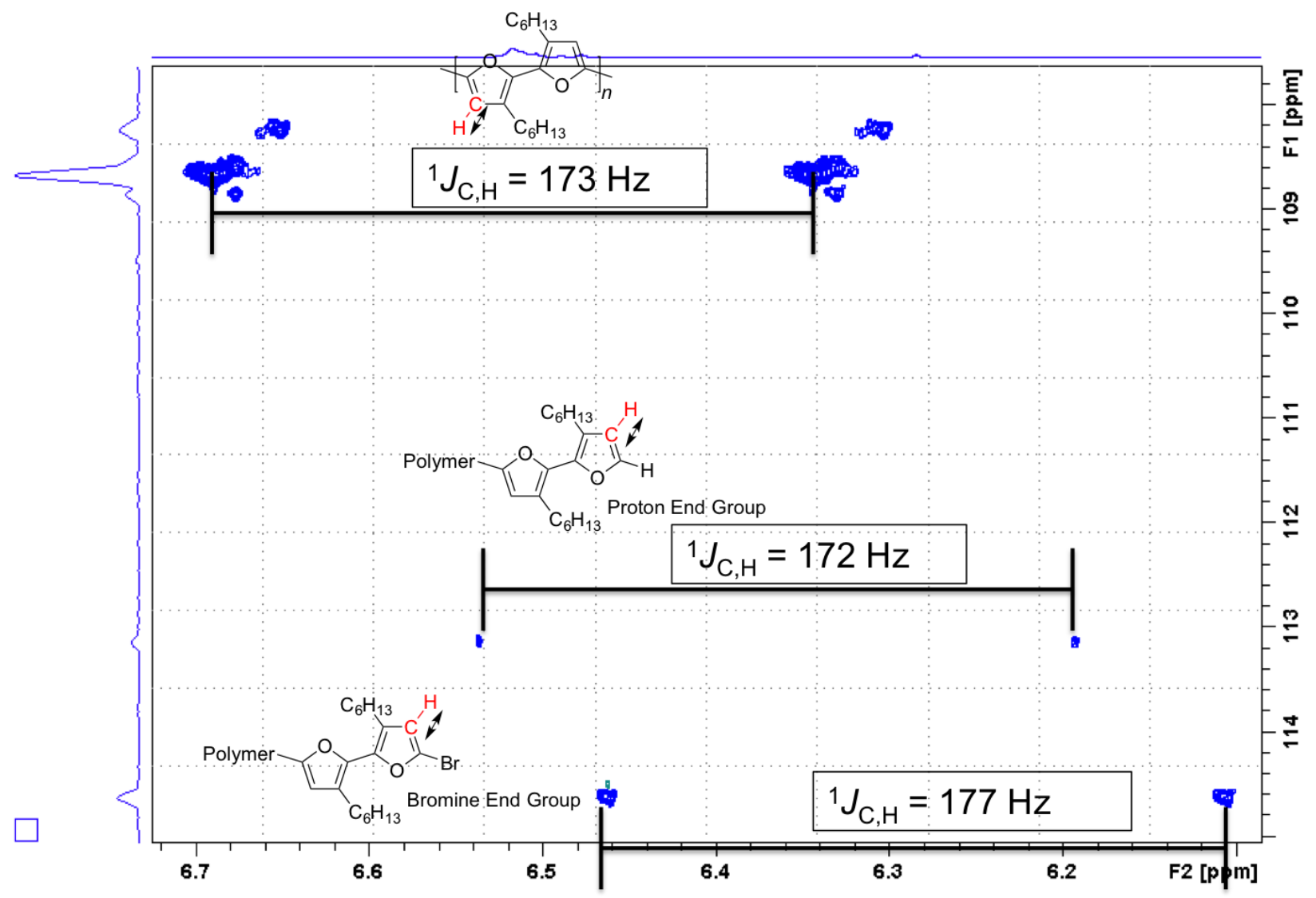

Figure S31. High resolution coupling HSQC illustrating ${ }^{1} J_{\mathrm{C}, \mathrm{H}}$ coupling constant between the aromatic proton and attached carbon atom for the polymer main chain as well as the $\mathrm{H}$ terminated and $\mathrm{Br}$ terminated end groups (HH-P3HF). 


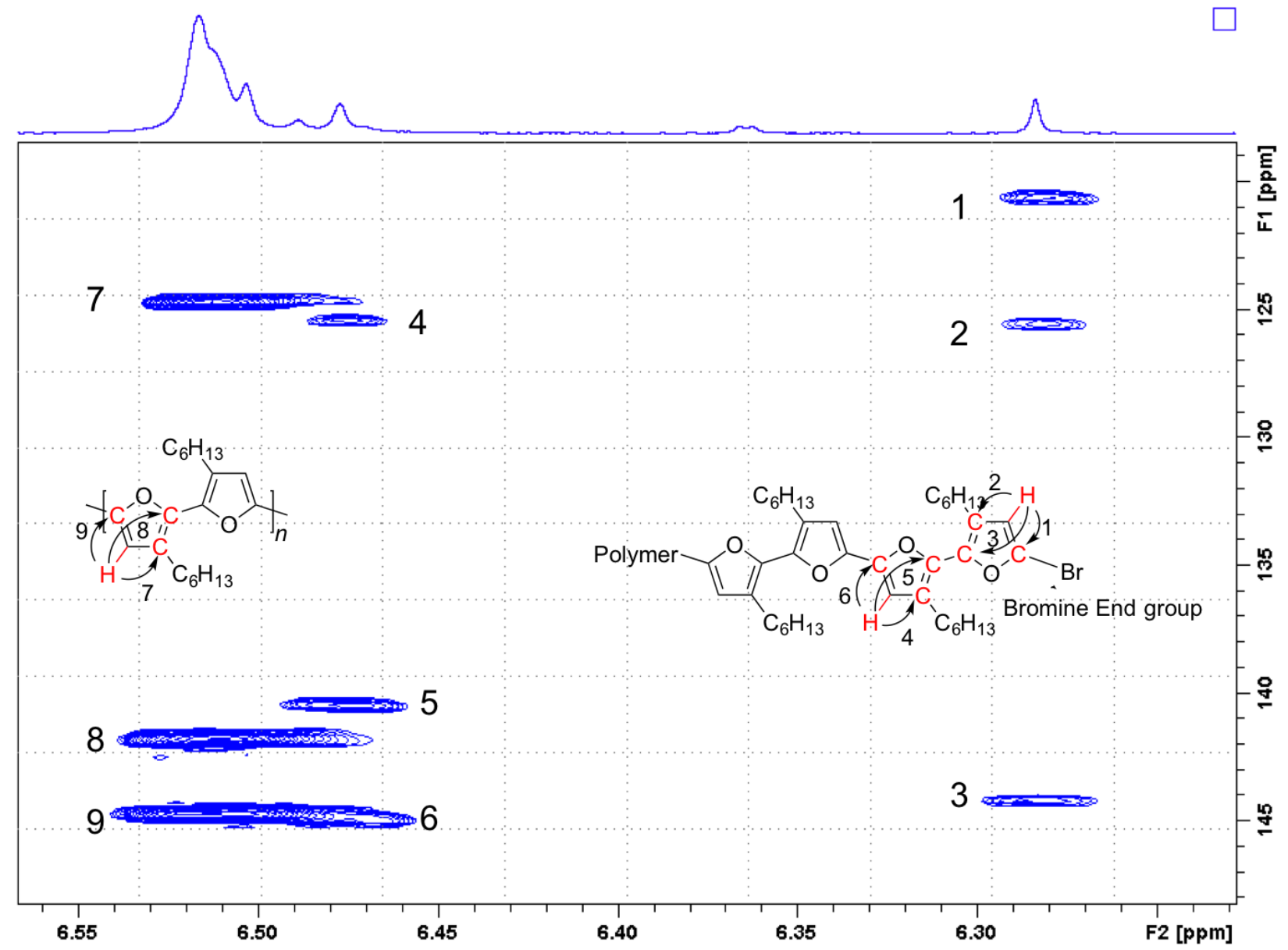

Figure S32. HMBC illustrating the long-range proton-carbon coupling for the main chain aromatic proton with the carbons of the furan ring. The same signals at the bromine end-group as well as the second site in the polymer chain are also visible (HH-P3HF). 


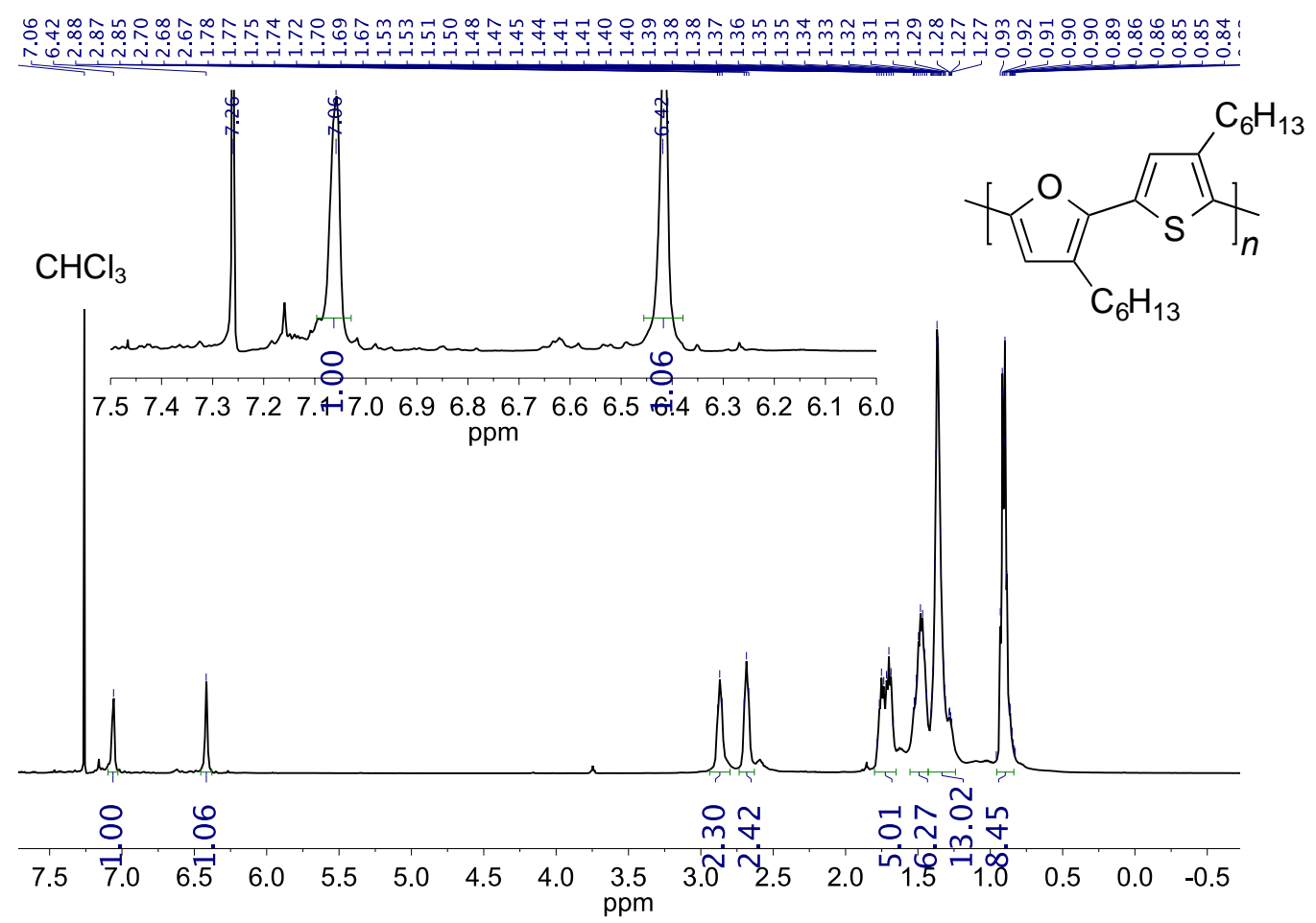

Figure S33. Polymer P3HF-a-P3HT ${ }^{1} \mathrm{H}$ NMR Spectrum - $500 \mathrm{MHz}, \mathrm{CDCl}_{3}$.

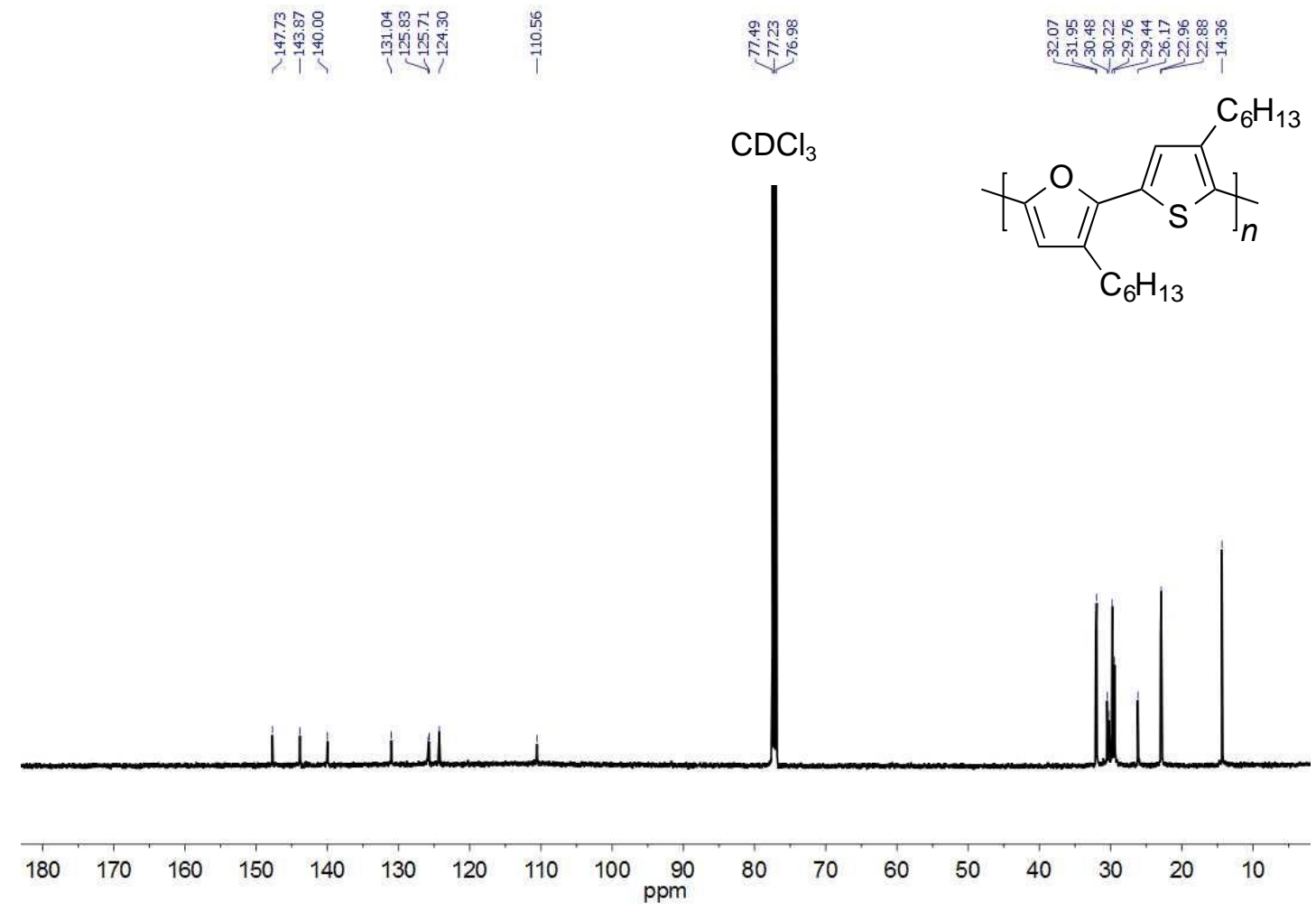

Figure S34. Polymer P3HF- $\boldsymbol{a}$-P3HT ${ }^{13} \mathrm{C}$ NMR Spectrum - $126 \mathrm{MHz}, \mathrm{CDCl}_{3}$. 


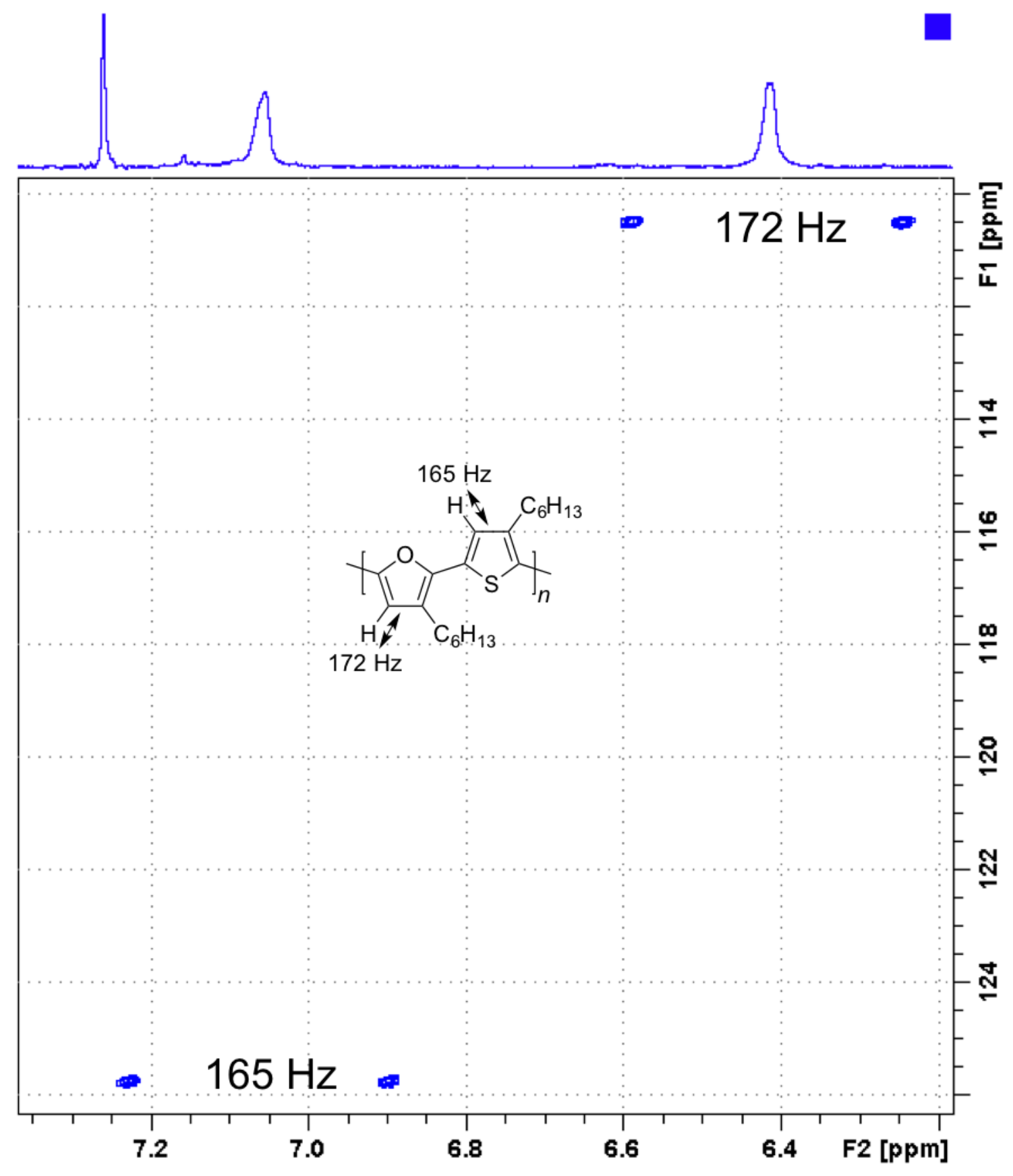

Figure S35. High resolution coupling HSQC illustrating ${ }^{1} J_{\mathrm{C}, \mathrm{H}}$ coupling constant between the aromatic proton and attached carbon atom for the polymer main chain (P3HF-a-P3HT). 


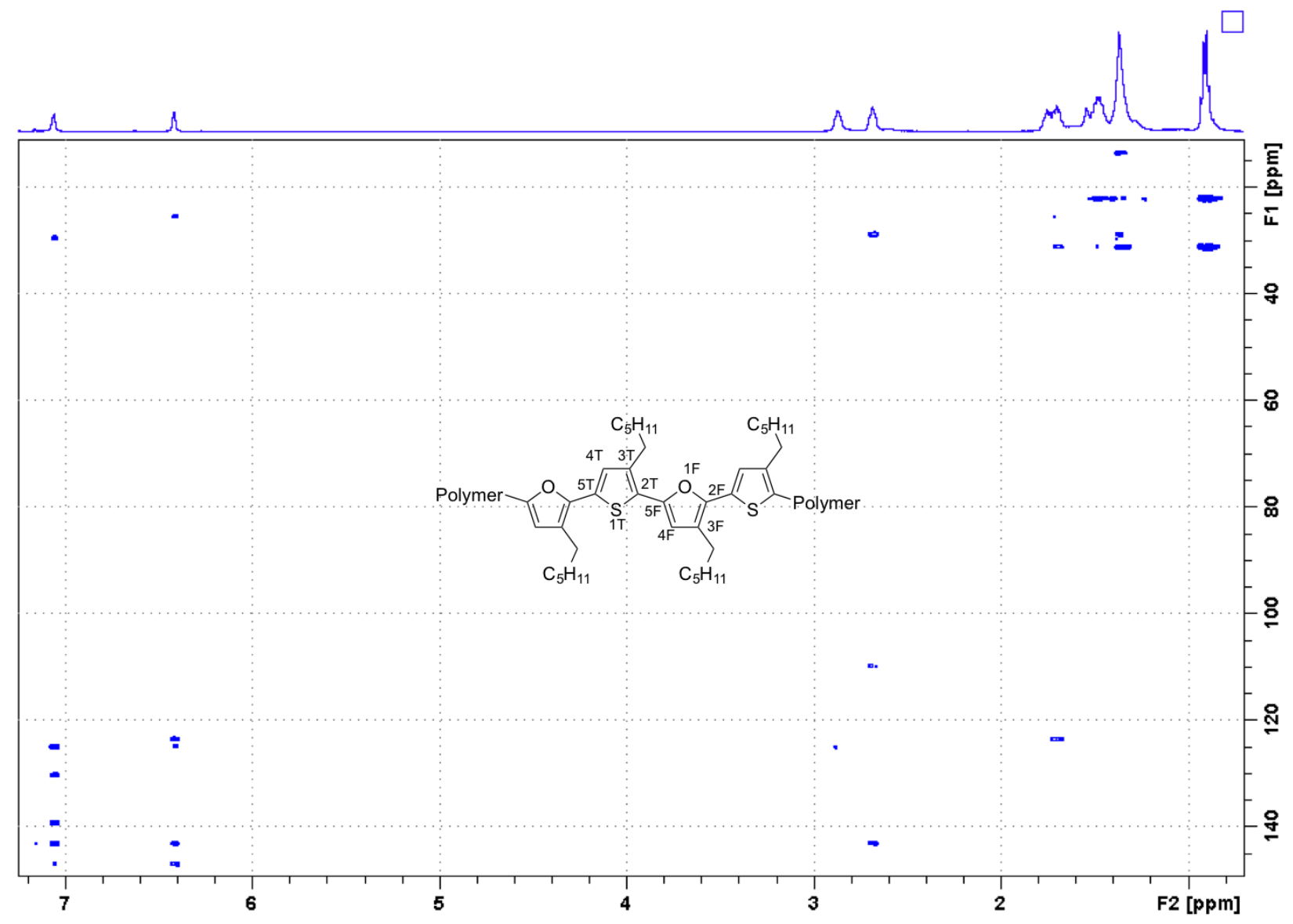

Figure S36. HMBC (4 Hz optimized) illustrating the long-range proton-carbon coupling for P3HF-a-P3HT. 


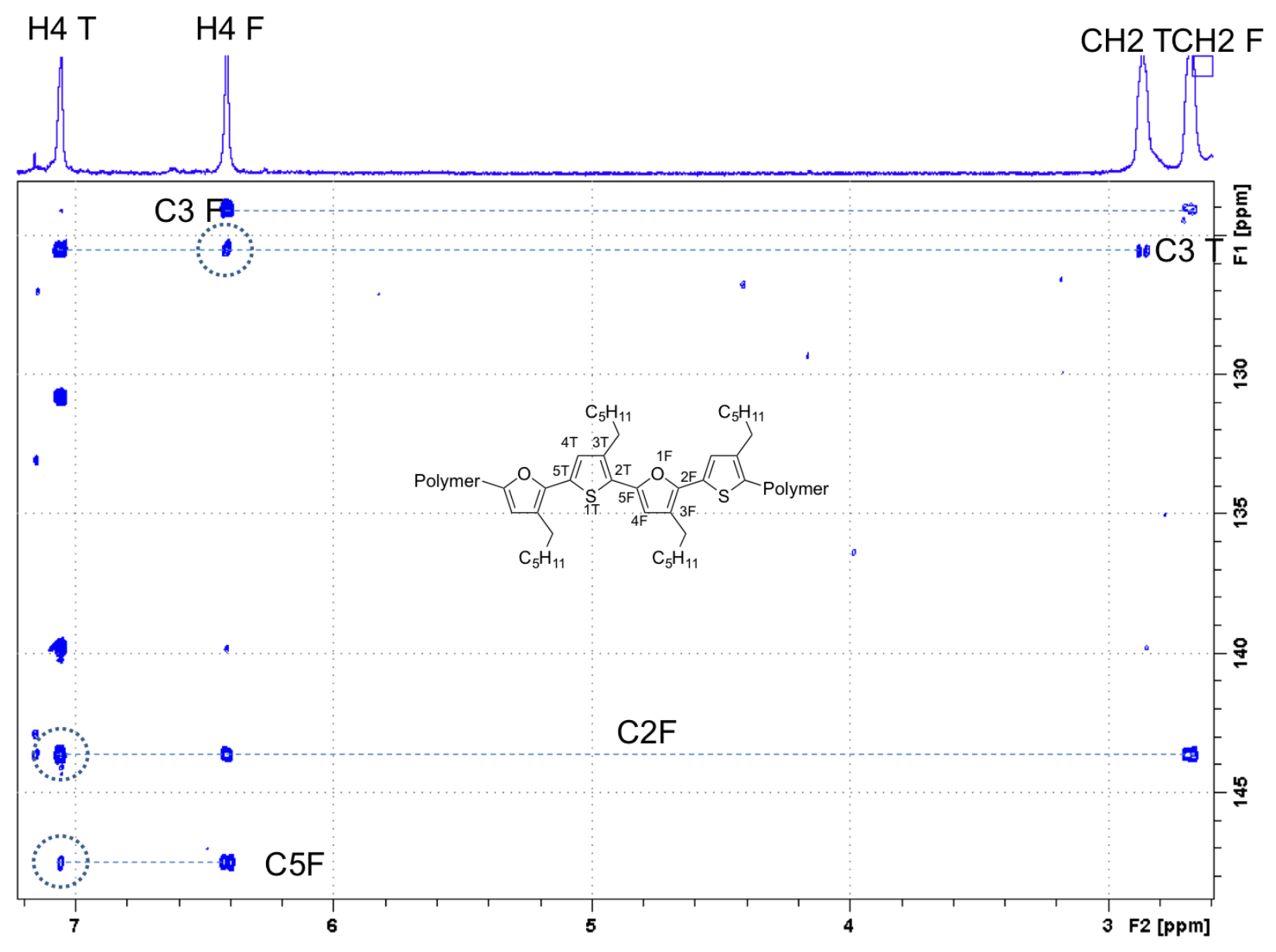

Figure S37.Aromatic and methylene region of the HMBC (4 Hz optimized) illustrating the long range proton-carbon coupling for P3HF-a-P3HT. The dotted circles are the critical inter-ring correlations highlighting the alternating nature of the polymer chain. 
Table S2. Summary of optical and electrochemical properties of HT-P3HF, HH-P3HF and P3HF- $a$-P3HT.

\begin{tabular}{|c|c|c|c|c|c|c|c|c|}
\hline & $\begin{array}{l}\lambda_{\max } \\
(\mathrm{nm}) \\
\mathrm{THF}\end{array}$ & $\begin{array}{l}\lambda_{\max } \\
(\mathrm{nm}) \\
\text { film }\end{array}$ & $\begin{array}{l}\mathrm{E}_{\mathrm{g}}^{\mathrm{opt}} \\
(\mathrm{eV})^{\mathrm{a}}\end{array}$ & $\begin{array}{c}\mathrm{E}_{\mathrm{ox}} \\
(\mathrm{eV})^{\mathrm{b}}\end{array}$ & $\begin{array}{c}\mathrm{E}_{\mathrm{red}} \\
(\mathrm{eV})^{\mathrm{b}}\end{array}$ & $\begin{array}{c}\mathrm{HOMO}_{\mathrm{AVG}} \\
(\mathrm{eV})^{\mathrm{c}}\end{array}$ & $\begin{array}{c}\text { LUMO }_{A V G} \\
(\mathrm{eV})\end{array}$ & $\begin{array}{l}\mathrm{E}_{\mathrm{g}}^{\mathrm{CV}} \\
(\mathrm{eV})\end{array}$ \\
\hline $\begin{array}{c}\text { HT- } \\
\text { P3HF }\end{array}$ & 465 & 489 & 2.19 & $\begin{array}{c}-0.013 \\
+/-0.037\end{array}$ & - & -5.09 & $-2.90^{\mathrm{d}}$ & - \\
\hline $\begin{array}{l}\text { HH- } \\
\text { P3HF }\end{array}$ & 458 & 486 & 2.19 & $\begin{array}{c}-0.039 \\
+/-0.030\end{array}$ & - & -5.06 & $-2.87^{\mathrm{d}}$ & - \\
\hline $\begin{array}{c}\text { P3HF-a- } \\
\text { P3HT }\end{array}$ & 476 & 531 & 2.00 & $\begin{array}{c}0.090 \\
+/-0.034\end{array}$ & $\begin{array}{c}-1.93 \\
+/-0.030\end{array}$ & -5.19 & $-3.17^{\mathrm{c}}$ & 2.02 \\
\hline
\end{tabular}

a) Determined by the onset of absorption edge (UV-Vis). ${ }^{\text {b) }}$ Determined by the average of initial onset and derivative onsets of oxidation and reduction potentials by cyclic voltammetry. ${ }^{c)}$ Estimated by the average onset of oxidation and reduction potentials by cyclic voltammetry.

${ }^{\mathrm{d})}$ Determined from the optical bandgap.

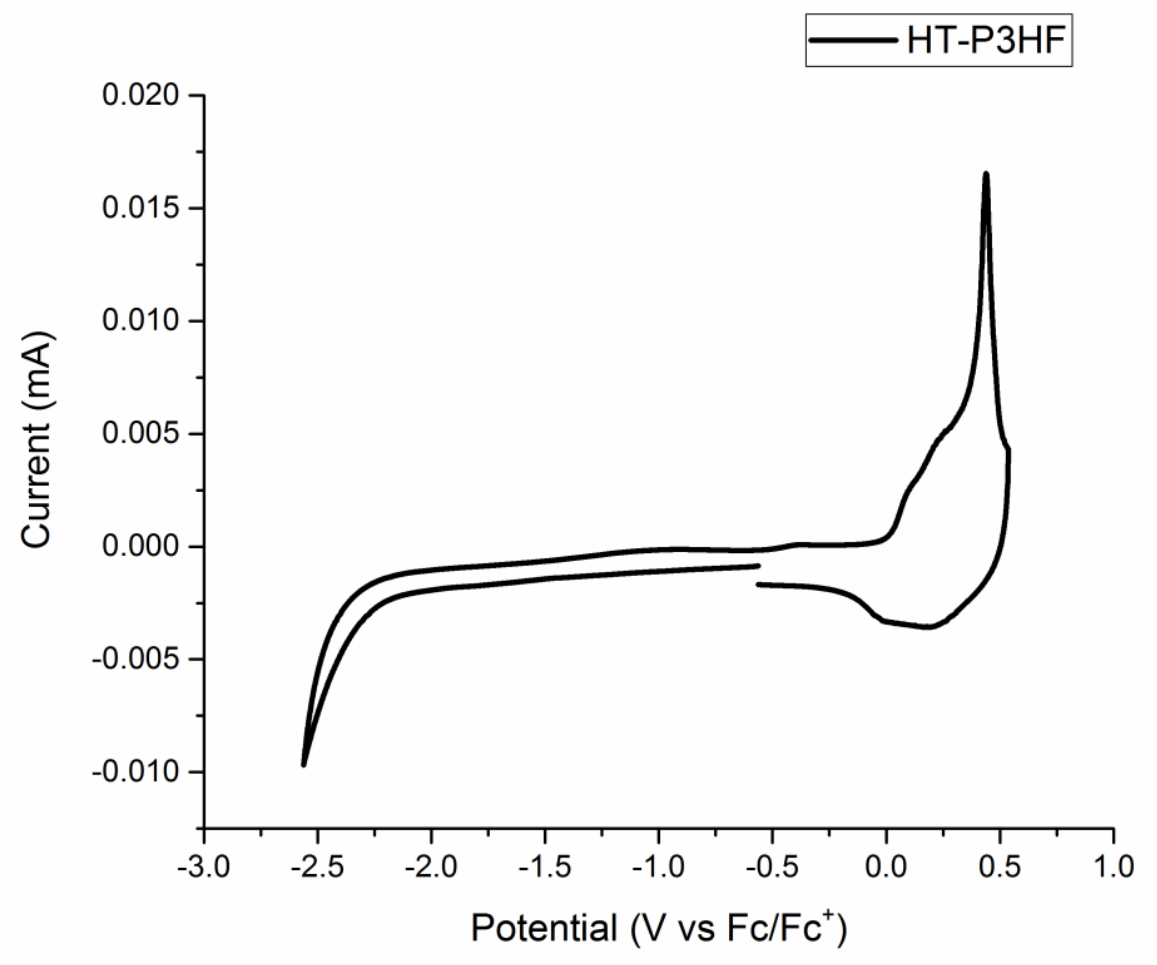

Figure S38. Cyclic voltammogram of HT-P3HF in thin film. 


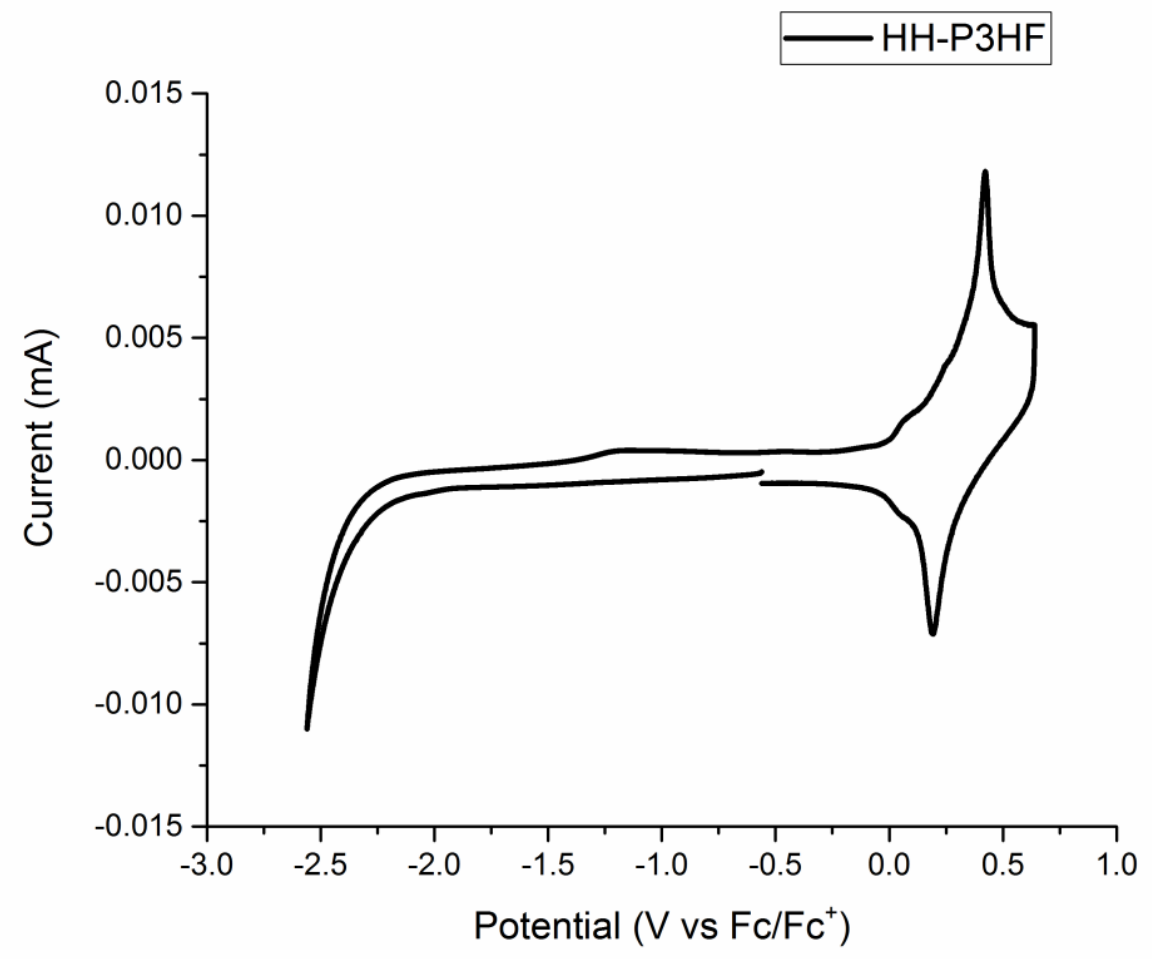

Figure S39. Cyclic voltammogram of HH-P3HF in thin film.

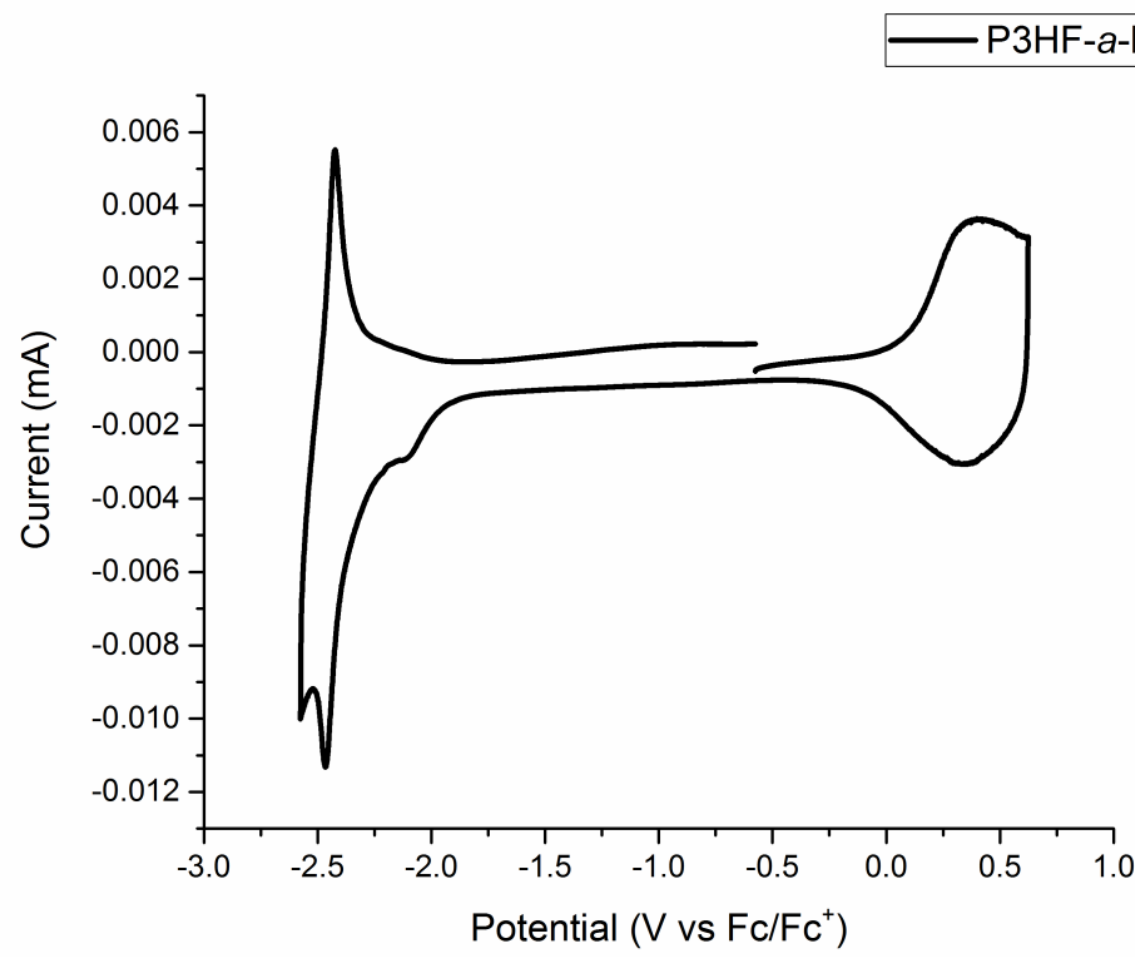

Figure S40. Cyclic voltammogram of P3HF-a-P3HT in thin film. 


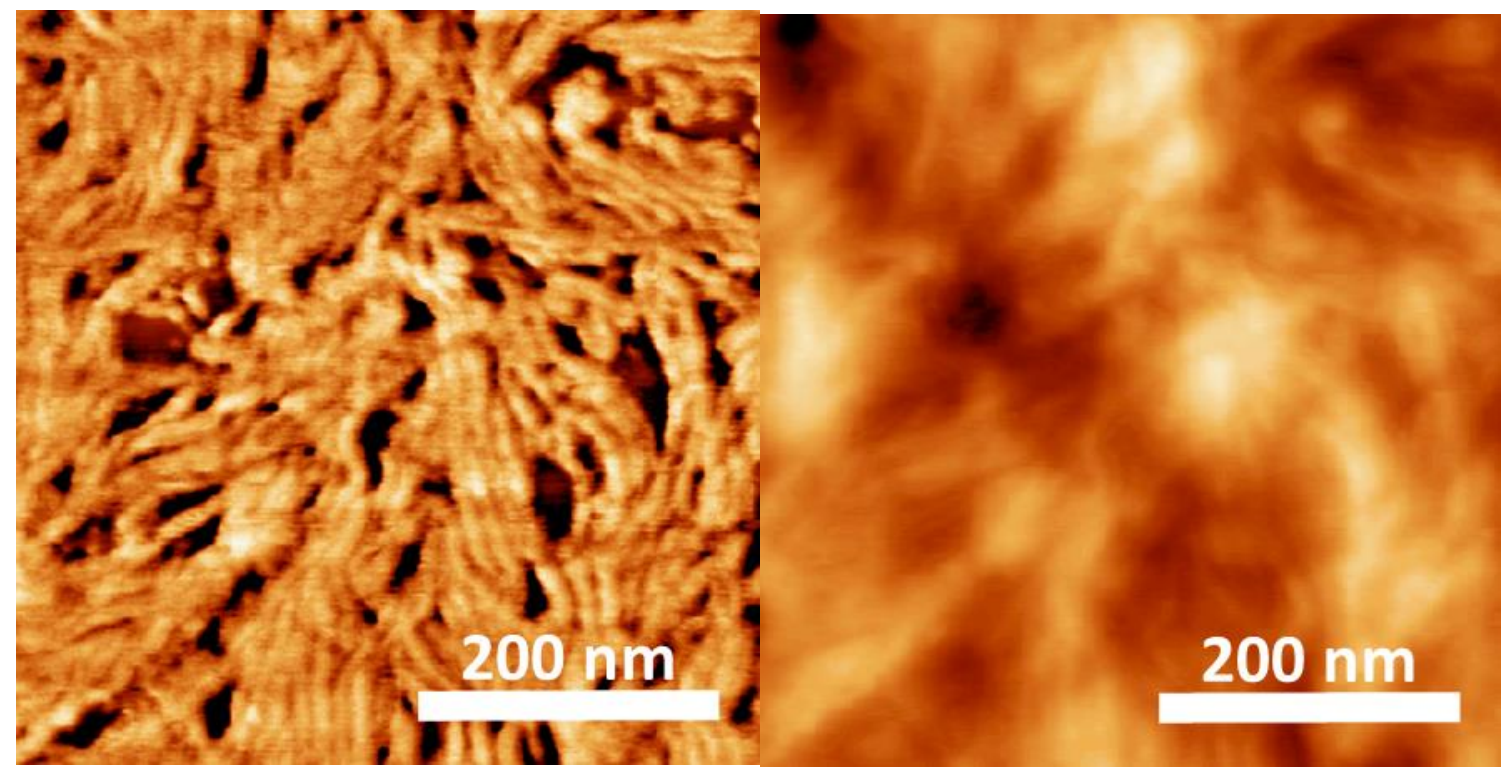

Figure S41. AFM phase and height images of HT-P3HF.

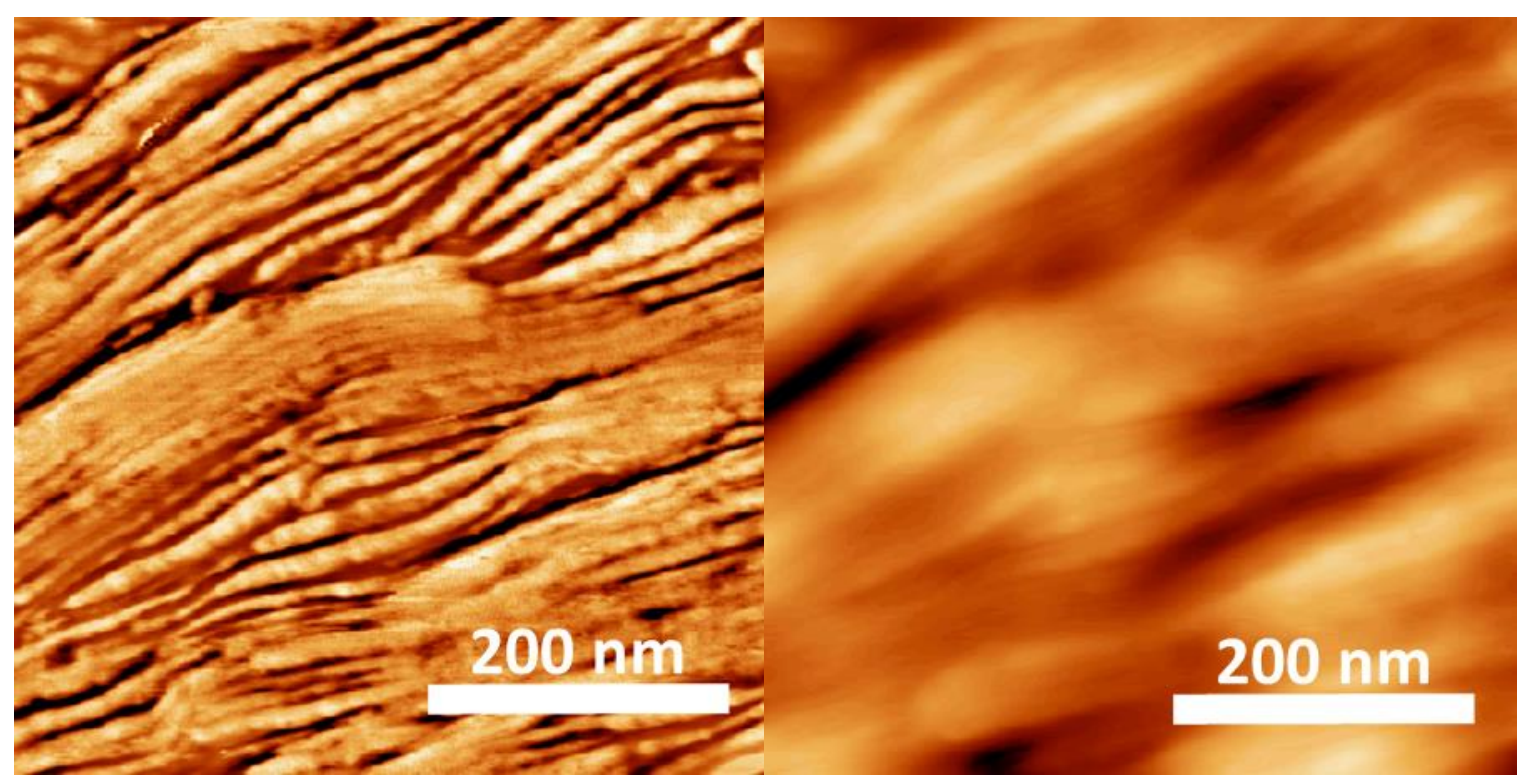

Figure S42. AFM phase and height images of HH-P3HF. 


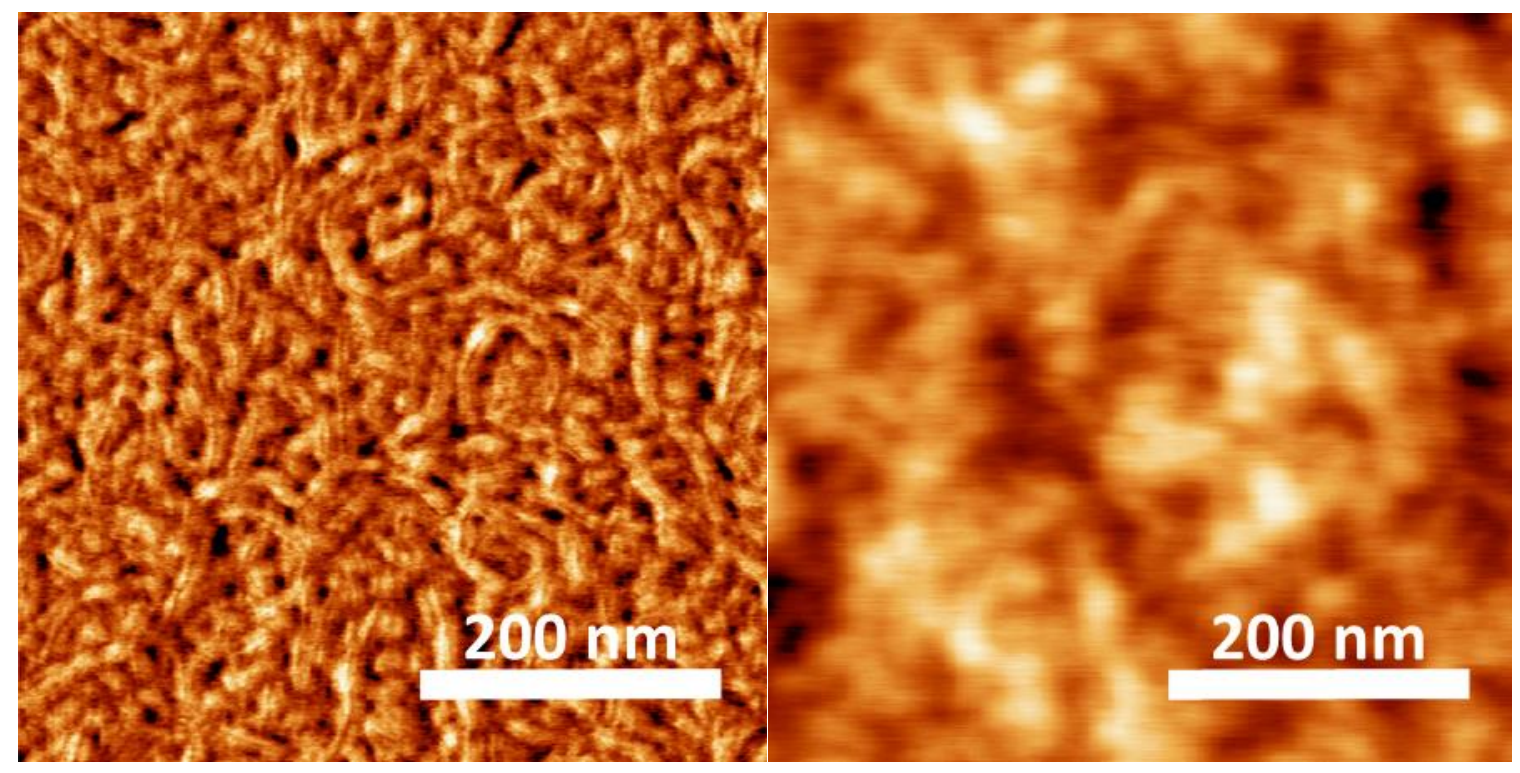

Figure S43. AFM phase and height images of P3HF-a-P3HT. 

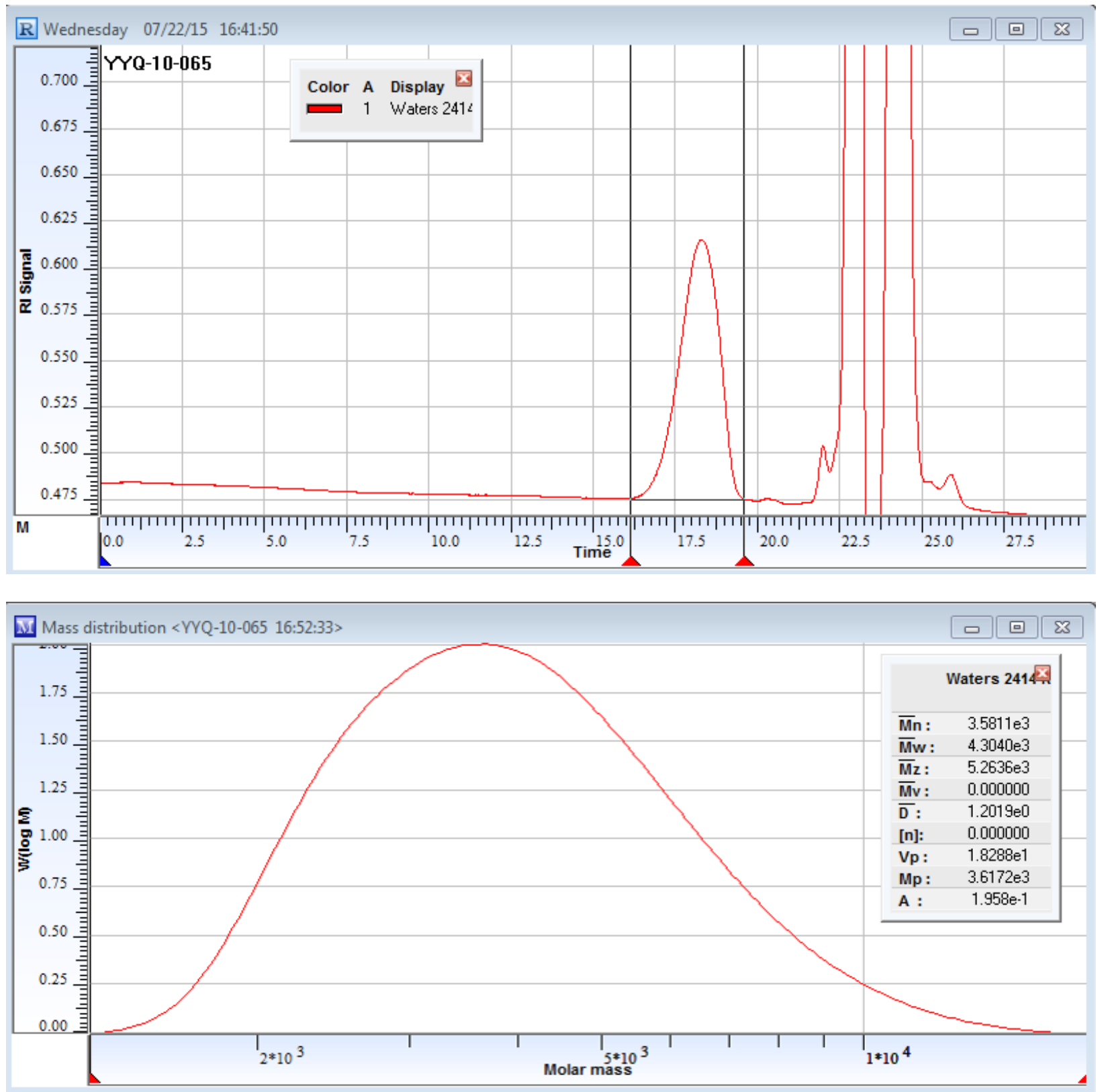

Figure S44. GPC Chromatogram and analysis of HT-P3HF sample. Entry 1 Table 1 in the Paper. 

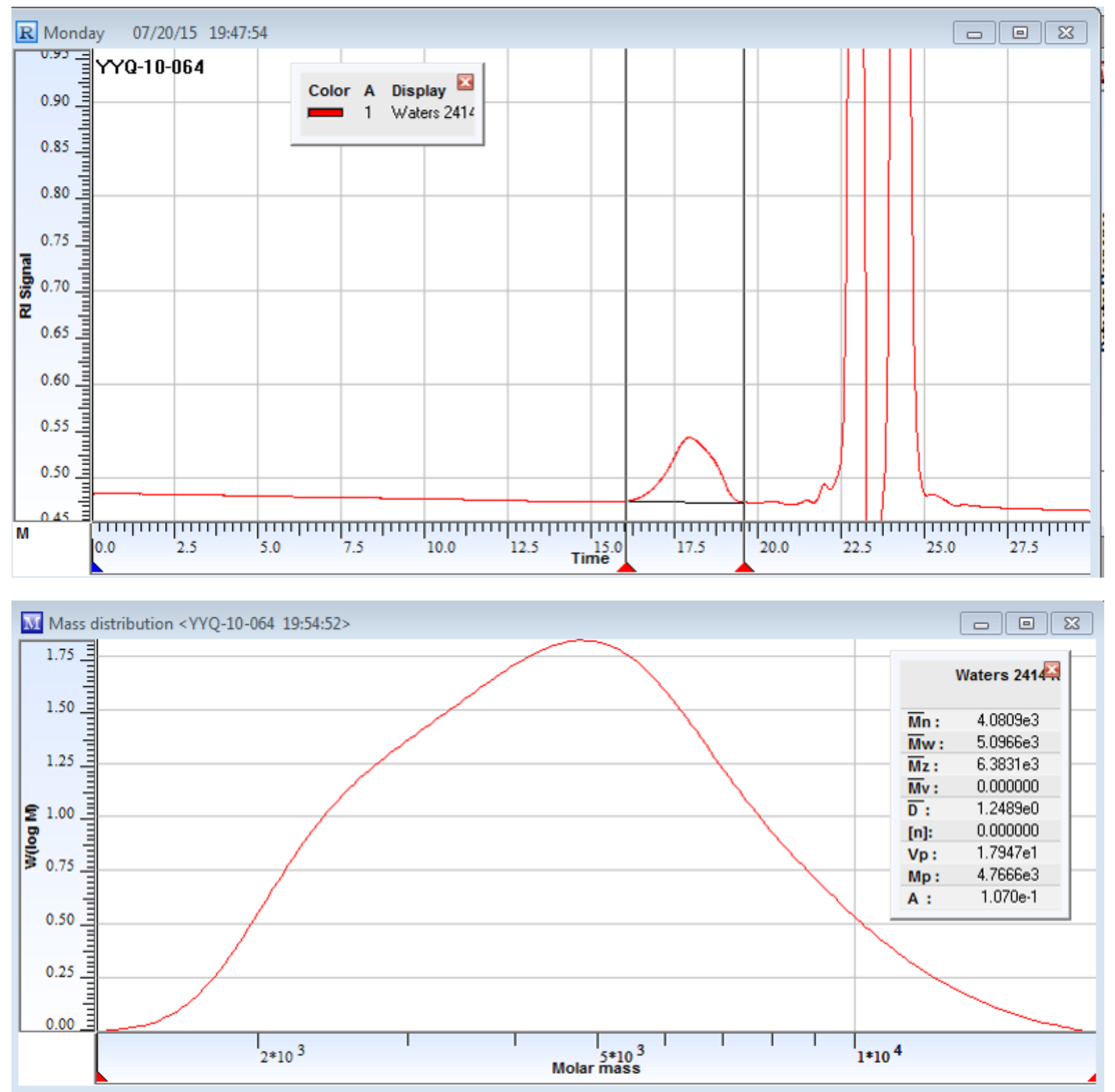

Figure S45. GPC Chromatogram and analysis of HT-P3HF sample. Entry 2 Table 1 in the Paper. 

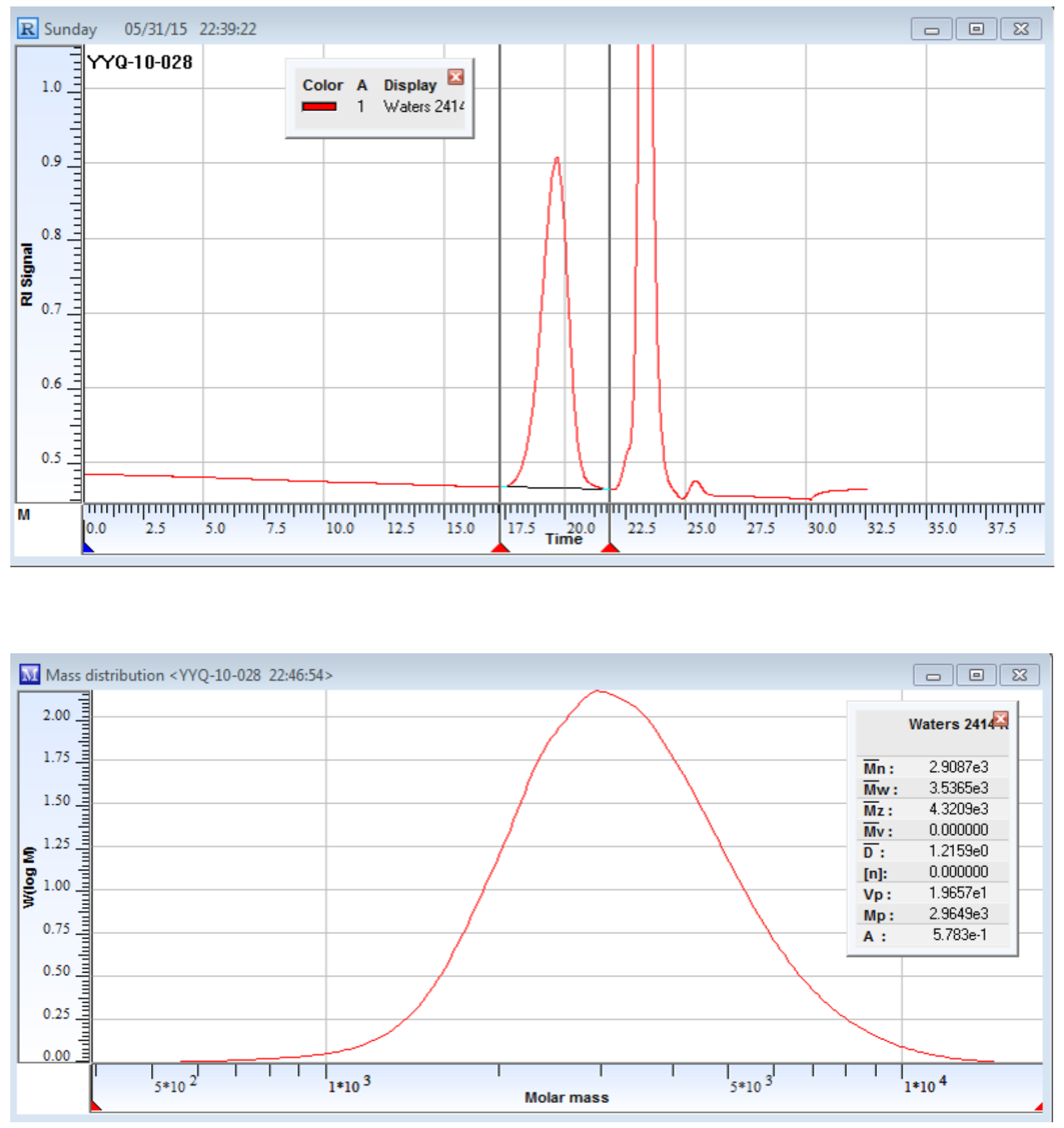

Figure S46. GPC Chromatogram and analysis of HH-P3HF sample. Entry 3 Table 1 in the Paper. 

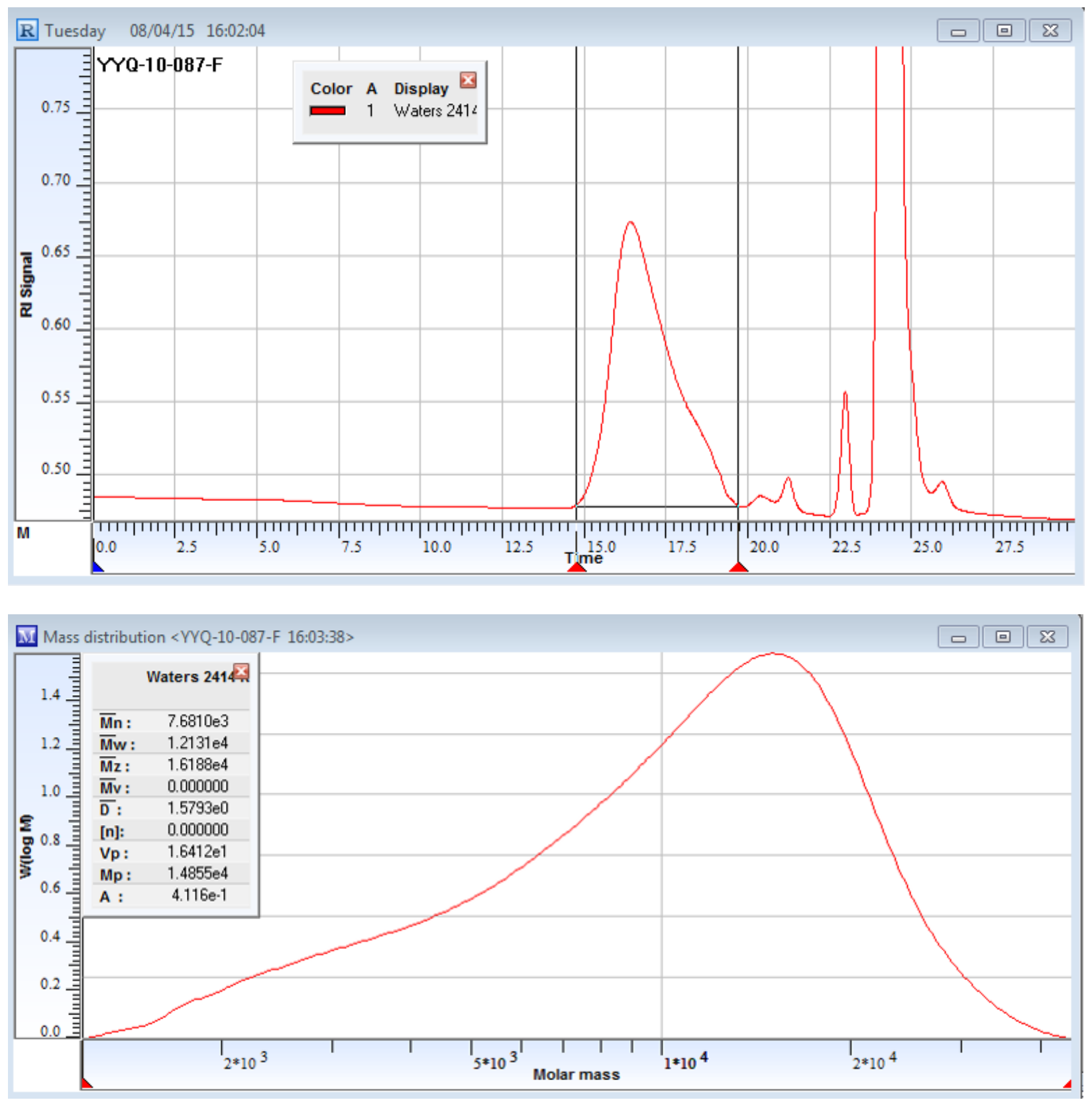

Figure S47. GPC Chromatogram and analysis of P3HF-a-P3HT sample. Entry 4 Table 1 in the Paper. 

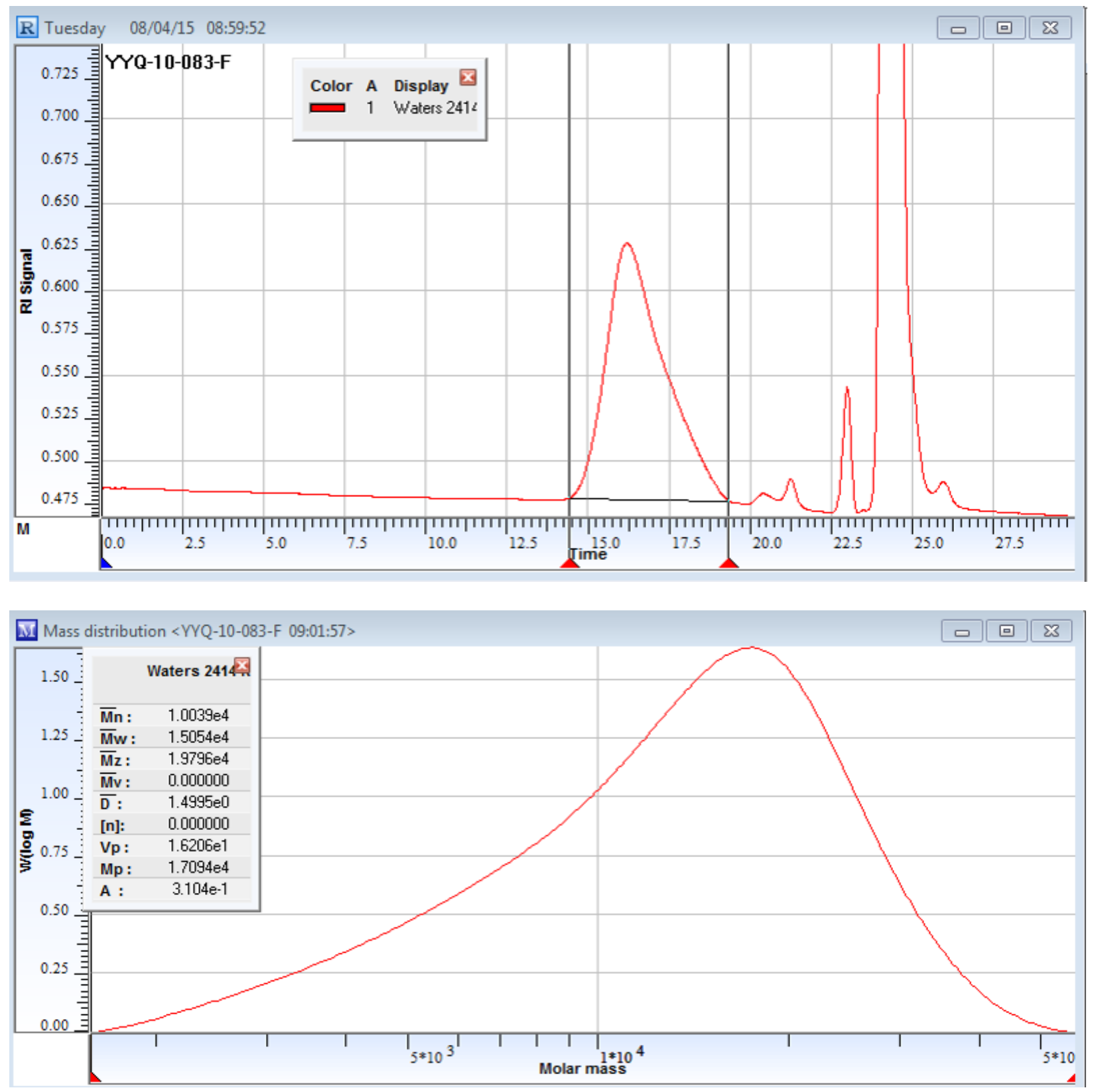

Figure S48. GPC Chromatogram and analysis of sample P3HF-a-P3HT. Entry 5 Table 1 in the Paper. 

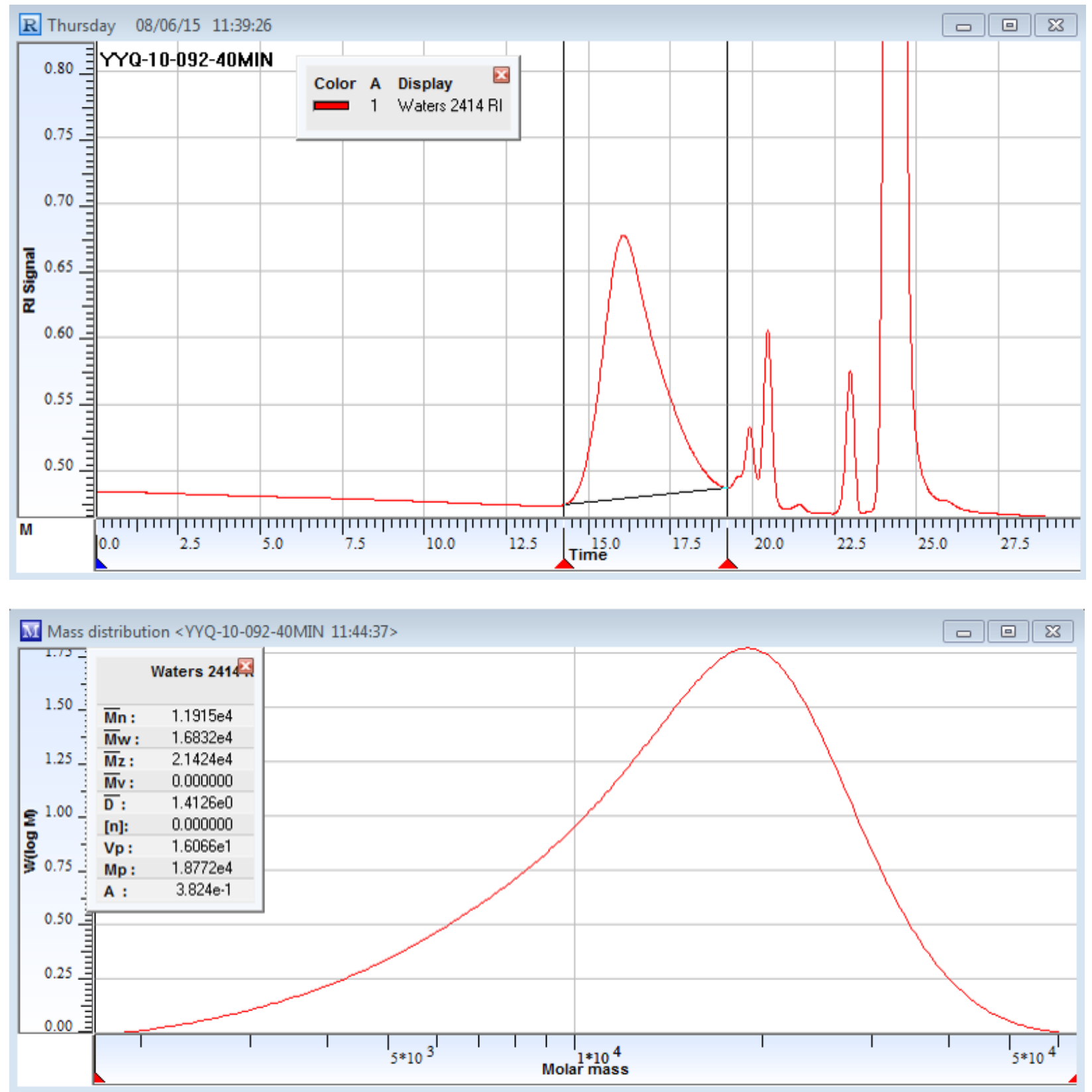

Figure S49. GPC Chromatogram and analysis of sample P3HF-a-P3HT. Entry 6 Table 1 in the Paper. 


\section{References}

(1) Li, J. C.; Lee, S. H.; Hahn, Y. B.; Kim, K. J.; Zong, K.; Lee, Y. S. Synth. Met. 2008, 158, $150-156$.

(2) Jin, X.-H.; Sheberla, D.; Shimon, L. J. W.; Bendikov, M. J. Am. Chem. Soc. 2014, 136, 25922601.

(3) Politis, J. K.; Nemes, J. C.; Curtis, M. D. J. Am. Chem. Soc. 2001, 123, 2537-2547.

(4) Qiu, Y.; Mohin, J.; Tsai, C.-H.; Tristram-Nagle, S.; Gil, R. R.; Kowalewski, T.; Noonan, K. J. T. Macromol. Rapid Commun. 2015, 36, 840-844.

(5) Castañar, L.; Sistaré, E.; Virgili, A.; Williamson, R. T.; Parella, T. Magn. Reson. Chem. 2015, 53, 115-119.

(6) Bard, A. J.; Faulkner, L. R. Electrochemical Methods: Fundamentals and Applications; John Wiley and Sons, Inc.: New York, 2001. 